\title{
Seal Joint Analysis and Design for the Ares-I Upper Stage LOX Tank
}

\author{
Dawn R. Phillips ${ }^{1}$ and Robert J. Wingate ${ }^{2}$ \\ Dynamics, Loads, and Strength Branch, NASA Marshall Space Flight Center, Huntsville, AL, 35812
}

\begin{abstract}
The sealing capability of the Ares-I Upper Stage liquid oxygen tank-to-sump joint is assessed by analyzing the deflections of the joint components. Analyses are performed using three-dimensional symmetric wedge finite element models and the ABAQUS commercial finite element software. For the pressure loads and feedline interface loads, the analyses employ a mixed factor of safety approach to comply with the Constellation Program factor of safety requirements. Naflex pressure-assisted seals are considered first because they have been used successfully in similar seal joints in the Space Shuttle External Tank. For the baseline sump seal joint configuration with a Naflex seal, the predicted joint opening greatly exceeds the seal design specification. Three redesign options of the joint that maintain the use of a Naflex seal are studied. The joint openings for the redesigned seal joints show improvement over the baseline configuration; however, these joint openings still exceed the seal design specification. RACO pressure-assisted seals are considered next because they are known to also be used on the Space Shuttle External Tank, and the joint opening allowable is much larger than the specification for the Naflex seals. The finite element models for the RACO seal analyses are created by modifying the models that were used for the Naflex seal analyses. The analyses show that the RACO seal may provide sufficient sealing capability for the sump seal joint. The results provide reasonable data to recommend the design change and plan a testing program to determine the capability of RACO seals in the Ares-I Upper Stage liquid oxygen tank sump seal joint.
\end{abstract}

\section{Introduction}

$\mathrm{T}$ HE objective of this paper is to perform analyses of the Ares-I Upper Stage liquid oxygen tank sump seal joint to predict relative deflections between the sump and the tank end cap to assess the feasibility that the Naflex seal used with the External Tank manhole covers can successfully be used for the Ares-I design. Ares-I is the two-stage crew launch vehicle for the NASA Constellation Program. Ares-I consists of a solid-fueled first stage and a liquidfueled Upper Stage (US) that uses liquid hydrogen (LH2) and liquid oxygen (LOX) to power a single J-2X engine.

The insulated US structure includes two tanks to hold the LH2 and LOX at cryogenic temperatures. The design of the tanks includes a common bulkhead, which functions as the aft dome for the LH2 tank and the forward dome for the LOX tank. The design of the forward dome of the LH2 tank includes a "manhole" to provide access to the inside of the tank. During final assembly, a cover will be placed over the manhole in the LH2 tank. The design of the aft dome of the LOX tank includes a similar hole to which a sump, and subsequently the LOX feedline, is attached. Because the common bulkhead precludes a manhole on the forward dome of the LOX tank, the hole for the sump/feedline also functions to provide access to the inside of the tank, and the sump must therefore be removable. To prevent leaking of the liquid propellant or ullage gas when the tanks are filled, seals will be placed between the access holes and the manhole cover on the LH2 tank and the sump on the LOX tank.

In the Saturn and Space Shuttle Programs, Naflex seals were used to seal the joints between the manholes and the covers in the propellant tanks. Naflex seals are spacer-type, deflection-activated, pressure-assisted, static seals. The seal configuration uses a cantilevered, deflection-loaded primary seal and a simple gasket-type secondary seal. A cross-sectional view of the seal is shown in Figure 1(b). The cantilevered beams or legs form a fork on the pressure side of the seal. In the uninstalled configuration, the tips of the cantilevered legs protrude beyond the rest of the seal in the $X$ direction (see Figure 1(b)). The seal is installed in the joint between two flat flanges, and during

\footnotetext{
${ }^{1}$ Aerospace Engineer, Senior Member, AIAA

${ }^{2}$ Aerospace Engineer and Team Lead, Member, AIAA.
} 


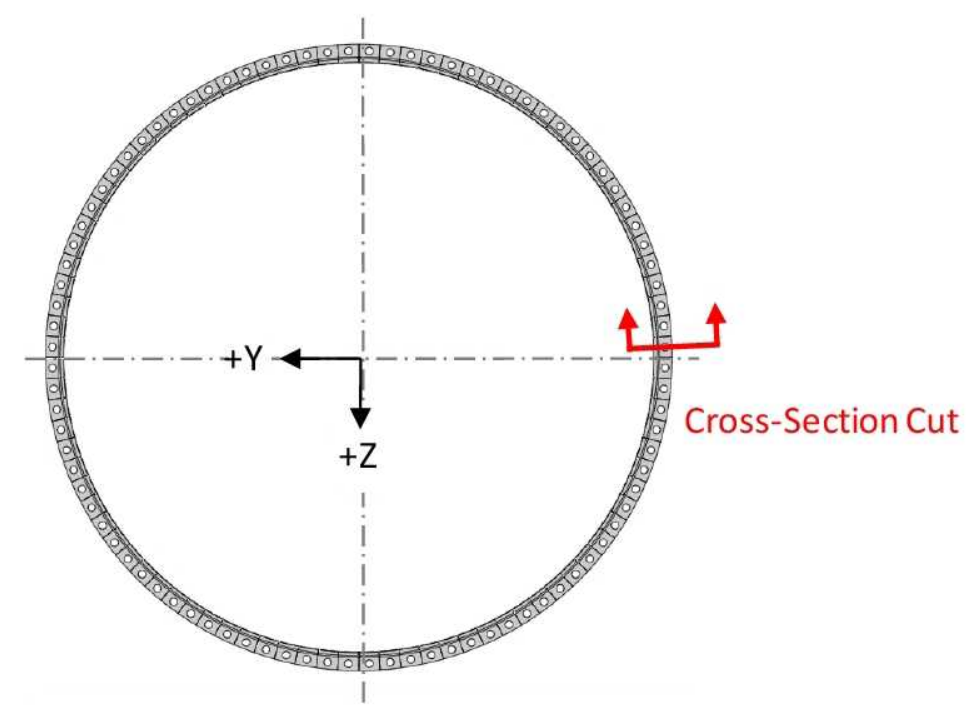

(a) Top view

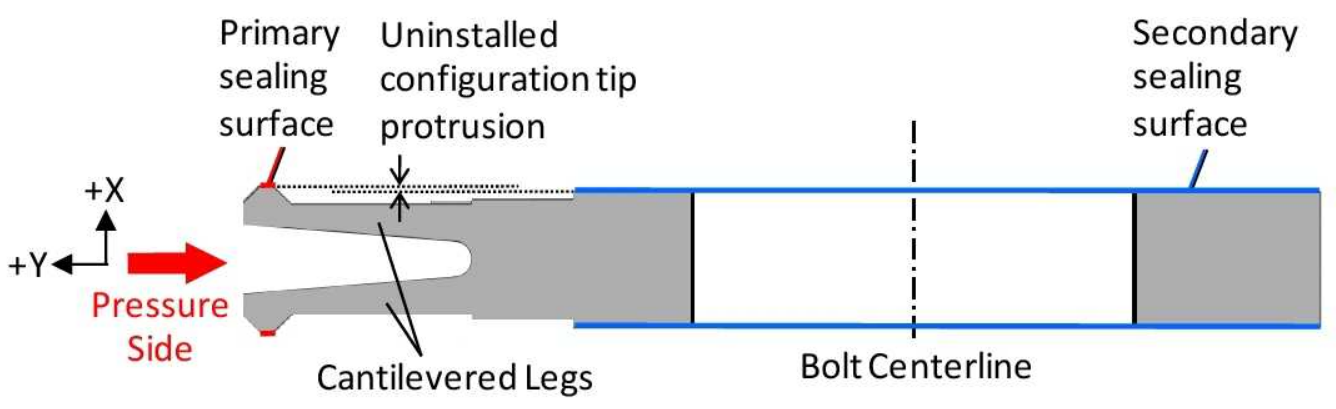

(b) Cross-sectional view

Figure 1. Naflex seal.

joint assembly, when the bolts are preloaded, deflection of the legs provides the initial contact load to accomplish sealing at the primary seal-flange interface. Pressurization of the joint forces the legs even tighter against the sealing surface (Anon, undated; Anon, ca. 2000; and Robbins and Ludtke, 1964). In addition, the area around the bolt hole provides a secondary sealing surface as it is also placed in compression due to the bolt preload. Naflex seals are commonly fabricated of Inconel 718 with a Teflon enamel coating. The manhole cover seal design used by the Space Shuttle External Tank (ET) Project has a heritage traceable to the Saturn S-II stage (Anon., 2001). This same Naflex seal is under consideration for the Ares-I US and is shown in Figure 1. The seal has a 92-hole bolt circle around the circumference.

The paper is organized as follows. First, some background on previous Naflex seal analyses is discussed. Then, the analyses performed for the Naflex seal in the Ares-I US LOX tank sump seal joint are presented. The seal is shown to not perform adequately, and several redesign options for the joint with the Naflex seal are discussed and analyzed. Finally, a redesign option that utilizes a different kind of seal, a RACO seal, is presented and analyzed.

\section{Background}

Seal analyses were previously performed for the Ares-I US LH2 tank manhole cover seal joint (Phillips and Wingate, 2010). Three-dimensional (3D), symmetric wedge finite element (FE) analyses were performed using the ABAQUS $^{3}$ commercial FE software. As a first step in a methodical approach to the analysis, symmetric wedge

${ }^{3} \mathrm{ABAQUS}$ is a registered trademark of Dassault Systèmes.

American Institute of Aeronautics and Astronautics 
models for the ET LH2 tank manhole cover seal joints were correlated with historical ET seal test results (see Gillespie, 1988). The 3D FE modeling practices established with the ET models were then used to construct an Ares-I US LH2 tank model to assess the manhole cover seal performance under flight environments (Phillips and Wingate, 2010).

To minimize developmental testing, the US Project decided to use the original joint opening specification that was specified for the Saturn and ET Projects (Anon, ca. 2009). The joint openings predicted for US are evaluated against the seal design specification for two-sided ${ }^{4}$ flange deflection $\Omega_{\text {spec }}$. In addition, the specification control drawing requires that one-sided flange deflection not exceed $\omega_{\text {spec }}=\Omega_{\text {spec }} / 2$.

Analysis results for the US LH2 tank manhole cover models subjected to flight environments showed that the one-sided flange deflections were predicted to be within the design specification; therefore, it was concluded that the US manhole cover design using the Naflex seal should perform adequately (Phillips and Wingate, 2010).

\section{Lox Tank Sump Seal Analysis}

\section{A. Baseline Model for Naflex Seal Analyses}

The aft portion of the Ares-I LOX tank is shown in Figure 2. The LOX feedline attaches to the sump. The Naflex seal is installed between the sump and the end cap. The end cap is welded to the dome gore panels, and the dome gore panels are welded to the tank barrel at the Y-ring.

The sump has a very different configuration than the LH2 tank manhole cover, and the seal joint is expected to behave differently for the sump than for the manhole cover.

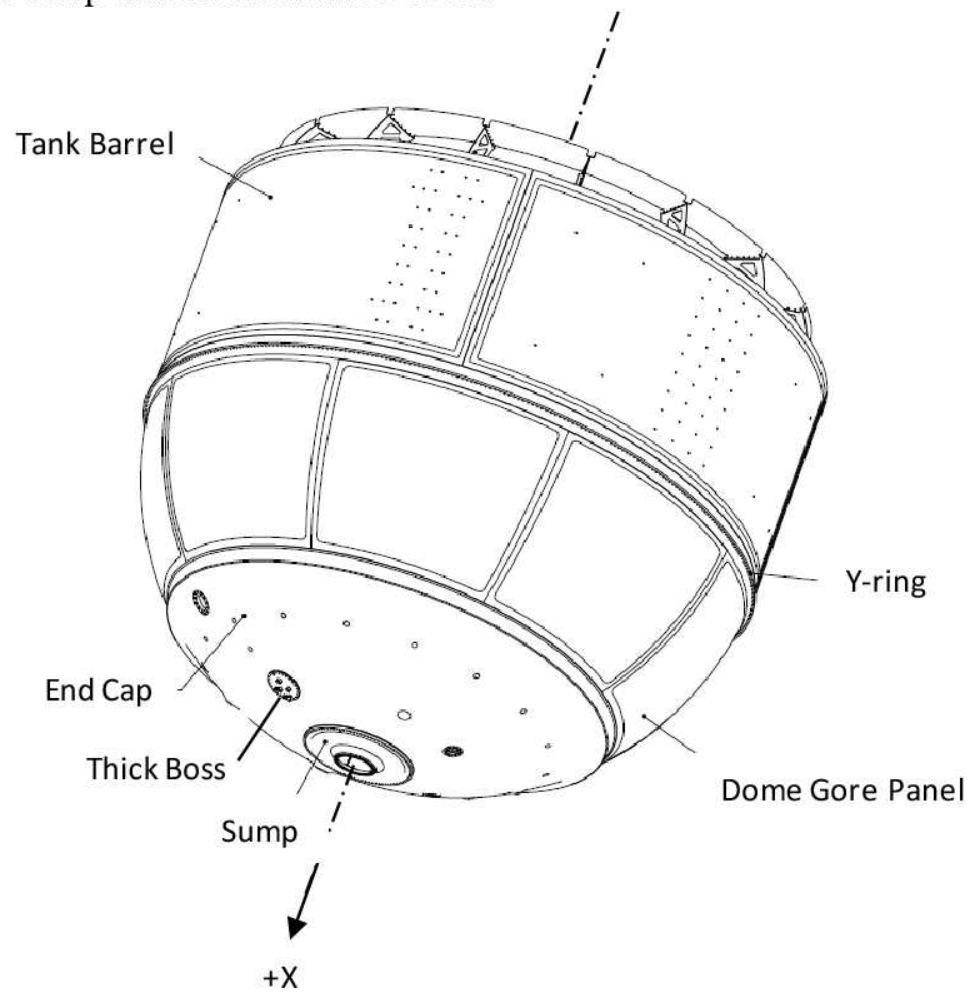

Figure 2. Aft portion of Ares-I US LOX tank.

The 3D FE model is constructed by taking advantage of the symmetry of the seal. A wedge section that encompasses a single bolt hole, or $3.913^{\circ}$, as shown in Figure 3, is used. To construct the model of the sump seal joint, similar $3.913^{\circ}$ portions of the sump, end cap, and dome gore panel are also used, as shown in Figure 4. Note the locations of the Y-ring, the seal joint, and the tank axis. Localized, non-symmetric features such as the thick bosses shown in Figure 2 are ignored, and the wedge models are constructed from the thin acreage regions of the tank dome.

${ }^{4}$ Two-sided flange deflection refers to the axial deflection between both flanges (i.e., on both sides of the seal) of the joint system. 


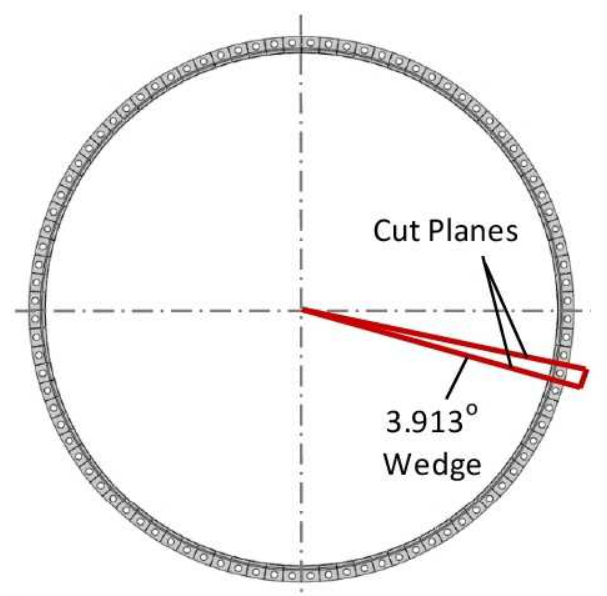

(a) Wedge around single bolt hole

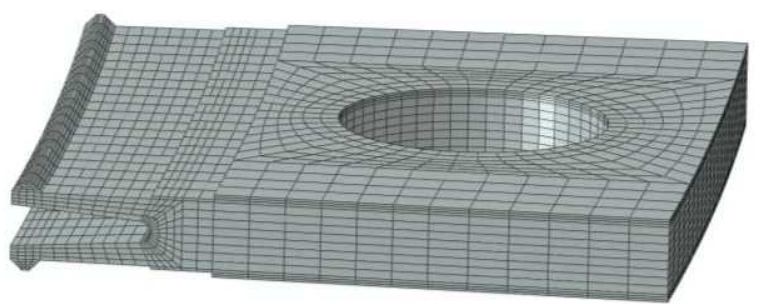

(b) Finite element model

Figure $3.3 .913^{\circ}$ wedge of Naflex seal.

(a) Seal symmetry
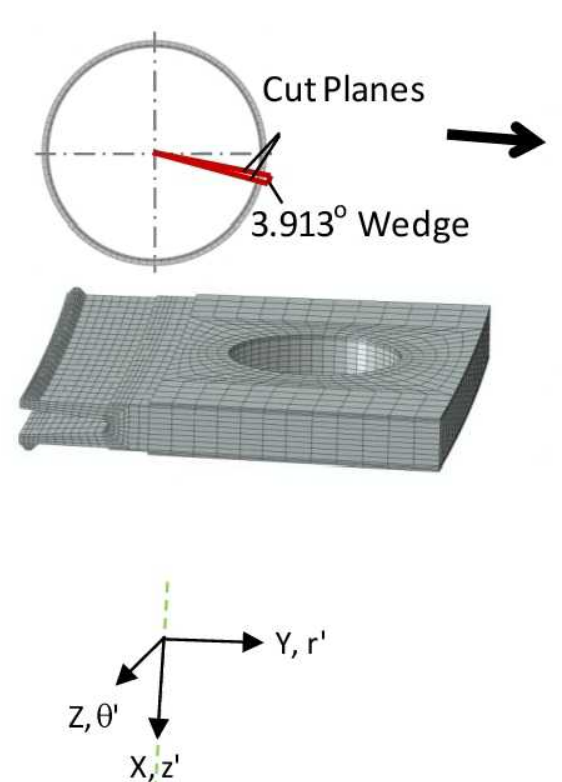

(b) Assume symmetric wedge

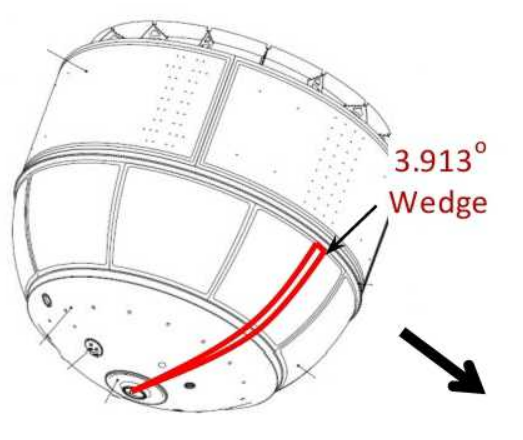

Dome

Gore Panel

Figure $4.3 .913^{\circ}$ symmetric wedge geometry for baseline model. 
Linear, elastic, temperature-dependent material properties are assumed for all of the materials. The materials and properties used for the analyses are provided in Table 1.

Table 1. Materials and properties for the sump seal joint analyses.

\begin{tabular}{|r|l|l|l|l|l|}
\hline \multicolumn{2}{|c|}{} & Dome Gore Panel & End Cap, Sump & Seal & Bolt \\
\cline { 3 - 6 } \multicolumn{2}{|c|}{} & $\begin{array}{l}\mathrm{Al} 2195 \\
\mathrm{~T}_{\text {ref }}=70^{\circ} \mathrm{F}\end{array}$ & $\begin{array}{l}\mathrm{Al} 2219 \\
\mathrm{~T}_{\text {ref }}=70^{\circ} \mathrm{F}\end{array}$ & $\begin{array}{l}\text { Inconel-718 } \\
\mathrm{T}_{\text {ref }}=70^{\circ} \mathrm{F}\end{array}$ & $\begin{array}{l}\mathrm{A} 286 \\
\mathrm{~T}_{\text {ref }}=70^{\circ} \mathrm{F}\end{array}$ \\
\hline \multirow{3}{*}{$70^{\circ} \mathrm{F} \mathrm{F}$} & $11 . \times 10^{6}$ & $10.5 \times 10^{6}$ & $29.4 \times 10^{6}$ & $29.1 \times 10^{6}$ \\
\cline { 2 - 6 } & $\mathrm{E}(\mathrm{psi})$ & 0.33 & 0.33 & 0.29 & 0.31 \\
\cline { 2 - 6 } & $\alpha$ & $12.2 \times 10^{-6}$ & $6.86 \times 10^{-6}$ & $9 . \times 10^{-6}$ \\
\hline \multirow{3}{*}{$-297^{\circ} \mathrm{F}$} & $\mathrm{F}\left(\mathrm{in} /{ }^{\circ} \mathrm{F}\right)$ & $12.5 \times 10^{-6}$ & -- & $30.9 \times 10^{6}$ & $29.8 \times 10^{6}$ \\
\cline { 2 - 6 } & $\mathrm{E}(\mathrm{psi})$ & $0.33 \times 10^{6}$ & $9.88 \times 10^{-6}$ & $5.56 \times 10^{-6}$ & 0.31 \\
\cline { 2 - 6 } & $\alpha\left(\mathrm{in} / \mathrm{in} /{ }^{\circ} \mathrm{F}\right)$ & $10.1 \times 10^{-6}$ & & $7.01 \times 10^{-6}$ \\
\hline
\end{tabular}

The modeling practices established for the LH2 tank manhole cover analyses that were previously anchored to ET test data (Phillips and Wingate, 2010) are employed for the LOX tank sump analyses. These modeling practices include element type and mesh refinement, boundary conditions and the use of shell-to-solid coupling, bolt modeling with beam elements, the use of "spider" constraints to simulate the effect of the washer bearing-surface size and bolt-to-insert engagement, and contact modeling at the seal primary and secondary sealing surfaces. Each of these practices, as they pertain to the LOX tank model, are described in this section.

\section{Element Type and Mesh Refinement}

The 3D symmetric wedge FE mesh in the local region of the sump seal joint is shown in Figure 5. The sump, seal, and end cap are modeled with solid elements, the dome gore panel is modeled with shell elements, and the bolt is modeled with beam elements. The solid elements are the ABAQUS C3D8I elements, which are 8-node brick elements with additional internal degrees of freedom introduced as incompatible modes for improved bending behavior $^{5}$. A mesh convergence study was performed during the previous ET analyses (Phillips and Wingate, 2010), and the mesh refinement for this LOX tank model is based on that study. The seal is used as the slave surface in the contact definitions (to be discussed later), and as such, the mesh refinement in the two non-thickness directions is twice the refinement of the end cap and sump. The shell elements are the ABAQUS S4 elements, which are 4-node quadrilateral elements, and the beam elements are the ABAQUS B31 elements, which are 2-node Timoshenko beam elements. The entire model contains approximately 43000 elements, including 42272 solid elements, 358 shell elements, and 8 beam elements.

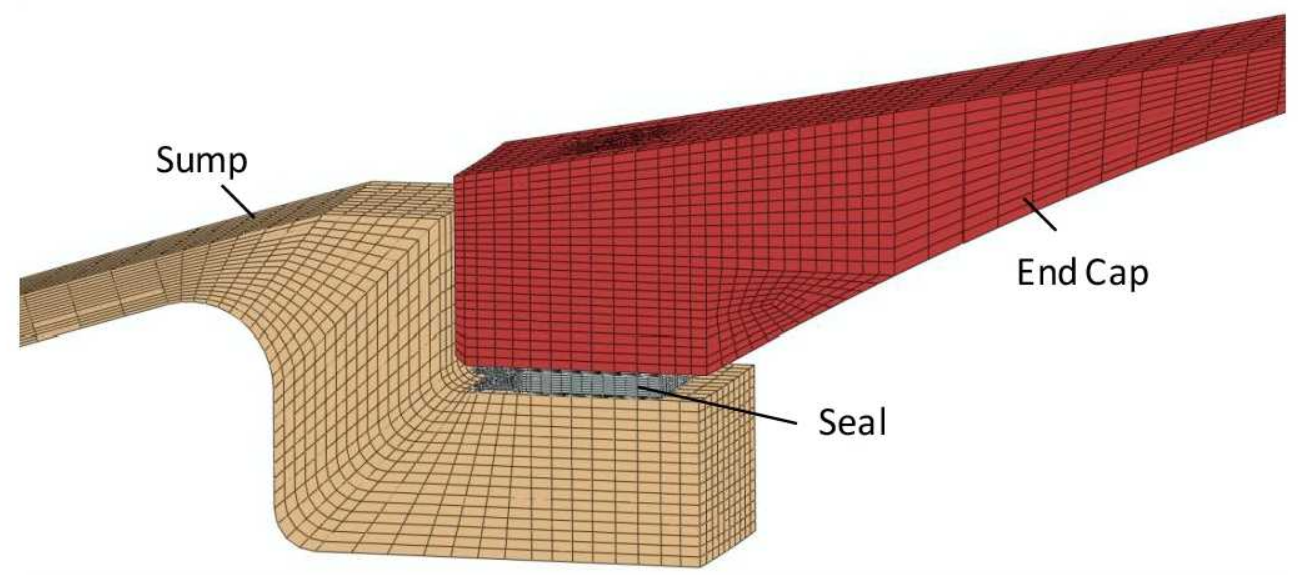

Figure 5. 3D symmetric wedge FE mesh in the local region of the sump seal joint.

\footnotetext{
${ }^{5}$ The C3D8I solid element has 8 nodes with three degrees of freedom per node plus 13 additional element variables associated with the incompatible deformation modes. The estimated total number of unknowns for a given finite element mesh using C3D8I elements is roughly equal to three times the number of nodes plus 13 times the number of C3D8I solid elements (Anon., 2009).
} 


\section{Boundary Conditions and Shell-to-Solid Coupling}

The boundary conditions (BCs) are shown in Figure 6. Symmetric boundary conditions (i.e., $u_{\theta}=0$ ) are applied to the $\theta=0$ and $\theta=3.913^{\circ}$ cut planes. In addition, the Y-ring is assumed to be rigid, and a fixed boundary condition (i.e., $u_{r}=u_{\theta}=u_{z}=\theta_{r}=\theta_{\theta}=\theta_{z}=0$ ) is applied to the top of the dome gore panel.

The shell and solid regions are joined using a shell-to-solid coupling constraint, as shown in Figure 6, for smooth transition of loads across the shell/solid interface. This practice enables the use of shell theory, which is appropriate for the thin-walled tank membrane, in conjunction with solid modeling, which is required to capture greater detail at the seal joint.

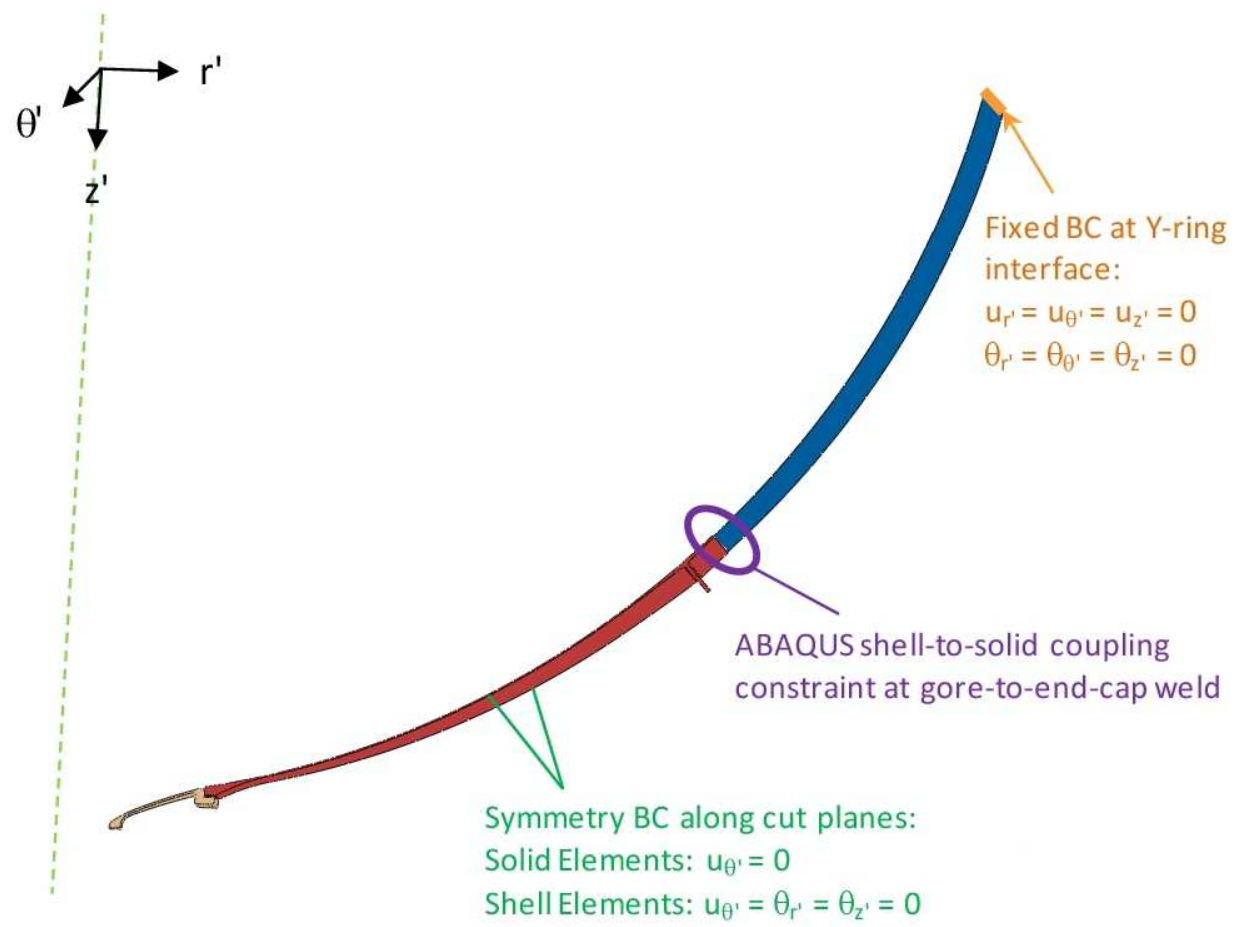

Figure 6. Boundary conditions and shell-to-solid coupling.

\section{Bolt Modeling}

The bolted connection in the sump seal joint consists of a bolt, a corresponding threaded insert in the end cap, and a washer between the bolt head and the sump, as shown in Figure 7(a). The bolted connection is modeled as established by the previously mentioned ET test analyses (Phillips and Wingate, 2010). Beam elements are used to represent the bolt, and "spider" constraints are used to represent the interaction of the bolt with the connected parts. On the sump side, the spider constraint couples the displacements of the chosen nodes on the outer surface of the sump, representing the size of the washer bearing surface, to the motion of a single node corresponding to the bolt head. On the end-cap side, the spider constraint couples the displacements of the chosen nodes on the inside surface of the threaded insert hole to a single node on the beam elements that represent the bolt. This spider constraint represents the bolt-to-insert-engagement. For the bolt-to-sump connection, the surface that extends to the ring of nodes midway between the bolt hole and the washer outer diameter (see Figure 7(c)) is used to represent the assumed bearing size of the washer, as shown on the left side of Figure 7(b). For the bolt-to-end-cap connection, the ring of nodes at the insert mid-depth is used to represent the bolt-to-insert engagement, as shown on the right side of Figure 7(b).

\section{Contact Modeling}

Contact is defined between the seal and the sump and between the seal and the end cap. As established by the ET test analyses (Phillips and Wingate, 2010), two separate contact interactions are defined for the primary sealing surface and the secondary sealing surface (see Figure 8). For both contact interactions, a finite-sliding, surface-tosurface formulation is used. The finite-sliding formulation utilizes the true representation (rather than a linear approximation) of the master surface for the slave surface interaction. The surface-to-surface formulation enforces 


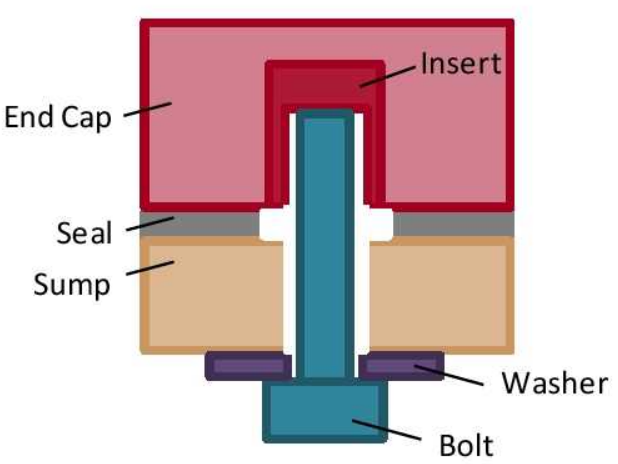

(a) Bolted joint in sump seal joint

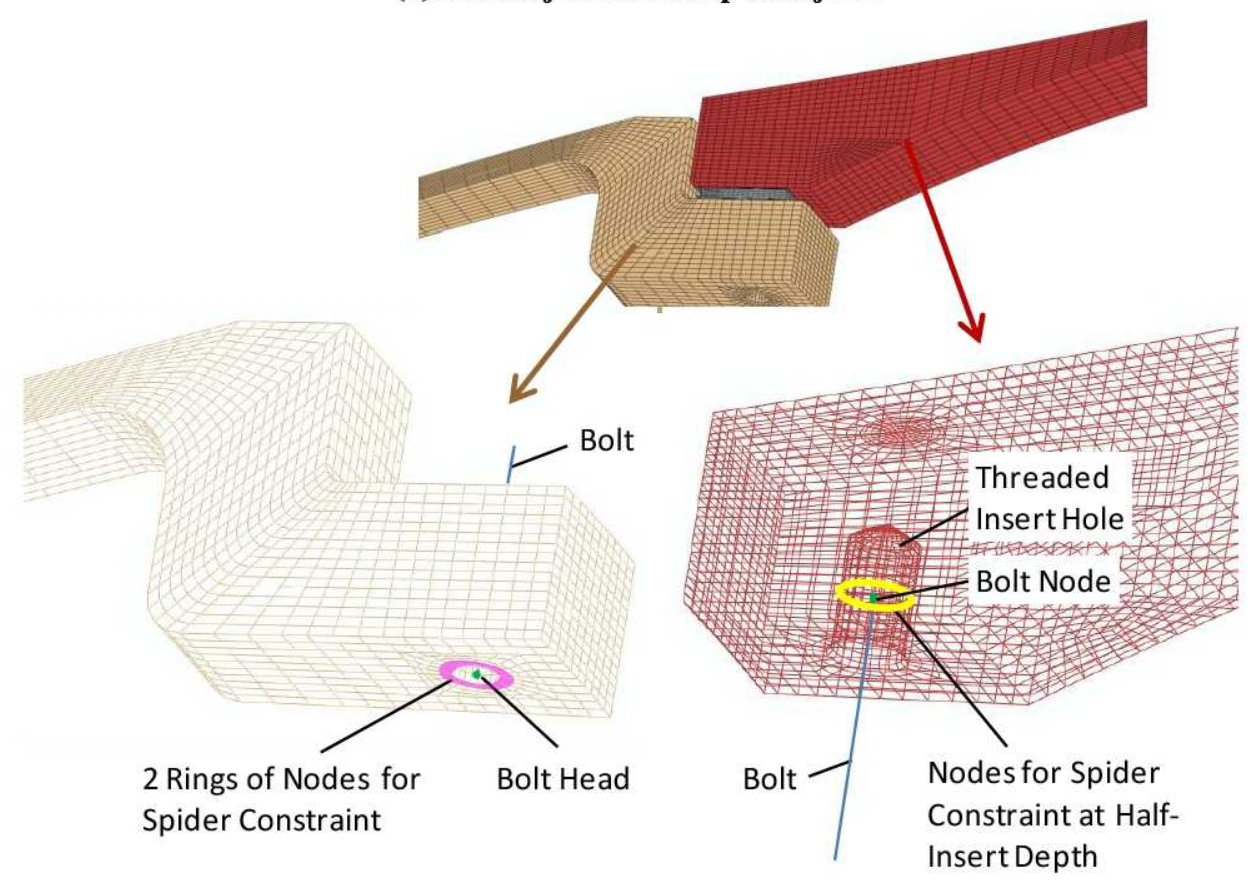

(b) Spider constraints in FE model

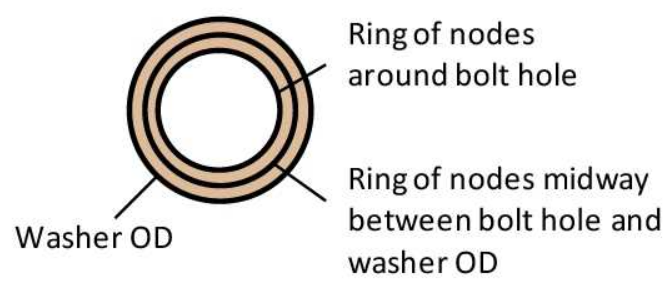

(c) Washer bearing-surface size

Figure 7. Bolt modeling in the FE model.

contact in an average sense over the slave surface, rather than enforcing contact at the individual nodes on the slave surface. Finite-sliding and surface-to-surface are the most general contact formulations available in ABAQUS, and they tend to yield better solutions for a wide range of problems than the other formulations (Anon, 2009). The constraint enforcement method in the direction normal to the contact surfaces is defined as "Hard" contact. In Hard contact, zero clearance between the contact surfaces is strictly enforced whenever contact pressure is detected. The 


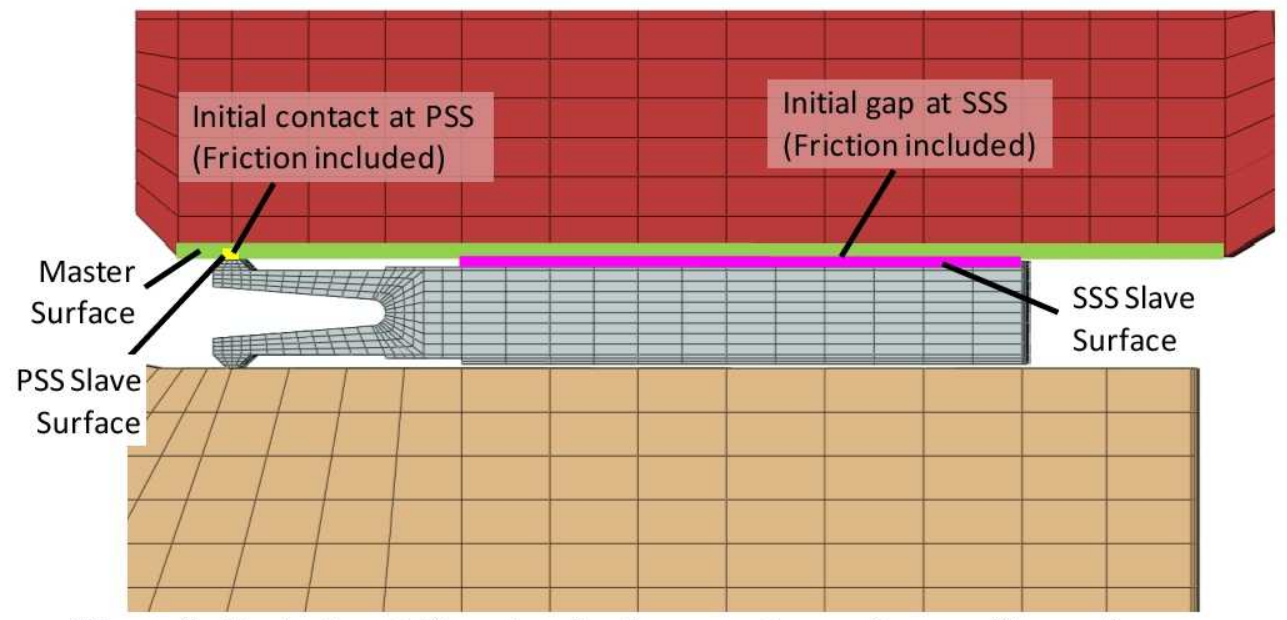

Figure 8. Contact modeling at seal primary and secondary sealing surfaces.

constraint enforcement method in the direction tangential to the contact surfaces uses a penalty formulation and a coefficient of friction ${ }^{6}$ of $\mu=0.05$.

\section{Three-Step Analysis}

All of the analyses presented in this paper are nonlinear analyses performed using the ABAQUS commercial FE software. During the initial set-up, all boundary conditions and constraints are applied, and an initial temperature of $70^{\circ} \mathrm{F}$ is applied to the entire model. During the first analysis step, the temperature is held constant at $70^{\circ} \mathrm{F}$, and the bolt preload is applied. During the second analysis step, the bolt length is fixed, and a temperature of $-297^{\circ} \mathrm{F}$ is applied to the entire model, resulting in a total temperature change $(\Delta \mathrm{T})$ of $-367^{\circ} \mathrm{F}$. In the third analysis step, the temperature is held constant at $-297^{\circ} \mathrm{F}$, and the pressure and feedline interface loads are applied.

\section{Loads}

The bolts are 5/16-in. diameter, $200 \mathrm{ksi}$, A286 fasteners, and the minimum preload is used in the analyses. The minimum preload is calculated by assuming the nominal preload to be $65 \%$ of the allowable yield stress of the bolt (180 ksi), incorporating $\pm 25 \%$ preload scatter, and incorporating a $5 \%$ preload relaxation:

$$
\text { Minimum Preload }=(0.65 \times 180 \mathrm{ksi}) \times 0.75 \times 0.95 \times A_{\text {bolt }}
$$

where $A_{\text {bolt }}$ is the nominal cross-sectional area of the bolt shank. For the current analyses, the minimum preload is $6394 \mathrm{lb}$. The bolt preload is applied using the ABAQUS bolt load capability: a pretension section is defined on the bolt, the preload is applied as a force to the pretension section, and then the bolt length is fixed.

The external loads are applied using a mixed factor of safety (FoS) approach. Per NASA CxP 70135 (Anon., 2008), the joint separation FoS for joints where separation causes a catastrophic hazard is FoS $=1.4$. In addition, for main propulsion system (MPS) interfaces whose loads are not expected to be simulated in the ultimate loads test of the Upper Stage, the factor of safety is FoS $=2.0$. Therefore, for the seal joint analyses, FoS $=1.4$ is applied to the pressure load, while $\mathrm{FoS}=2.0$ is applied to the feedline interface loads.

The pressure load is applied, as indicated in Figure 9, along the entire inside surface of the assembly and around the pressure side of the seal legs to the centerline of the primary sealing surface. The ultimate pressure (i.e., incorporating $\mathrm{FoS}=1.4$ ) varies with $\mathrm{X}$-station (see Figure 2) and is applied as a distribution to the FE model.

The feedline interface loads are aligned with the FE wedge model, as shown in Figure 10, and calculated for worst-case joint opening. For worst case joint opening:

- $P$ (axial) in the $+X$ direction pries the joint open

- $T$ (torque) has no affect

- $V$ (shear) applied in the $+Y$ direction pries the joint open

- $M$ (overturning moment) applied in the $+Z$ direction pries the joint open

${ }^{6}$ From the Dupont website, accessed 12 September 2010, http://www2.dupont.com/Teflon_Industrial/en_US/products/selection_guides/properties.html, the coefficient of friction of Teflon coating is in the range 0.05 to 0.2 . For the finite element model, the lower bound is chosen. 


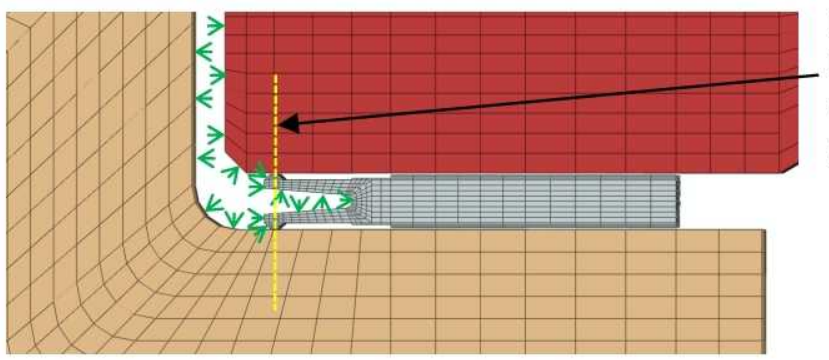

End Cap and Sump:

Pressure application extends

to centerline of seal primary

sealing surface
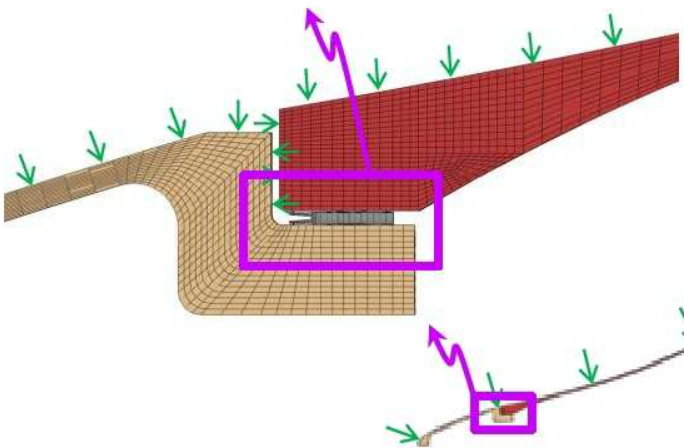

Figure 9. Pressure load applied to the 3D symmetric wedge finite element model of the sump seal joint assembly.
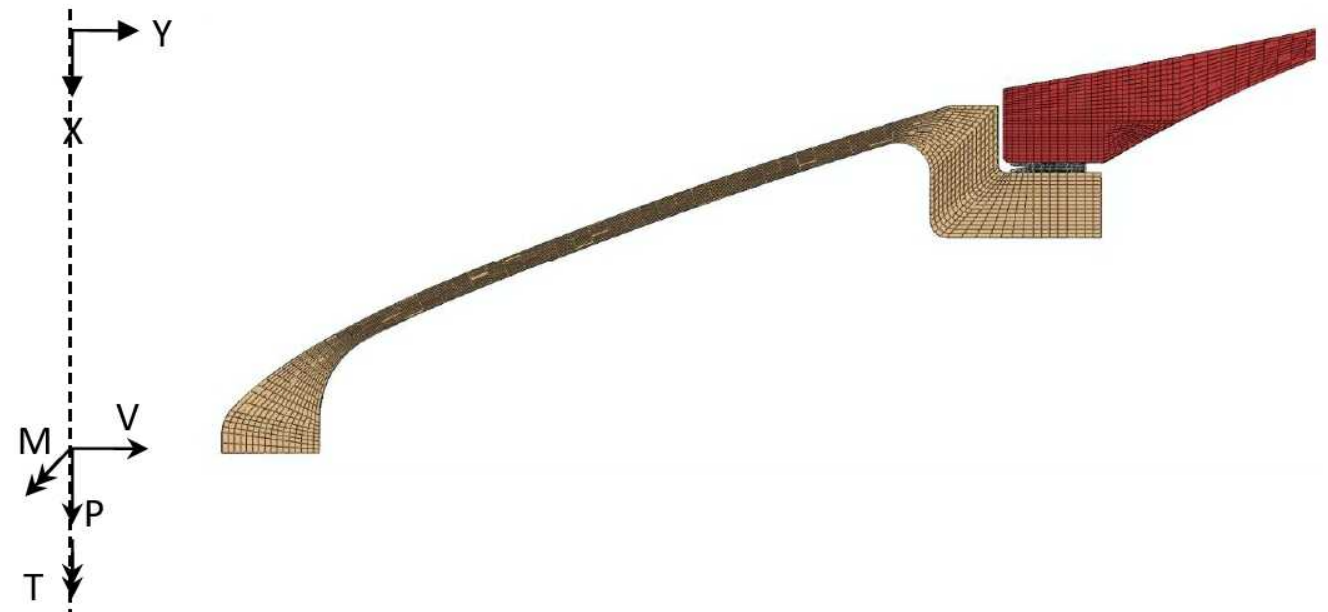

Figure 10. Feedline interface loads aligned with the 3D symmetric wedge finite element model for worst-case joint opening.

The axial load $P$ is applied as a pressure over the bottom surface of the sump, as shown in Figure 11(b). Of the total axial load, $83 \%$ is due to the pressure thrust load, and therefore the pressure FoS of 1.4 is used for the axial feedline interface load component only.

The shear load $V$ is applied as a concentrated force at the center point of the bottom of the sump inner diameter, as shown in Figure 11(c). The FoS for the shear load is 2.0.

The overturning moment $M$ is applied as a pressure over the bottom surface of the sump, as shown in Figure 11(d). The FoS for the overturning moment is 2.0 .

American Institute of Aeronautics and Astronautics 


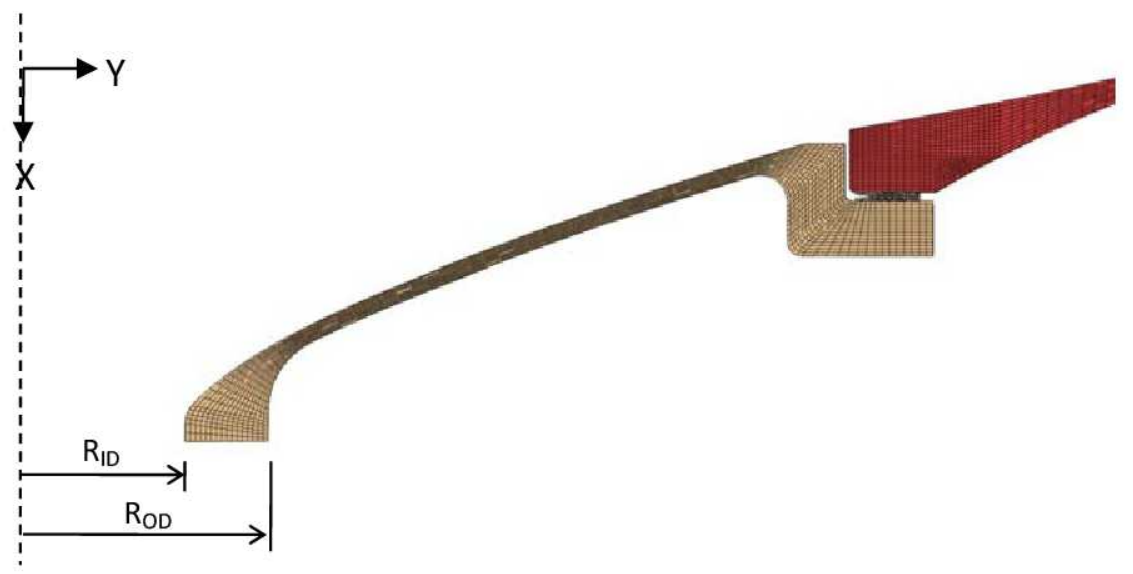

(a) Location of feedline interface loads

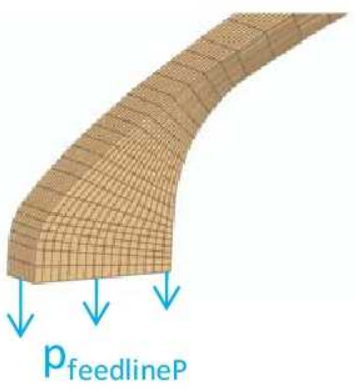

(b) Axial load (including pressure thrust load) applied as pressure

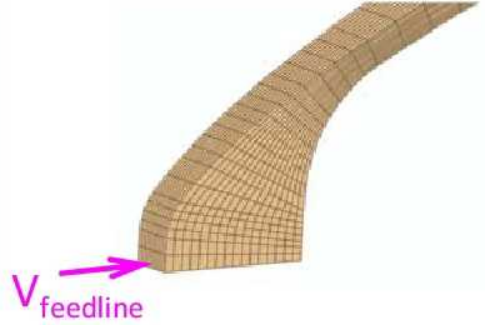

(c) Shear load applied as concentrated force

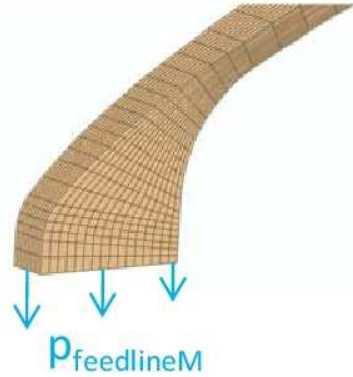

(d) Overturning moment applied as pressure

Figure 11. Feedline interface loads applied to the 3D symmetric wedge finite element model of the sump seal joint assembly.

\section{B. Seal Behavior and Joint Opening}

The behavior of the seal is illustrated in Figure 12. After the bolt preload is applied, the seal primary sealing surfaces are in contact with the sump and end cap flanges, as shown in Figure 12(a). A representative von Mises stress distribution is overlaid on the seal in the figure to illustrate the spring loading in the seal legs. After some external load is applied, the flanges begin to separate, relieving some of the spring loading in the seal legs, as shown in Figure 12(b). If the flanges separate enough, all of the spring loading in the seal legs is relieved, and the primary sealing surfaces are no longer in contact with the flanges, as shown in Figure 12(c).

The two-sided joint opening $\Omega$ is computed using the axial (i.e., global $X$ ) deflections between the sump and the end cap, as shown in Figure 13. The distance between the two flanges at the primary seal after the application of the bolt preload is subtracted from the distance between the two flanges after the pressure and interface loads are applied:

$$
\Omega=\delta_{X}^{\text {load }}-\delta_{X}^{\text {preload }}
$$

In this paper, the normalized joint opening, $\left(\Omega / \Omega_{\text {spec }}\right)$, is reported. If $\left(\Omega / \Omega_{\text {spec }}\right)$ is less than or equal to unity, then the integrity of the seal is possibly maintained, and the one-sided opening $\omega$ can be examined. 


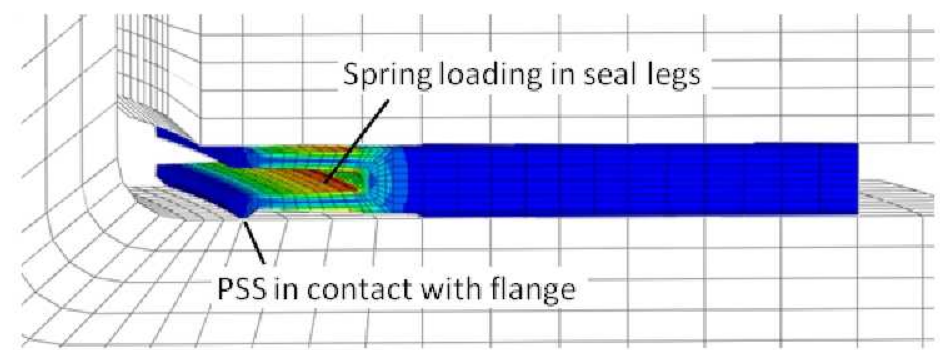

(a) After bolt preload applied

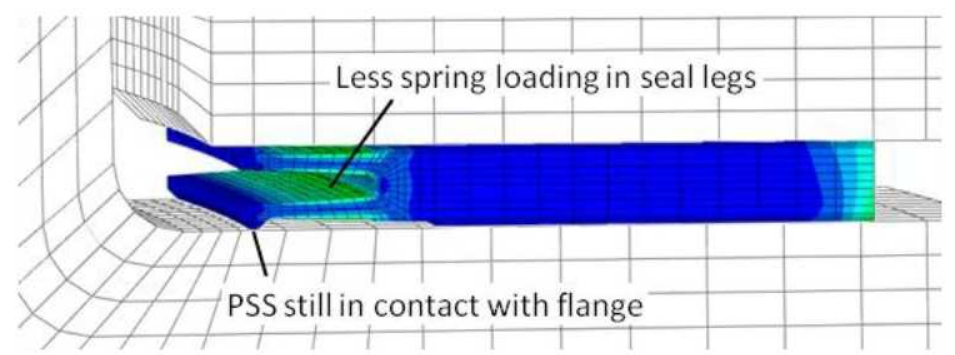

(b) After some external load applied

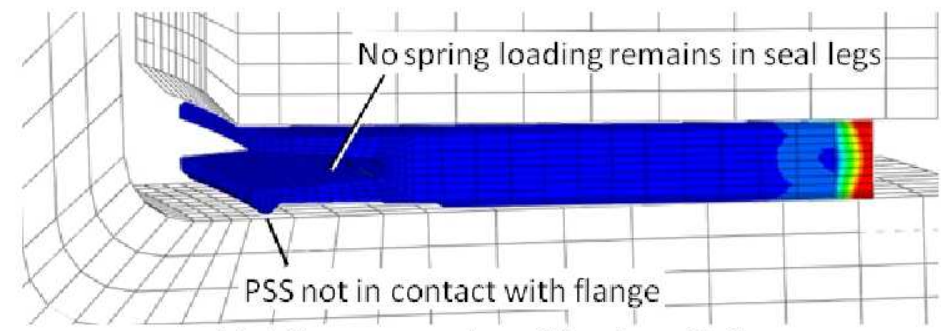

(c) After more external load applied

Figure 12. Seal behavior.

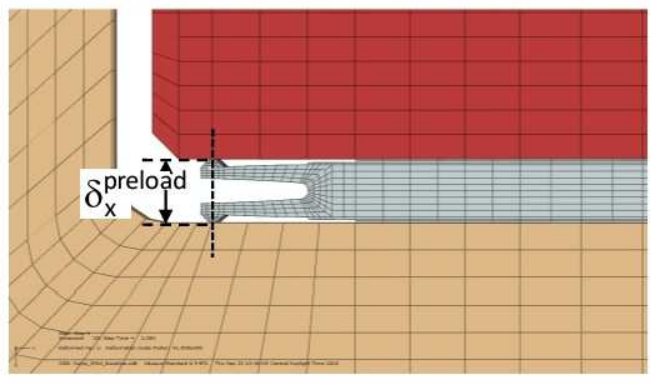

(a) After preload step

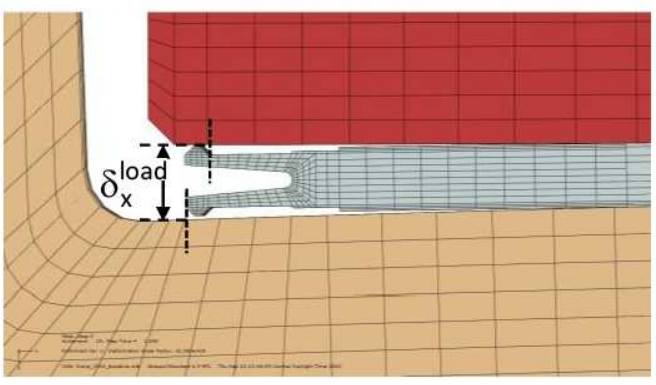

(b) After load step

Figure 13. Calculation of joint opening using global $X$ deflections.

\section{Baseline Model Results}

For the baseline model, $\left(\Omega / \Omega_{\text {spec }}\right)=6.5$, indicating the predicted joint opening is 6.5 times greater than the specification limit for acceptable seal performance. Hence, the integrity of the seal is not maintained. The seal joint must be redesigned.

There is a strong desire to use the Naflex seal because it is an existing ET part. Therefore, design changes that could be made to continue with the Naflex seal are explored. The deformed configuration of the baseline seal joint is shown in Figure 14. As the external loads are applied, the sump flange rotates due to bolt bending, and the sump bends. Three redesign options are considered to reduce this sump rotation and bending. These redesign options and their results are presented next. 


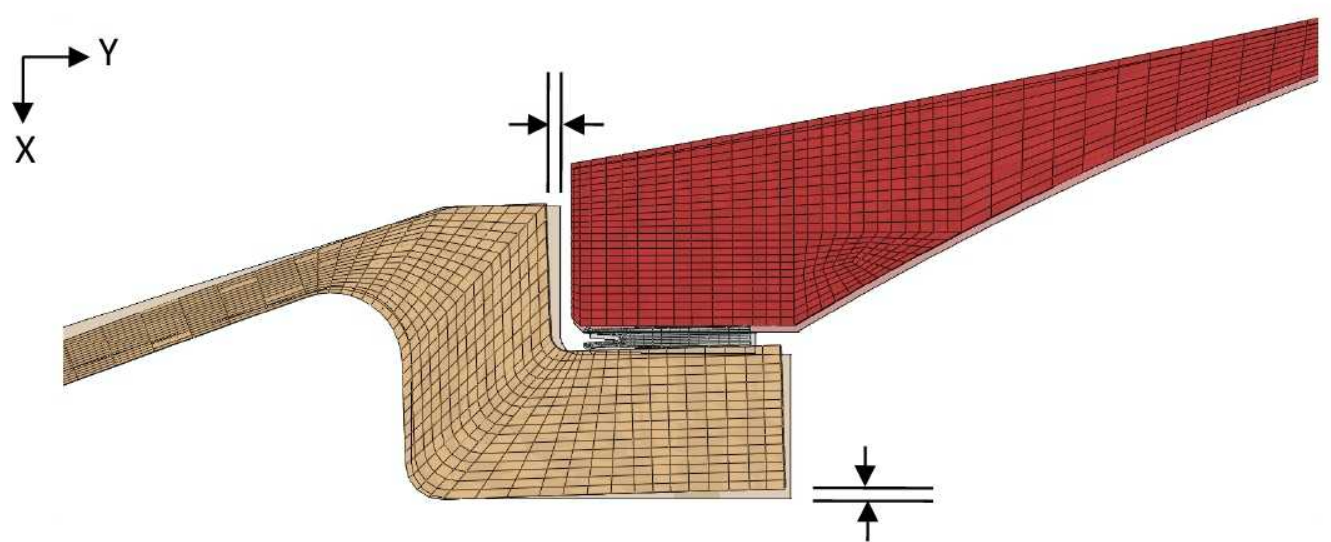

Figure 14. Sump rotation due to bolt bending.

\section{Joint Redesign Using Naflex Seal}

\section{A. Joint Redesign Option \#1}

\section{Analysis}

Because the bolt in the baseline configuration provides the only resistance to sump rotation, all of the load must be reacted through the bolt, causing the bolt to bend. If some of this load could be reacted somewhere else, the bolt bending could be relieved, thereby reducing the sump rotation.

Previous seal analyses were performed for the Ares-I US LH2 tank manhole cover (Phillips and Wingate, 2010). The previously analyzed manhole cover (MHC) seal joint is shown in Figure 15. The LH2 tank MHC includes a lip that overlaps the dome-cover flange. A close-up of the MHC seal joint cross section is shown in Figure 16(a). There is a nominal initial clearance between the MHC lip and the dome-cover flange. When the internal pressure is applied, the lip comes into contact with the dome-cover flange, as shown in Figure 16(b), providing a mechanical stop that resists rotation of the $\mathrm{MHC}^{7}$.

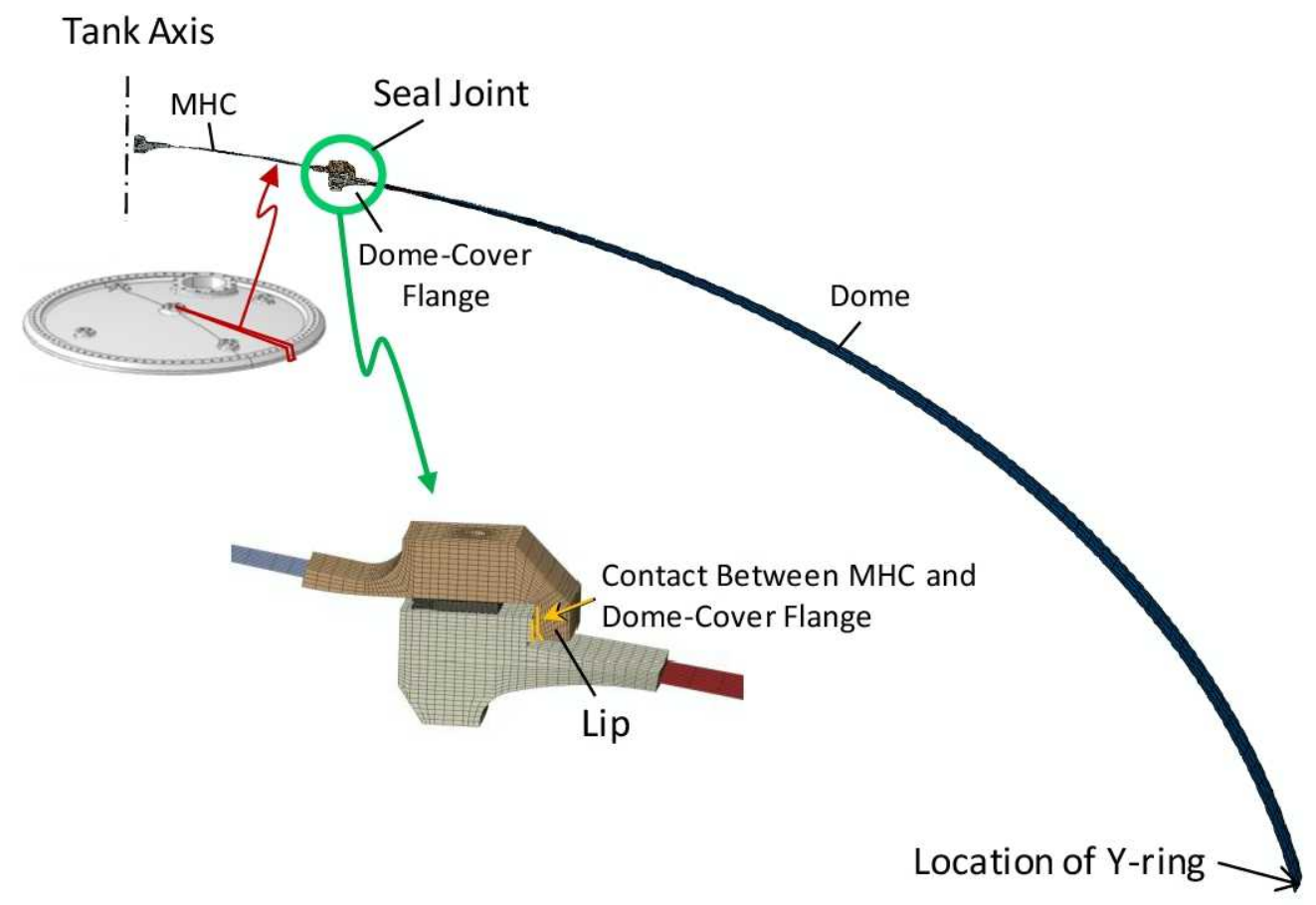

Figure 15. Previously analyzed Ares-I Upper Stage LH2 tank manhole cover.

${ }^{7}$ This was unlikely the original design intention; however, it is a side-effect.

American Institute of Aeronautics and Astronautics 


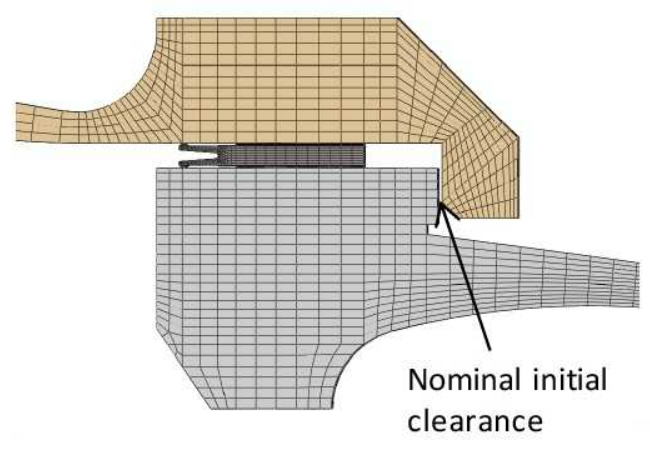

(a) Before load applied

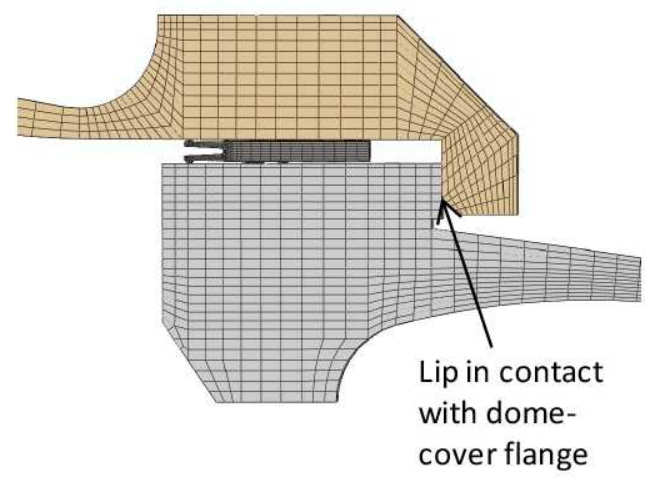

(b) After load applied

Figure 16. Close-up of Ares-I US LH2 tank MHC seal joint before and after pressure load applied.

To relieve the bolt bending and reduce the sump rotation in the LOX tank sump seal joint, an alternate configuration that incorporates a mechanical stop such as the one in the LH2 tank manhole cover is examined. The existing models for the sump and end cap are modified within a Design of Experiments (DOE) matrix to assess which factors affect the joint opening the most and how the factors interact with each other.

The modifications to the sump and end cap and the DOE factors considered are shown in Figure 17. Three factors are considered, with two levels each, yielding a total of eight unique experiments to run. The factors considered are the lip height, lip angle, and clearance. The levels for each of these factors are presented in Table 2. For the lip height, "Full" height is chosen to line up with the top of the sump for machining purposes. For clearance,

$$
\begin{gathered}
\text { Minimum = nominal }- \text { tolerance }, \text { and } \\
\text { Maximum }=\text { nominal }+ \text { tolerance }
\end{gathered}
$$

with the nominal dimension and tolerance based on the LH2 tank MHC drawing.

The DOE orthogonal experiment matrix is presented in Table 3, and close-ups of the seal joint for each of these experiments are shown in Figure 18.

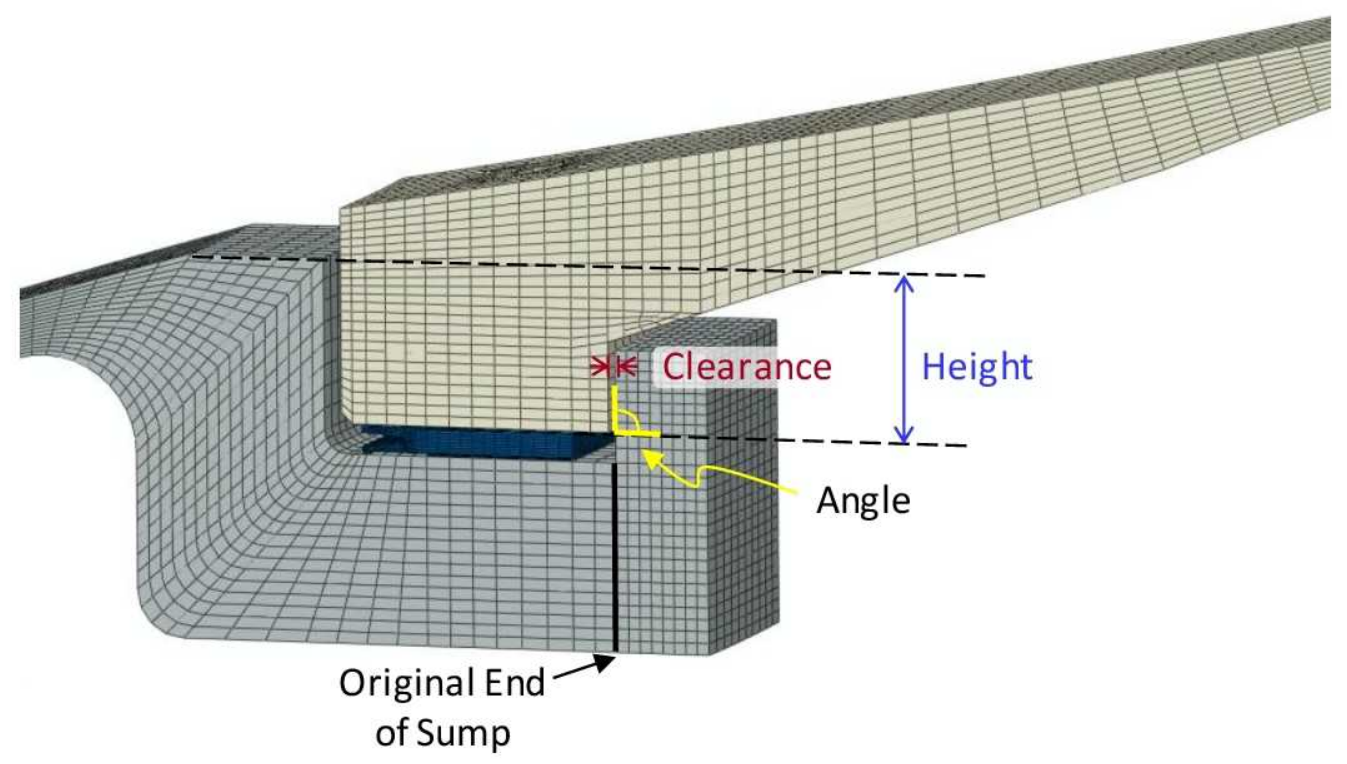

Figure 17. Modifications to sump seal joint model and DOE factors considered. 
Table 2. DOE factors and levels.

\begin{tabular}{|c|c|c|}
\hline \multirow{2}{*}{ Factor } & \multicolumn{2}{|c|}{ Level } \\
\cline { 2 - 3 } & + & - \\
\hline \hline A. Lip height & Full & Half \\
\hline B. Lip angle & $45^{\circ}$ & $90^{\circ}$ \\
\hline C. Clearance & Minimum & Maximum \\
\hline
\end{tabular}

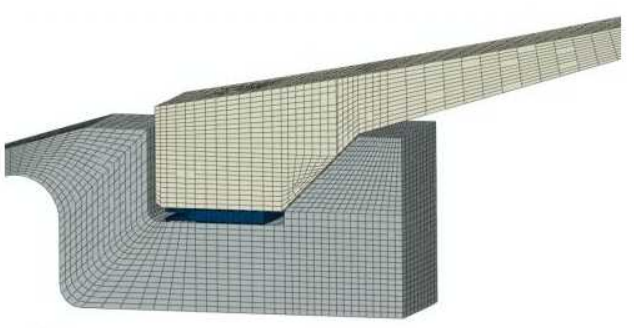

(a) Experiment \#1

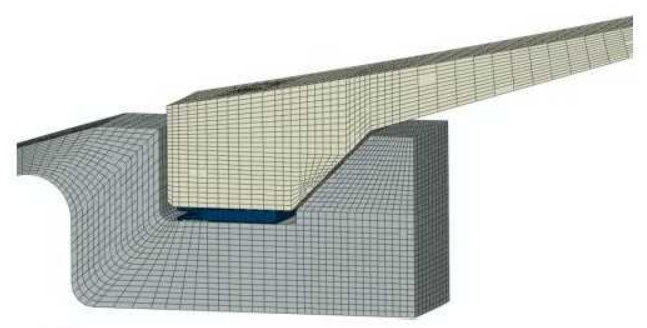

(c) Experiment \#3

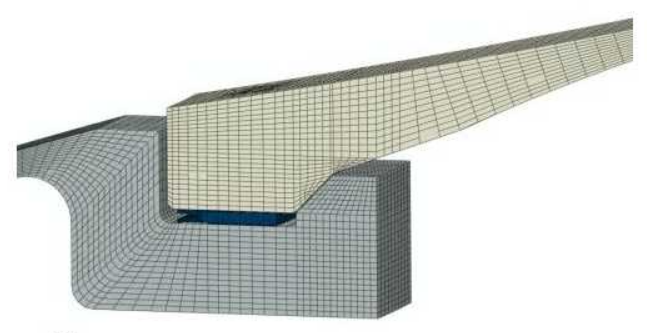

(e) Experiment \#5

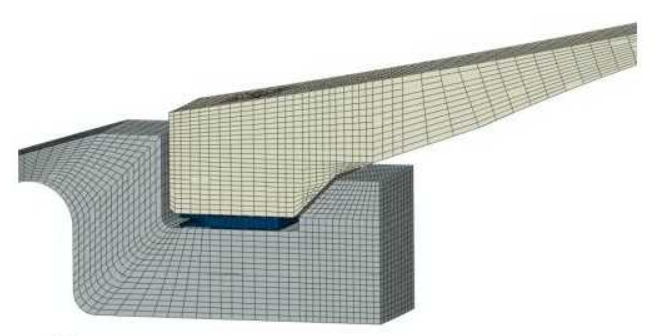

(g) Experiment \#7
Table 3. DOE orthogonal experiment matrix.

\begin{tabular}{|c|c|c|c|}
\hline Experiment \# & A & B & C \\
\hline \hline 1 & + & + & + \\
\hline 2 & + & - & + \\
\hline 3 & + & + & - \\
\hline 4 & + & - & - \\
\hline 5 & - & + & + \\
\hline 6 & - & - & + \\
\hline 7 & - & + & - \\
\hline 8 & - & - & - \\
\hline
\end{tabular}

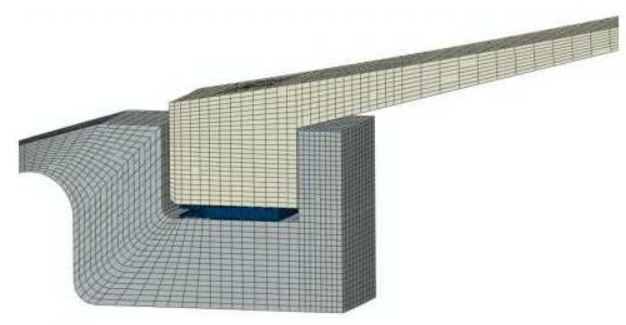

(b) Experiment \#2

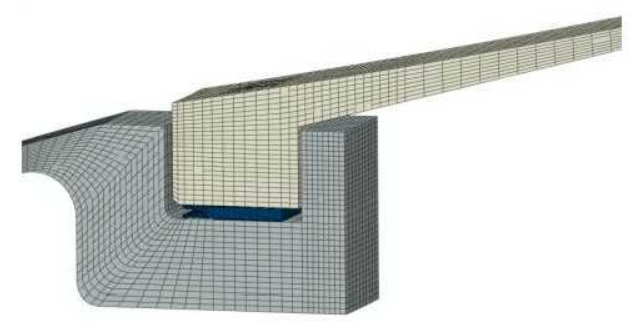

(d) Experiment \#4

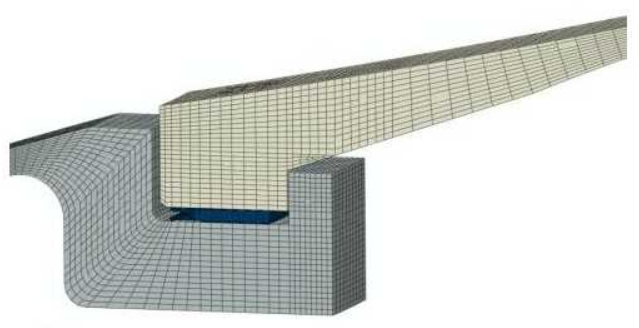

(f) Experiment \#6

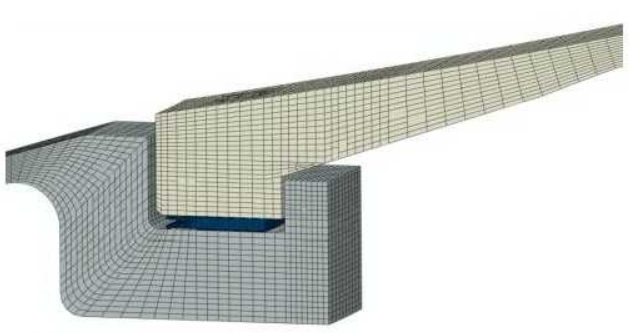

(h) Experiment \#8

Figure 18. Close-up view of seal joint for each DOE experiment. 


\section{Results}

The results from the DOE analyses are presented in Table 4. First, these results show that all of the configurations considered yield an improved joint opening from the baseline configuration (i.e., $\left(\Omega / \Omega_{\text {spec }}\right)=6.5$ ); however all of the computed joint openings still exceed the specification (i.e., $\left(\Omega / \Omega_{\text {spec }}\right)>1.0$ ). Second, these results show that lip angle has the largest effect on joint opening. Third, these results show that three of the interactions, height-to-angle, angle-to-clearance, and height-to-angle-to-clearance, can be ignored. Fourth, these results show that the preferred levels for the factors are $\mathrm{A}+, \mathrm{B}+$, and $\mathrm{C}+$, or

- Lip height: Full

- Lip angle: $45^{\circ}$

- Clearance: Minimum

Table 4. DOE results.

\begin{tabular}{|c|c|c|c|c|c|c|c|c|c|c|c|c|c|c|c|}
\hline \multirow{2}{*}{ Expt. } & \multirow{2}{*}{$(\Omega$} & \multicolumn{2}{|c|}{$\mathrm{A}$} & \multicolumn{2}{|c|}{$\mathrm{B}$} & \multicolumn{3}{|c|}{$\mathrm{C}$} & \multicolumn{2}{|c|}{$\mathrm{AB}$} & \multicolumn{3}{|c|}{$\mathrm{AC}$} & \multicolumn{3}{|c|}{$\mathrm{BC}$} & \multicolumn{2}{c|}{$\mathrm{ABC}$} \\
\cline { 3 - 18 } & $/ \Omega_{\text {spec }}$ & + & - & + & - & + & - & + & - & + & - & + & - & + & - \\
\hline 1 & 1.33 & 1.33 & & 1.33 & & 1.33 & & 1.33 & & 1.33 & & 1.33 & & 1.33 & \\
\hline 2 & 3.75 & 3.75 & & & 3.75 & 3.75 & & & 3.75 & 3.75 & & & 3.75 & & 3.75 \\
\hline 3 & 1.45 & 1.45 & & 1.45 & & & 1.45 & 1.45 & & & 1.45 & & 1.45 & & 1.45 \\
\hline 4 & 4.00 & 4.00 & & & 4.00 & & 4.00 & & 4.00 & & 4.00 & 4.00 & & 4.00 & \\
\hline 5 & 1.73 & & 1.73 & 1.73 & & 1.73 & & & 1.73 & & 1.73 & 1.73 & & & 1.73 \\
\hline 6 & 4.15 & & 4.15 & & 4.15 & 4.15 & & 4.15 & & & 4.15 & & 4.15 & 4.15 & \\
\hline 7 & 2.85 & & 2.85 & 2.85 & & & 2.85 & & 2.85 & 2.85 & & & 2.85 & 2.85 & \\
\hline 8 & 4.75 & & 4.75 & & 4.75 & & 4.75 & 4.75 & & 4.75 & & 4.75 & & & 4.75 \\
\hline Avg. & 3.00 & 2.63 & 3.37 & 1.84 & 4.16 & 2.74 & 3.26 & 2.92 & 3.08 & 3.17 & 2.83 & 2.95 & 3.05 & 3.08 & 2.92 \\
\hline Effect & & -0.74 & -2.32 & -0.52 & -0.16 & +0.34 & -0.1 & +0.16 \\
\hline
\end{tabular}

The configuration that yields the lowest value for joint opening, $\left(\Omega / \Omega_{\text {spec }}\right)=1.33$, is Experiment \#1, which includes full lip height, $45^{\circ}$ lip angle, and minimum clearance. This configuration will be studied further to determine if the joint opening can be brought within the specification. However, because of machining and assembly tolerancing, minimum clearance cannot always be guaranteed. In addition, the DOE revealed an interaction between lip height and clearance. Therefore, the same configuration but with maximum clearance (i.e., Experiment \#3) will also be studied further. The configuration of Experiment \#3, which includes full lip height, $45^{\circ}$ lip angle, and maximum clearance, yields a joint opening of $\left(\Omega / \Omega_{\text {spec }}\right)=1.45$.

The joint opening vs. percent ultimate load for the baseline model, Experiment \#1, and Experiment \#3 is presented in Figure 19. The joint opening specification is also plotted. In Experiment \#1, the sump lip makes contact with the end cap before the joint opening exceeds the specification, and then the joint opening continues to increase. In contrast, in Experiment \#3, the sump lip makes contact with the end cap after the joint opening exceeds the specification $\left(\left(\Omega / \Omega_{\text {spec }}\right)=1.75\right.$ at $50 \%$ ultimate load $)$, and then the joint opening decreases slightly. For the seal to perform successfully, the joint opening must remain below the specification during the entire load history. Some parametric studies are performed next to study whether this goal can be met.

Effect of Bolt Size: The effect of using larger-diameter bolts to improve the response of Experiments \#1 and \#3 is studied. The expectation is that the larger diameter and associated higher preload will reduce bolt bending and hence joint opening. The bolt sizes considered, and their associated minimum preload values (see Eq. 1), are presented in Table 5. Because the bolt is modeled with beam elements, for simplicity, no changes are made to the sump or end cap meshes (i.e., a larger hole is not incorporated).

Table 5. Bolt sizes considered.

The joint opening vs. percent ultimate load for the three bolt sizes are presented in Figure 20 for the minimum clearance and in Figure 21 for the maximum clearance. For the minimum clearance (Figure 20), for all the bolt sizes considered, the sump lip makes contact with the end cap before the joint opening exceeds the specification, even though the larger bolts require greater load for the sump lip to make contact with the end cap. Also, as the bolt size increases, the final joint opening decreases. The 3/8-in. bolt almost meets the joint opening specification, and the 7/16-in. bolt meets the joint opening specification. 

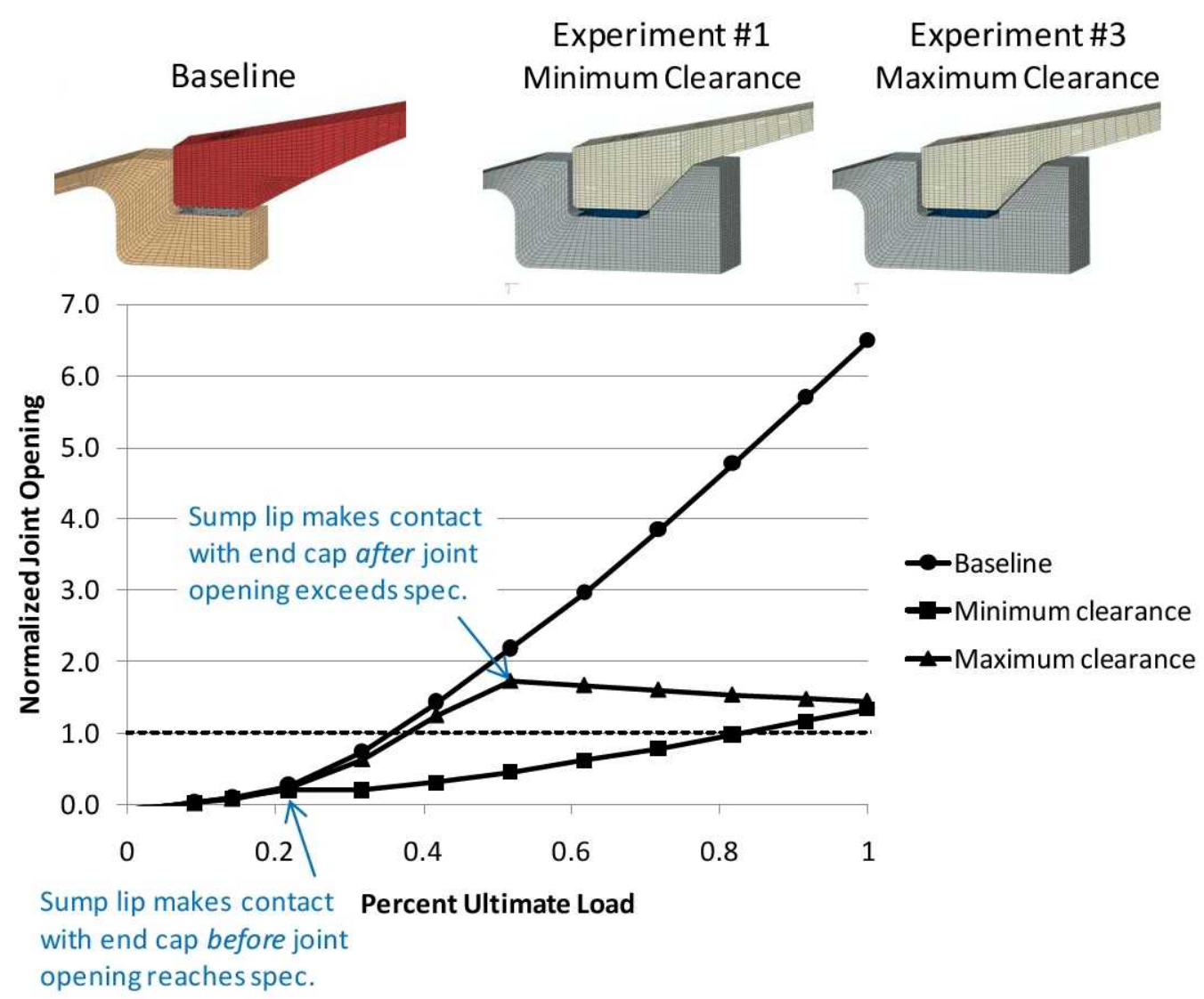

Figure 19. Joint opening vs. percent ultimate load for the baseline model, Experiment \#1, and Experiment \#3 - 5/16-in. bolt with minimum preload.

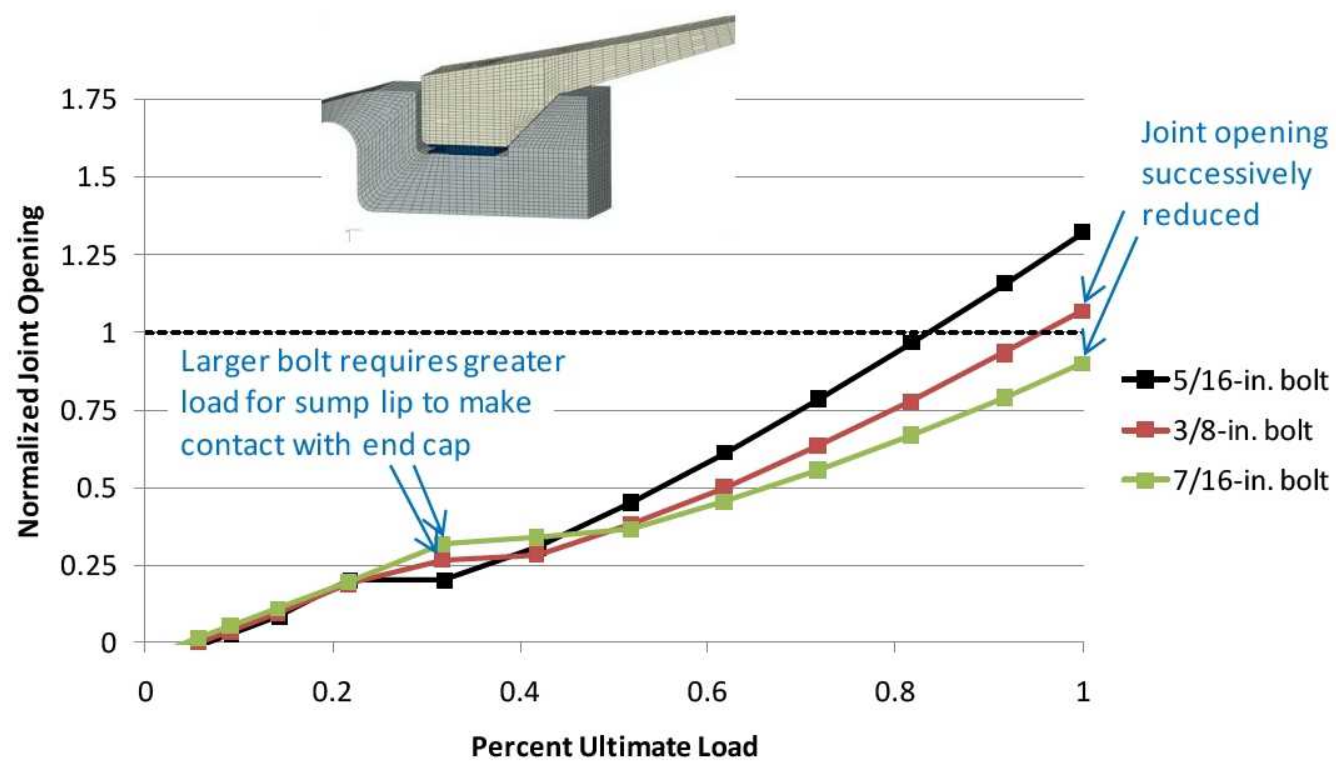

Figure 20. Joint opening vs. percent ultimate load for the three bolt sizes with minimum preload - minimum clearance. 


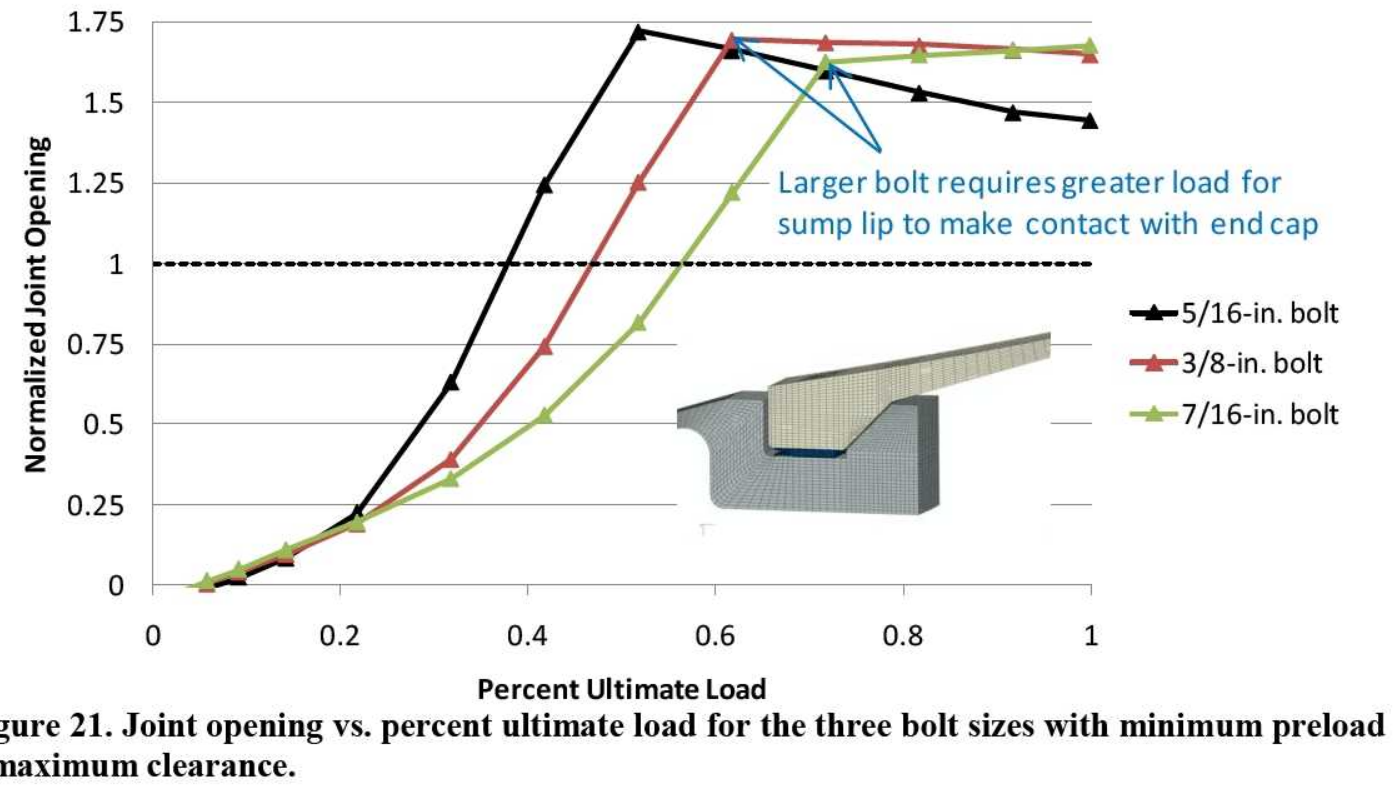

For the maximum clearance (Figure 21), for all the bolt sizes considered, the sump lip makes contact with the end cap after the joint opening exceeds the specification, and the larger bolts also require greater load for the sump lip to make contact with the end cap. However, the final joint opening does not decrease as the bolt size is increased. These results demonstrate that the load at which the sump makes contact with the end cap influences the final joint opening. In addition, the interaction of the lip clearance with other configuration parameters is demonstrated; the joint deflection exhibits complex behavior.

Effect of Increased Bolt Preload: The effect of increased bolt preload (that could be obtained using better process control during assembly and installation) is studied. The bolt preload is assumed to be $80 \%$ of the yield stress:

$$
\text { Increased Preload }=(0.8 \times 180 \mathrm{ksi}) \times A_{\text {bolt }}
$$

The three previously studied bolt sizes and their associated increased preload values (see Eq. 4), are presented in Table 6 .

Table 6. Increased bolt preload values considered.

\begin{tabular}{|c|c|}
\hline Bolt Diameter & Increased Preload (Eq. 4) \\
\hline $5 / 16$ in. & $11045 \mathrm{lb}$ \\
\hline $3 / 8$ in. & $15840 \mathrm{lb}$ \\
\hline $7 / 18$ in. & $21600 \mathrm{lb}$ \\
\hline
\end{tabular}

The joint opening vs. percent ultimate load for the three bolt sizes are presented in Figure 22 for the minimum clearance and in Figure 23 for the maximum clearance. For the minimum clearance (Figure 22), for all the bolt sizes considered with increased preload, the sump lip still makes contact with the end cap before the joint opening exceeds the specification. Also, as the bolt preload is increased, the final joint opening is decreased. All the bolts with increased preload meet the two-sided joint opening specification, with $\left(\Omega / \Omega_{\text {spec }}\right)=0.75$ being the best joint opening computed (see Figure 22 for the 7/16-in. bolt with increased preload). However, all the bolts fail the onesided joint opening specification ${ }^{8}$.

For the maximum clearance (Figure 23), for all the bolt sizes considered with increased preload, the sump lip still makes contact with the end cap after the joint opening exceeds the specification, and the final joint opening exceeds the specification.

In summary, the redesign configuration with full lip height and $45^{\circ}$ lip angle shows the most improvement over the baseline configuration. For the lip with minimum clearance, regardless of bolt diameter

- Sump lip makes contact with end cap before joint opening specification is reached

- Joint opening steadily increases as external load is applied

- Increasing bolt preload decreases joint opening

- Joint opening could meet two-sided specification, but fails one-sided specification

\footnotetext{
${ }^{8}$ The two-sided opening specification is compared to the relative deflection of one flange to the other, whereas the one-sided opening specification is compared to the relative deflection of each flange to the seal mid-plane.
} 


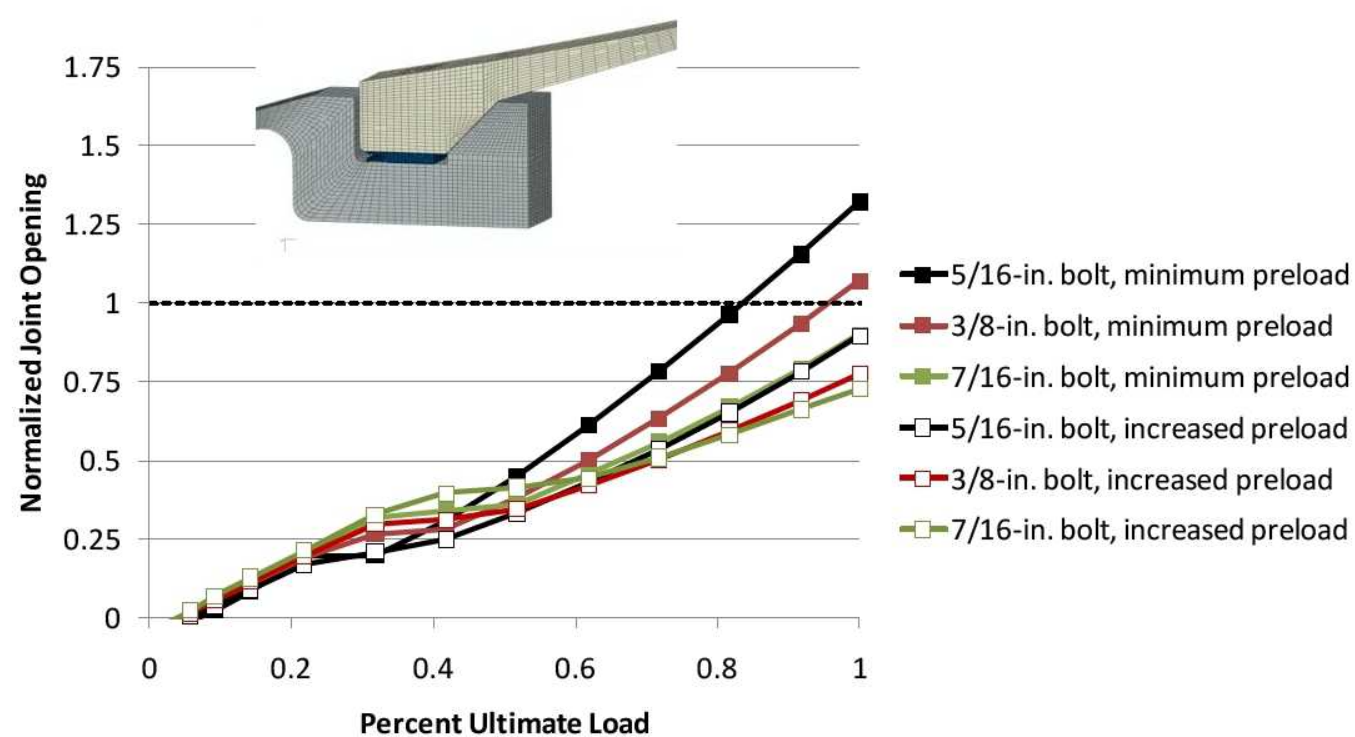

Figure 22. Joint opening vs. percent ultimate load for the three bolt sizes with increased preload - minimum clearance.

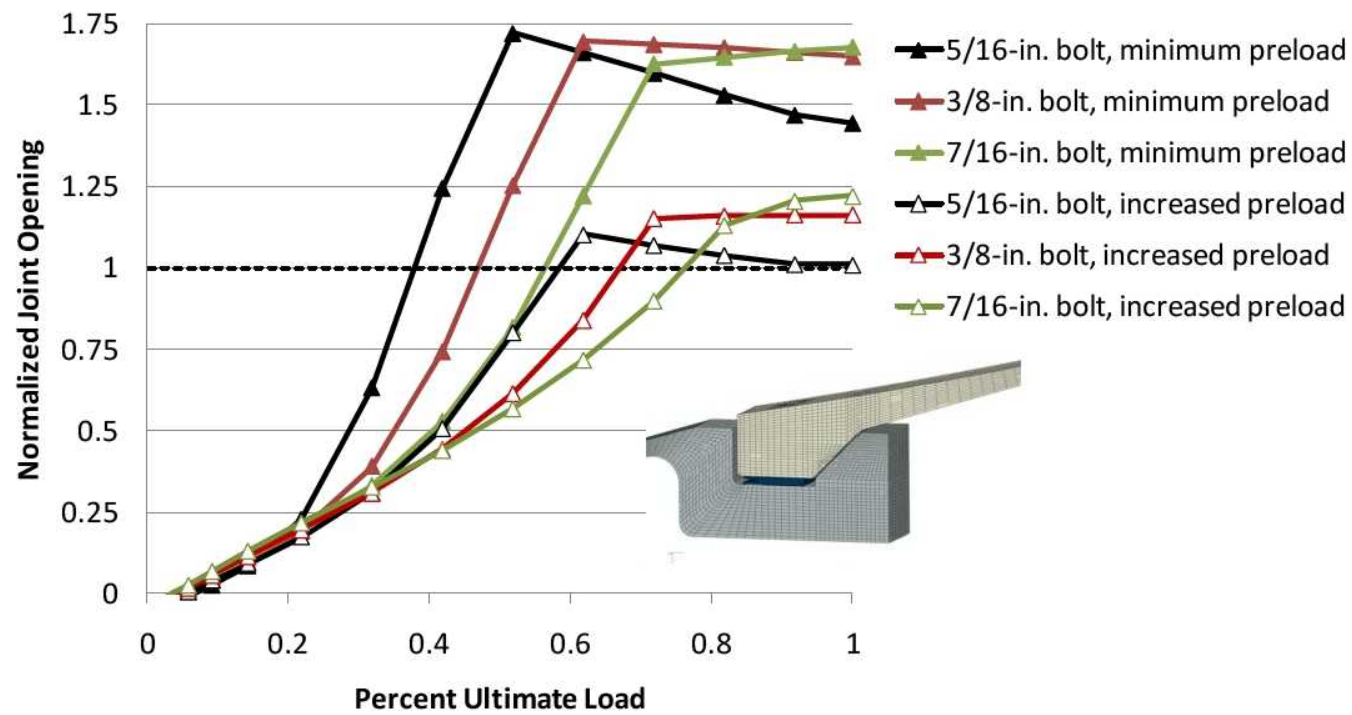

Figure 23. Joint opening vs. percent ultimate load for the three bolt sizes with increased preload - maximum clearance.

For the lip with maximum clearance,

- Sump lip makes contact with end cap after joint opening specification is reached

- Joint opening steadily increases as external load is applied until sump lip makes contact with end cap. Joint behavior after contact depends on bolt diameter

- Larger diameter bolts result in larger joint openings at ultimate load than the 5/16-in. bolt

- Joint opening does not meet specification

It appears that the joint opening is sensitive to not only the bolt preload and the lip clearance, but also the interaction between the two parameters. And, as mentioned previously, because of machining and assembly tolerancing, minimum clearance cannot always be guaranteed. Therefore, the results for maximum clearance must not be ignored. For the redesign configuration with full lip height and $45^{\circ}$ lip angle, the two-sided joint opening is $\left(\Omega / \Omega_{\text {spec }}\right) \leq 1.75$, which is a significant improvement over the baseline configuration $\left(\left(\Omega / \Omega_{\text {spec }}\right)=6.5\right)$ but still violates the specification.

Alternative redesign options are discussed next. 


\section{B. Joint Redesign Option \#2}

\section{Analysis}

As mentioned previously, the sump in the baseline configuration rotates as shown in Figure 14. Note the presence of heel-toe prying at the outer diameter of the seal. A redesign option that incorporates a Naflex seal with a larger outer diameter is considered. The seal outer diameter is assumed to extend to the outer diameter of the end cap bottom surface. It is expected that the larger-diameter seal will reduce the heel-toe prying, thereby reducing the sump rotation and joint opening.

\section{Results}

The deformed geometry is compared to the deformed geometry of the baseline configuration in Figure 24 . As expected, the sump rotation is reduced. The joint opening for the seal with the larger outer diameter is $\left(\Omega / \Omega_{\text {spec }}\right)=3.8$, which is a noticeable improvement over the baseline configuration, but still violates the seal specification. In addition, the larger diameter would require a redesign of the Naflex seal, negating the benefit of using an existing design. Therefore, this redesign is not explored further.

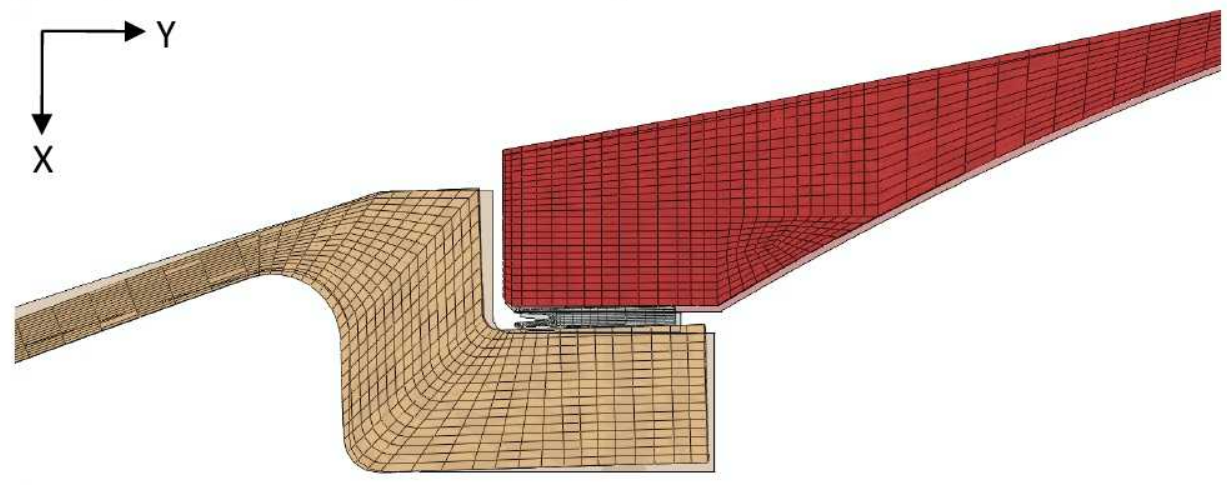

(a) Baseline configuration

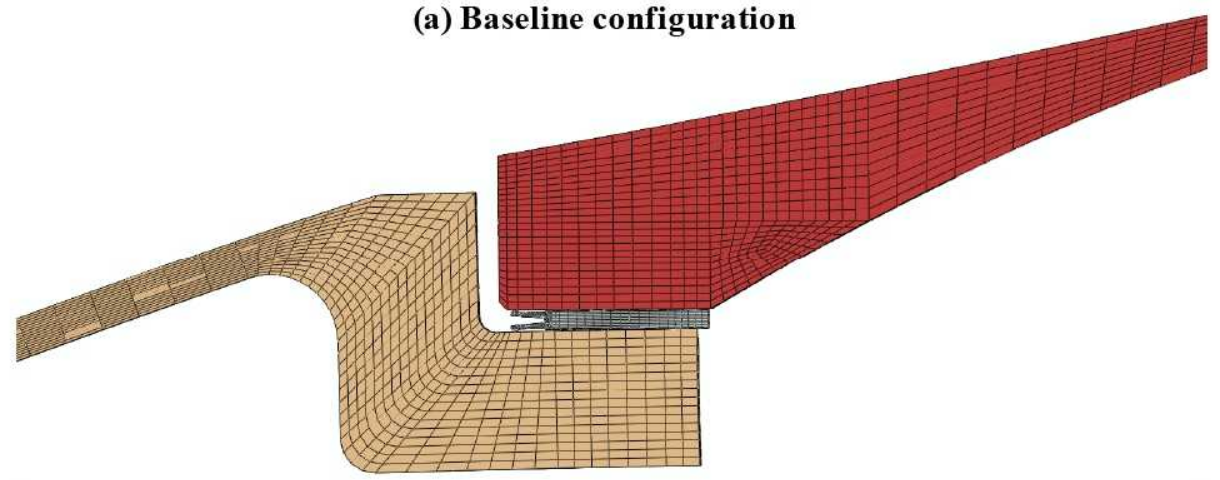

(b) Redesign with larger-diameter Naflex seal

Figure 24. Deformed geometries for baseline configuration and redesign with larger-diameter Naflex seal.

\section{Joint Redesign Option \#3}

\section{Analysis}

As mentioned previously, sump bending contributes to the joint opening. A redesign option that includes gussets on the sump, as shown in Figure 25(a), is considered. The gussets are assumed to be the same material as the sump (Al-2219).

\section{Results}

The deformed geometry is presented in Figure 25(b). The joint opening for the sump with the gussets is $\left(\Omega / \Omega_{\text {spec }}\right)=5.8$, which is a small improvement over the baseline configuration. This small improvement indicates that bending of the sump flange is a small contributor to joint opening compared to bolt bending. The joint opening violates the seal specification. This redesign is not explored further. 


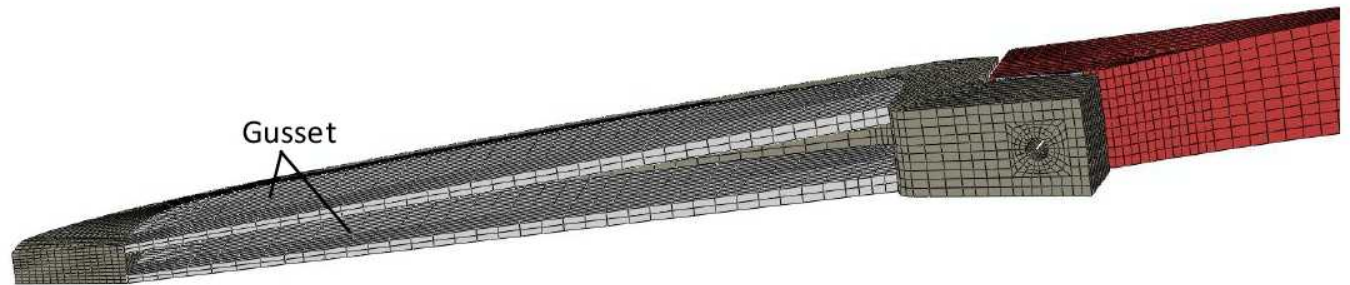

(a) Sump with gussets

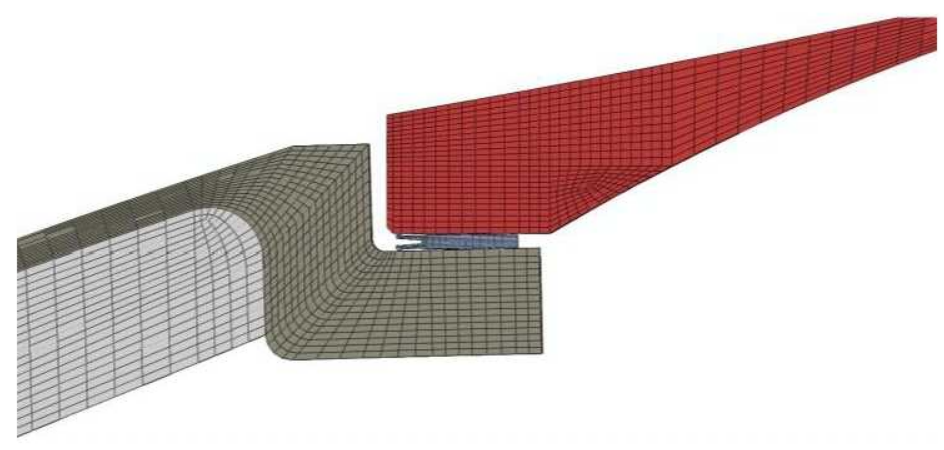

(b) Deformed geometry

Figure 25. Redesign that includes gussets on the sump.

\section{Summary}

For the Ares-I Upper Stage LOX tank sump seal joint with a Naflex seal, the baseline configuration with minimum bolt preload and "worst-case" external loads yields a two-sided joint opening of $\left(\Omega / \Omega_{\text {spec }}\right)=6.5$. Three redesign options were considered:

- Incorporating a lip on the sump to provide a mechanical stop feature yields joint openings in the range $0.75 \leq\left(\Omega / \Omega_{\text {spec }}\right) \leq 4.75$

- Using a seal with a larger outer diameter yields a joint opening of $\left(\Omega / \Omega_{\text {spec }}\right)=3.8$

- Adding gussets to the sump yields a joint opening of $\left(\Omega / \Omega_{\text {spec }}\right)=5.8$

The few redesign configurations that meet the two-sided joint opening specification all incorporate a sump lip with minimum clearance to the end cap. However, minimum clearance cannot be guaranteed. In addition, these configurations fail the one-sided joint opening specification. Therefore, it is concluded that the Naflex seal does not provide sufficient sealing capability for LOX tank sump seal joint. A redesign that uses a completely different type of seal is considered next.

\section{Joint Redesign Using RACO Seal}

The Space Shuttle ET LO2 feedline sections contain RACO and Creavey seals, as shown in Figure 26 (Anon., 1997). The RACO seal acts as the primary seal, and the Creavey seal acts as the secondary seal. For this type of seal joint, the joint opening allowable is much larger than the specification for the Naflex seals (Pilet and Geiman, 1997). For this reason, an inside-facing RACO seal is considered for use in the Ares-I LOX tank sump seal joint.

RACO seals are spring-actuated, pressure-assisted sealing devices consisting of a polymer jacket and a U-shaped metal spring (Anon., 2007). The jacket is usually Teflon, and the spring is usually Inconel-718 (Anon., 1997). RACO seals are recommended for extreme sealing conditions and cryogenic temperatures (Anon., 2007); in fact, RACO seals are designed specifically for cryogenic service. Diameter shrinkage of the joint assembly does not significantly affect the seal contact integrity. RACO seals with diameters to accommodate the Ares-I LOX tank sump seal joint can be readily manufactured (Anon., 2007 and Phillips, 2010).

The cross section of a RACO seal is shown in Figure 27. The seal sits in a groove in the bottom flange of the joint. The seal is initially in an open configuration. When the top flange is placed over the seal and the joint is tightened, the U-shape squeezes together, spring-loading the seal and bringing the primary sealing surfaces into tight contact with the two flanges. 

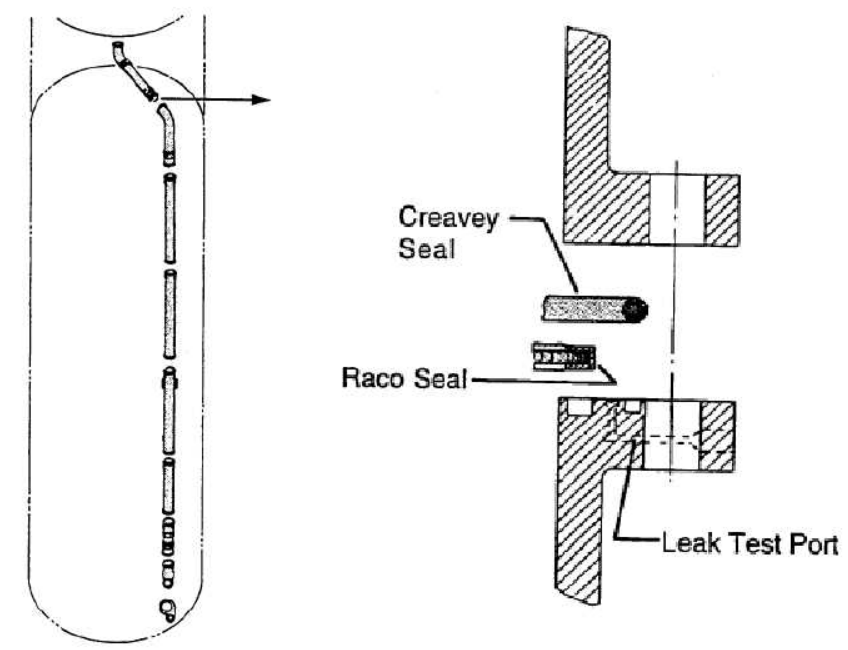

Figure 26. Typical RACO-Creavey seal joint used in Space Shuttle ET LO2 feedline (Anon., 1997).

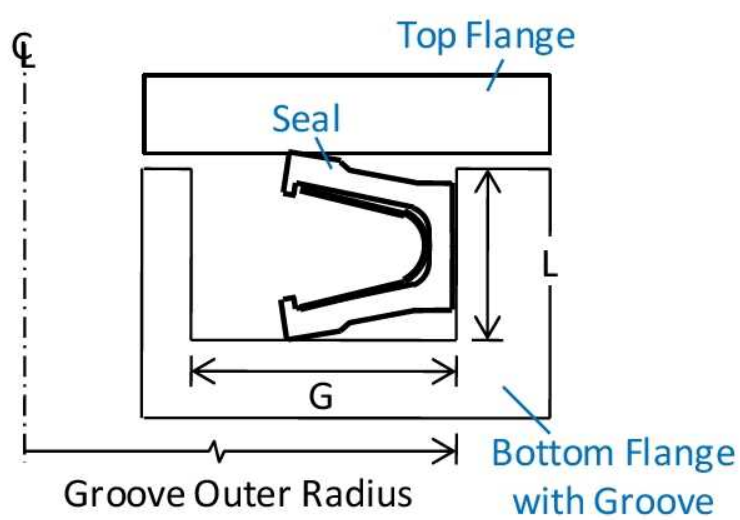

(a) Groove dimensions

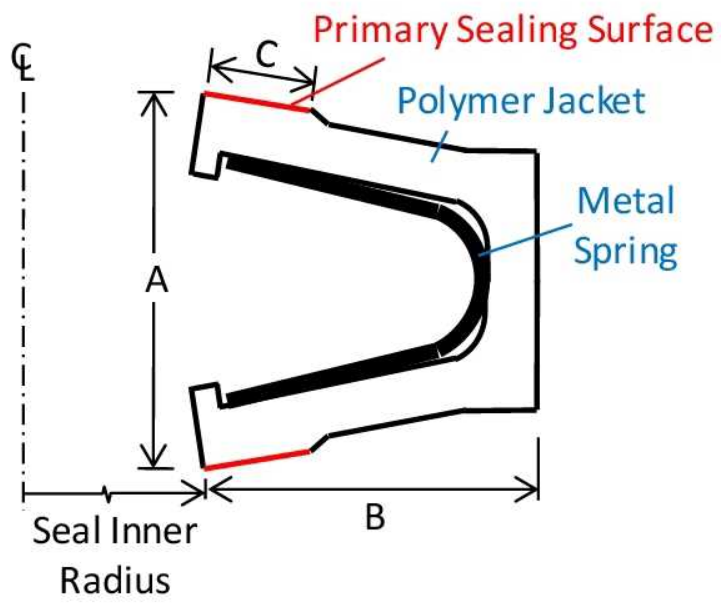

(b) Seal dimensions

Figure 27. RACO seal.

\section{A. Analysis}

The finite element model for the RACO seal analyses is created by modifying the existing geometries of the sump and end cap, as shown in Figure 28. The location of the bolt circle does not change, and the primary sealing surface is in approximately the same location as was the Naflex seal primary sealing surface. A groove is incorporated into the sump. The bottom of the end cap is extended down to mate with the sump surface.

A close-up of the modified seal joint cross section is shown in Figure 29. The dimensions for the groove and primary sealing surface are the nominal dimensions shown in Figure 27. Note that the seal is not explicitly included in the finite element model.

Unlike with the Naflex seal, because the RACO seal sits in a groove, the number of bolts around the circumference of the tank is not predefined. Therefore, a $5^{\circ}$ symmetric wedge is considered ( 72 bolts around the circumference), as shown in Figure 30.

The sump and end cap are also modified, as shown in Figure 31, to accommodate a 3/8-in. diameter bolt and its corresponding threaded insert.

The same modeling practices that were used for the Naflex seal analyses are used for the RACO seal analyses.

The linear-elastic, temperature-dependent material properties for the dome gore panel, end cap, sump, and bolt are provided in Table 1. 
The analyses are performed in three steps using the ABAQUS commercial FE software:

- Initial set-up: boundary conditions and shell-to-solid coupling (see Figure 6) and initial temperature

- Step 1: bolt preload

- Step 2: temperature load

- Step 3: pressure load and feedline interface loads

The sump and end cap, dome gore panel, and bolt are modeled with the ABAQUS C3D8I solid elements, S4 shell elements, and B31 beam elements, respectively. The entire model contains approximately 41500 elements, including 40938 solid elements, 380 shell elements, and 8 beam elements.

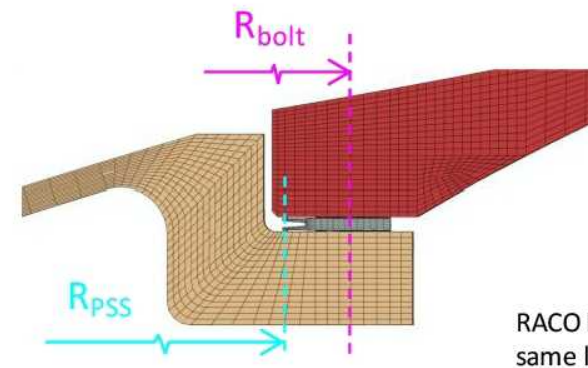

(a) Baseline geometry for joint with Naflex seal

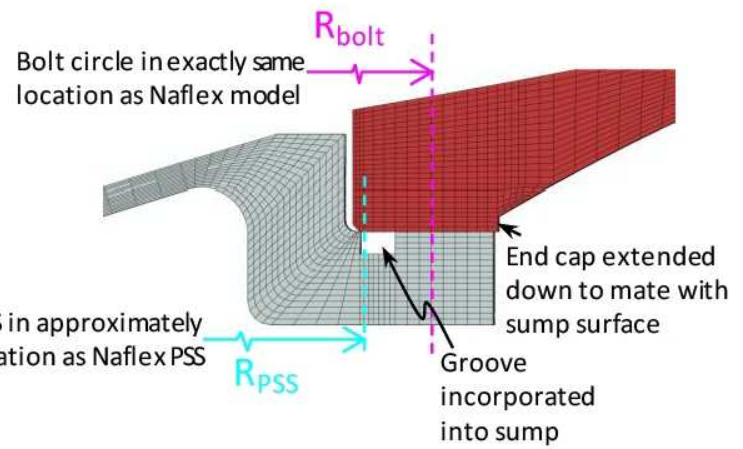

(b) Modified geometry for RACO seal

Figure 28. Modified geometry for the RACO seal analyses.

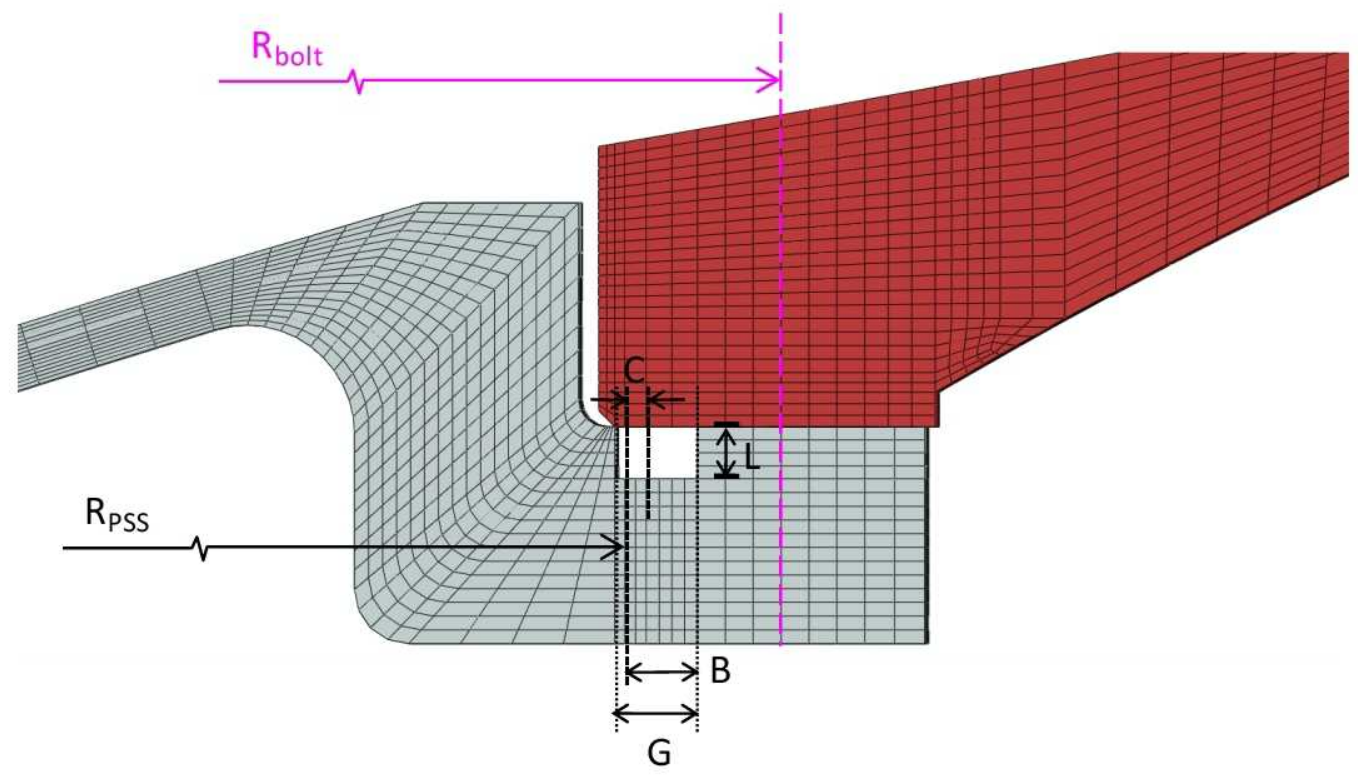

Figure 29. Close-up of modified cross section for the RACO seal analyses. 
(a) Assume $5^{0}$ symmetric wedge

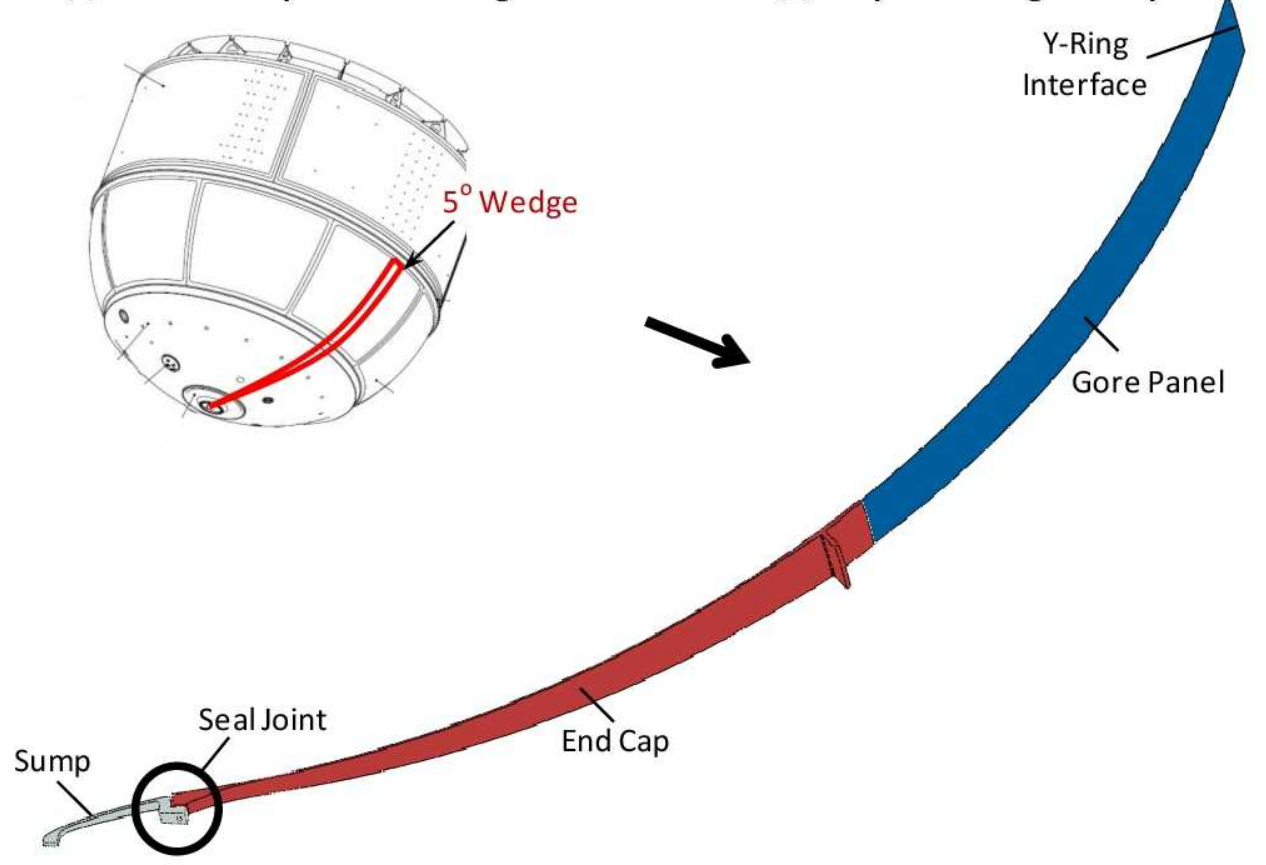

Figure $30.5^{\circ}$ symmetric wedge geometry for RACO seal analyses.

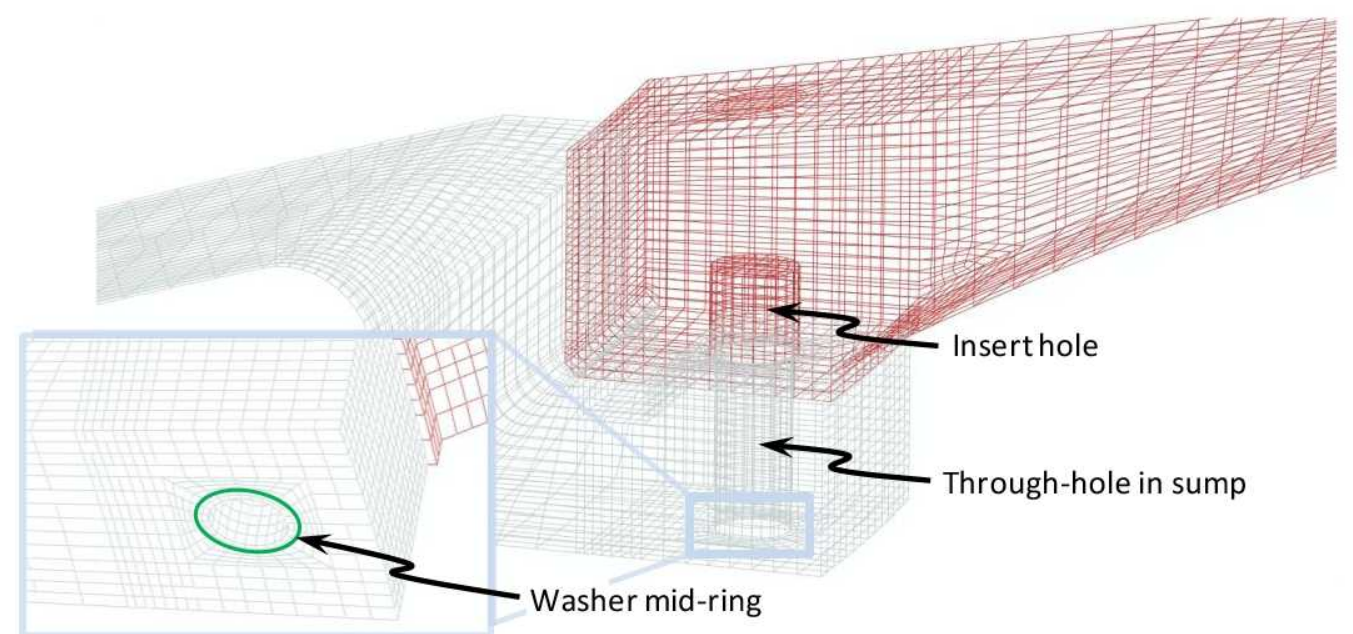

Figure 31. Modifications to sump and end cap to accommodate a 3/8-in. diameter bolt and its corresponding threaded insert.

Contact is defined between the sump and the end cap as shown in Figure 32. The sump is the slave surface, and the end cap is the master surface. The contact interaction is the finite-sliding, surface-to-surface formulation. The constraint enforcement methods in the directions normal to and tangential to the contact surfaces are "Hard" and "Frictionless," respectively.

The bolts are 3/8-in. diameter, $200 \mathrm{ksi}, \mathrm{A} 286$ fasteners, and the minimum preload (see Eq. 1) is used in the analyses. The minimum preload is $9207 \mathrm{lb}$.

The external loads are applied using the mixed FoS approach. The pressure load is applied, as indicated in Figure 33, along the entire inside surface of the assembly to the inner diameter of the groove in the sump. The same ultimate pressure (i.e., incorporating $\mathrm{FoS}=1.4$ ) that varies with X-station that was used for the Naflex seal analyses is applied as a distribution to the FE model. The worst case feedline interface loads (incorporating FoS $=2.0$ ) are applied to the bottom of the sump as shown in Figure 11.

The model described in this section will be referred to as the Baseline-RACO model.

American Institute of Aeronautics and Astronautics 


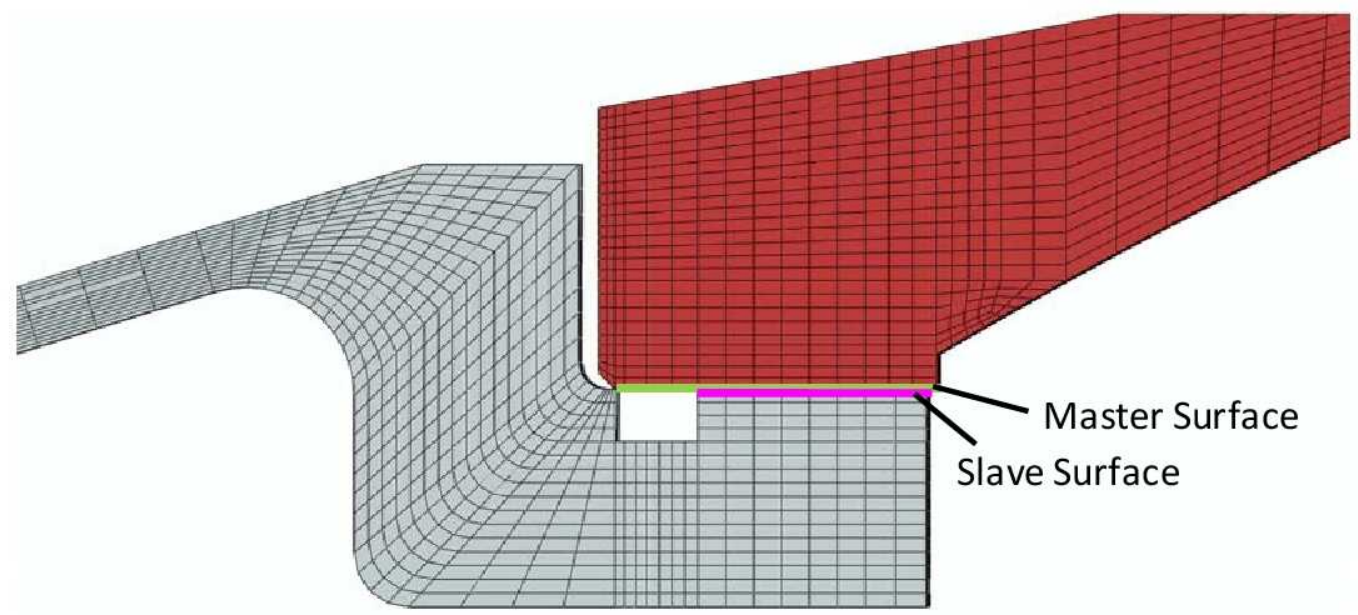

Figure 32. Contact modeling for the RACO seal analyses.

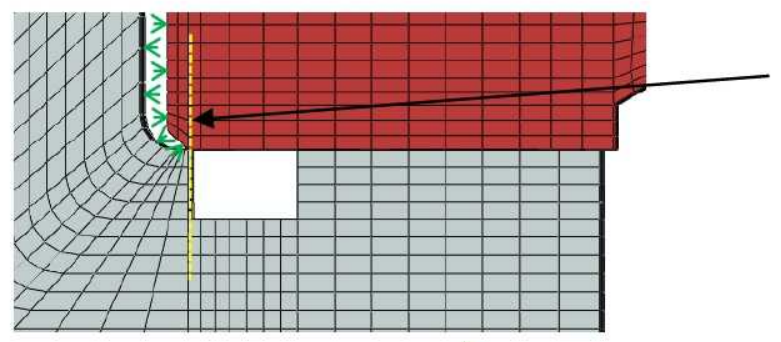

End Cap and Sump:

Pressure application extends to ID of groove
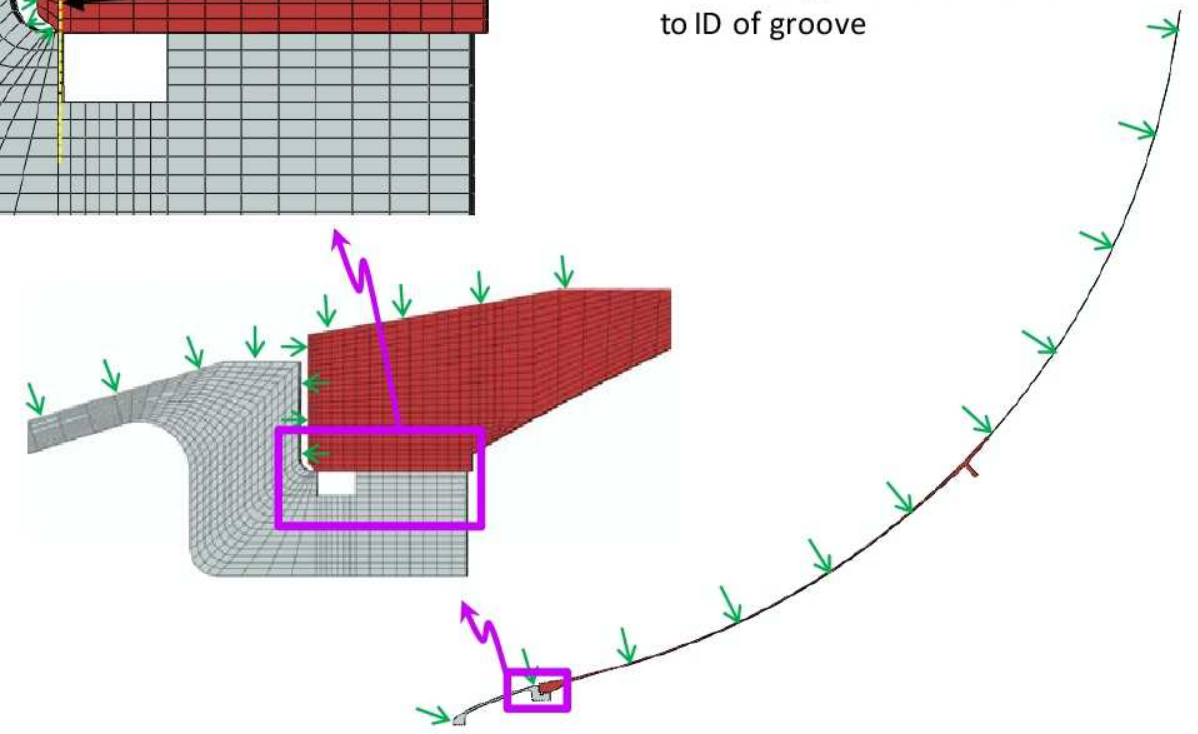

Figure 33. Pressure load applied to the 3D symmetric wedge finite element model for the RACO seal analyses.

\section{B. Seal Behavior and Joint Opening}

The joint opening $\Omega$ is computed using nodes at four locations:

- In line with the bolts (i.e., at the center of the wedge), at the primary sealing surface inner diameter (ID) and outer diameter (OD)

- Midway between successive bolts (i.e., on the symmetry plane), at the primary sealing surface ID and OD and using the axial (i.e., global $X$ ) deflections between the sump and the end cap, as shown in Figure 34 . The distance between the two flanges at the primary seal after the application of the bolt preload is subtracted from the distance between the two flanges after the external load is applied:

$$
\Omega=\delta_{X}^{\text {load }}-\delta_{X}^{\text {preload }}
$$




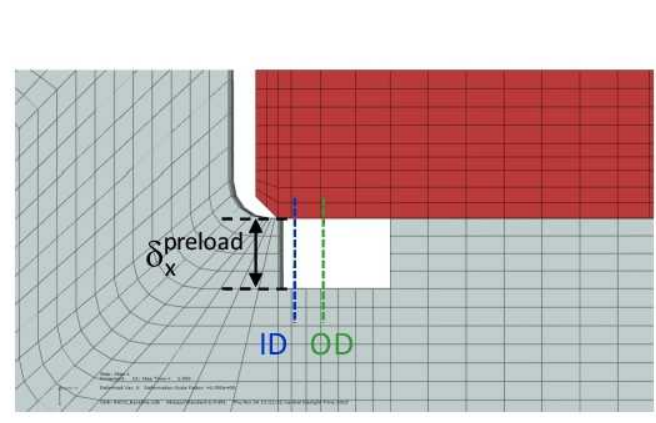

(a) After preload step

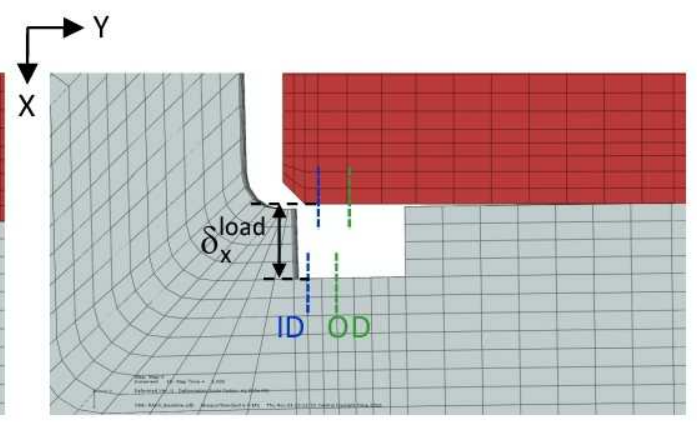

(b) After load step

Figure 34. Joint opening computation and locations for the RACO seal analyses.

This computation assumes negligible $X$-direction dimensional changes to the groove (i.e., negligible material deformation).

There are three available recommendations for the joint opening allowable for the RACO seals.

1. The first allowable is a heritage ET pre-test requirement (Anon., 1987). The test report refers to an even older qualification test program in which test flanges were designed for an allowable deflection with a predefined internal pressure. This joint opening allowable will be referred to as $\Omega_{\text {pre-ET }}$.

2. The second allowable is the design value resulting from the heritage ET test. The RACO seal was tested to a total deflection larger than $\Omega_{\text {pre-ET }}$ with no leakage (Pilet and Geiman, 1997). This joint opening allowable will be referred to as $\Omega_{\text {post-ET}}$.

3. The third allowable is from a seal vendor and is larger than $\Omega_{\text {pre-ET }}$ but smaller than $\Omega_{\text {post-ET }}$. The seals are not certified to an official deflection limit at the vendor level, and hence this allowable is a verbal recommendation only (Phillips, 2010). This joint opening allowable will be referred to as $\Omega_{\text {vendor }}$.

The computed values for joint opening are compared to all three of the joint opening allowables and are presented as normalized values (i.e., $\left(\Omega / \Omega_{\text {pre-ET }}\right.$ ), etc.). If the normalized values at the ID and $\mathrm{OD}$ are less than unity, then the integrity of the seal is maintained.

\section{Results}

The deformed geometry for the Baseline-RACO model is presented in Figure 35. The four joint opening values, normalized by each of the allowables, are presented in Table 7. As expected, the joint opening at the primary sealing surface ID is larger than at the OD. In addition, there is a negligible difference between the joint opening on the symmetry plane and on the plane in line with the bolt, indicating that 72 bolts around the circumference is sufficient to minimize joint opening waviness. The joint opening at the primary sealing surface ID exceeds all available recommendations for a joint opening allowable.

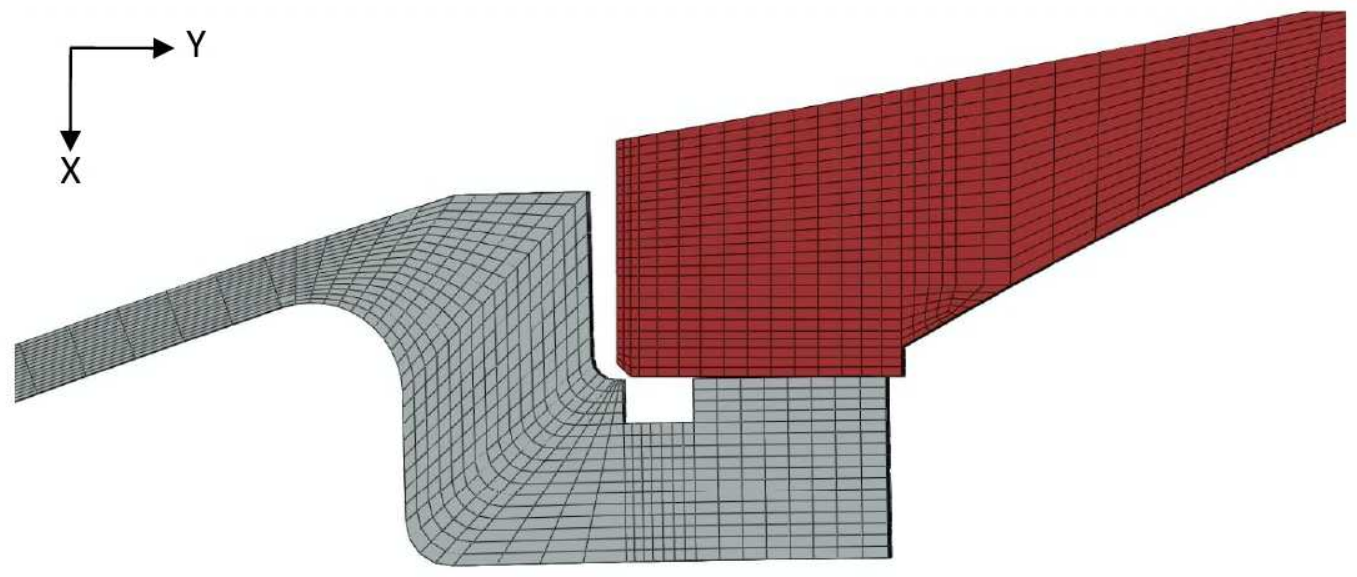

Figure 35. Deformed geometry for the Baseline-RACO model. 
Table 7. Joint opening values for the Baseline-RACO model.

\begin{tabular}{|c|c|c|c|c|}
\hline \multicolumn{2}{|c|}{} & $\left(\Omega / \Omega_{\text {pre-ET }}\right)$ & $\left(\Omega / \Omega_{\text {vendor }}\right)$ & $\left(\Omega / \Omega_{\text {post-ET }}\right)$ \\
\hline \hline \multirow{2}{*}{$\begin{array}{c}\text { On symmetry plane (i.e., } \\
\text { between bolts) }\end{array}$} & $\Omega_{\mathrm{D}}$ & 2.01 & 1.61 & 1.07 \\
\cline { 2 - 5 } & $\Omega_{\mathrm{OD}}$ & 1.75 & 1.40 & 0.93 \\
\hline \multirow{2}{*}{ In line with bolt } & $\Omega_{\mathrm{DD}}$ & 1.99 & 1.59 & 1.06 \\
\cline { 2 - 5 } & $\Omega_{\mathrm{OD}}$ & 1.72 & 1.38 & 0.92 \\
\hline
\end{tabular}

The effect of using a larger-diameter bolt to improve the response of the Baseline-RACO model is studied. The effect of increased bolt preload (that could be obtained using better process control during assembly and installation) is also studied. The bolt sizes and the preload values considered are presented in Table 8. Because the bolt is modeled with beam elements, for simplicity, no changes are made to the sump or end cap meshes (i.e., a larger hole is not incorporated).

Table 8. Bolt sizes and preload values considered.

\begin{tabular}{|c|c|c|}
\hline Bolt Diameter & Minimum Preload (Eq. 1) & Increased Preload (Eq. 4) \\
\hline $3 / 8$ in. & $9207 \mathrm{lb}$ & $15840 \mathrm{lb}$ \\
\hline $7 / 16$ in. & $12530 \mathrm{lb}$ & $21600 \mathrm{lb}$ \\
\hline
\end{tabular}

The joint opening values on the symmetry plane (i.e., between bolts), normalized by each of the allowables, are presented in Table 9. As expected, the joint opening decreases with increasing bolt diameter and increasing preload.

Table 9. Joint opening values for the various bolt size/preload combinations.

\begin{tabular}{|c|c|c|c|c|c|c|c|}
\hline \multicolumn{2}{|c|}{} & \multicolumn{2}{|c|}{$\left(\Omega / \Omega_{\text {pre-ET }}\right)$} & \multicolumn{2}{c|}{$\left(\Omega / \Omega_{\text {vendor }}\right)$} & \multicolumn{2}{c|}{$\left(\Omega / \Omega_{\text {post-ET }}\right)$} \\
\hline Bolt Diameter & Preload & $\Omega_{\mathrm{ID}}$ & $\Omega_{\mathrm{OD}}$ & $\Omega_{\mathrm{ID}}$ & $\Omega_{\mathrm{OD}}$ & $\Omega_{\mathrm{ID}}$ & $\Omega_{\mathrm{OD}}$ \\
\hline \multirow{2}{*}{$3 / 8$ in. } & Minimum & 2.01 & 1.75 & 1.61 & 1.40 & 1.07 & 0.93 \\
\cline { 2 - 8 } & Increased & 1.20 & 1.01 & 0.96 & 0.81 & 0.64 & 0.54 \\
\hline \multirow{2}{*}{$7 / 16$ in. } & Minimum & 1.49 & 1.26 & 1.19 & 1.01 & 0.79 & 0.67 \\
\cline { 2 - 8 } & Increased & 0.79 & 0.61 & 0.63 & 0.49 & 0.42 & 0.33 \\
\hline
\end{tabular}

\section{Summary}

A summary of whether the joint opening meets each of the available allowables is presented in Table 10. The joint opening for the model with the 7/16-in. bolt and increased preload meets all three of the allowables. For the remaining bolt size/preload combinations, the joint opening exceeds the smallest allowable $\left(\Omega_{\text {pre-ET }}\right)$ but meets the largest allowable $\left(\Omega_{\text {post-ET }}\right)$. Therefore, it is concluded that the RACO seal may provide sufficient sealing capability for the LOX tank sump seal joint. The analyses and results presented in this paper provide reasonable data to recommend the design change and plan a testing program to determine the capability of RACO seals in the Ares-I US LOX tank sump seal joint.

Table 10. Summary of whether the joint opening for each bolt size/preload combination in the sump seal joint using a RACO seal meets each of the available allowables.

\begin{tabular}{|c|c|c|c|}
\hline Bolt & $\left(\Omega / \Omega_{\text {pre-ET }}\right)$ & $\left(\Omega / \Omega_{\text {vendor }}\right)$ & $\left(\Omega / \Omega_{\text {post-ET }}\right)$ \\
\hline \hline 3/8-in., Minimum Preload & No & No & Yes (at OD only) \\
\hline 3/8-in., Increased Preload & No & Yes & Yes \\
\hline 7/16-in., Minimum Preload & No & No & Yes \\
\hline 7/16-in., Increased Preload & Yes & Yes & Yes \\
\hline
\end{tabular}

\section{Concluding Remarks}

Analyses of the Ares-I Upper Stage LOX tank sump seal joint were performed to predict relative deflections between the sump and the LOX tank end cap to assess the feasibility that the Naflex seal used with the Space Shuttle External Tank manhole covers can successfully be used for the Ares-I design.

The original joint opening specification that was specified for the Saturn and ET Projects was used to assess the capability of the Naflex seal in the Ares-I seal joints. The joint openings predicted for Ares-I were evaluated against the design specification for two-sided flange deflection. 
All of the analyses in this paper are three-dimensional symmetric wedge finite element analyses performed using the ABAQUS commercial finite element software. Modeling practices that were previously established for the LH2 tank manhole cover analyses and anchored to ET test data were employed for the LOX tank sump analyses.

For the baseline sump seal joint, the joint opening exceeded the design specification. Therefore, several redesign options were explored. First, because there is a strong desire to use the Naflex seal because it is an existing ET part, design changes that could be made to continue with the Naflex seal were explored. The large values for joint opening in the baseline configuration were determined to be due to sump and bolt bending. Three redesign options were considered to reduce this bending.

An alternate configuration that incorporates a mechanical stop (i.e., a lip) such as the one in the LH2 tank manhole cover was examined. The existing FE models for the sump and end cap were modified within a Design of Experiments matrix, the analyses were performed, and the factors that affect the joint opening the most were assessed. The redesign configuration with full lip height and $45^{\circ}$ lip angle showed the most improvement over the baseline configuration; however, the joint opening still exceeded the design specification.

A redesign option that incorporates a Naflex seal with a larger outer diameter was considered. The joint opening for the seal with the larger outer diameter showed noticeable improvement over the baseline configuration; however, the joint opening still exceeded the design specification.

A redesign option that includes gussets on the sump was considered. The joint opening for the sump with the gussets showed only a small improvement over the baseline configuration, indicating that most of the bending is due to the bolt. The joint opening exceeded the design specification.

Because all three redesign options that utilize the existing Naflex seal predicted joint openings that exceed the design specification, it was concluded that the Naflex seal does not provide sufficient sealing capability for the AresI Upper Stage LOX tank sump seal joint. Therefore, a redesign that uses a completely different type of seal was considered.

An inside-facing RACO seal was considered for use in the Ares-I Upper Stage LOX tank sump seal joint. Seals of this type are also used on the Space Shuttle ET and can accommodate larger joint deflections than Naflex seals.

The finite element model for the RACO seal analyses was created by modifying the existing geometries of the sump and end cap. The same modeling practices that were used for the Naflex seal analyses were used for the RACO seal analyses. Several bolt sizes and preload values were considered.

There are three available recommendations for the joint opening allowable for the RACO seals. The first and smallest allowable is a requirement from a heritage ET test. The second and largest allowable is the design value that was determined during the heritage ET test. The third allowable is from a seal vendor. The joint opening values computed from the finite element results were compared to each of these allowables.

For most of the bolt size/preload combinations considered, the joint opening exceeded the smallest allowable but met the largest allowable. Therefore, it was concluded that the RACO seal may provide sufficient sealing capability for the LOX tank sump seal joint. The analyses and results presented in this paper provide reasonable data to recommend the design change and plan a testing program to determine the capability of RACO seals in the Ares-I Upper Stage LOX tank sump seal joint.

\section{References}

Anon. (undated): "Static Cryogenic Seals for Launch Vehicle Applications," NASA Preferred Reliability Practice No. PDED-1208.

Anon. (1987): Flange Deflection Capability Test for Creavey and Naflex Secondary Seals, MMC-ET-SE05-223, 27 October 1987.

Anon. (1997): Space Shuttle External Tank System Definition Handbook, SLWT, Document No. LMC-ET-SE61-1, Volume 1, Section 9.2.1, December 1997.

Anon. (ca. 2000): "Naflex Cryogenic and High-Temperature Static Face Seals by Langley," Product brochure by Magellan Aerospace Turbine Services, LLC.

Anon. (2001): Space Shuttle External Tank Critical Items List (CIL), Doc. No. MMC-ET-RA04b-K, Lockheed Martin Michoud Space Systems.

Anon. (2007): OmniSeal Handbook, Saint-Gobain Performance Plastics, Document No. BST-4075-3M-1107-SGCS, 2007.

Anon. (2008): Constellation Program Structural Design and Verification Requirements, NASA CxP 70135, Change 004, 25 August 2008 .

Anon. (ca. 2009): Specification Control Drawing: Flange Seals, George C. Marshall Space Flight Center Drawing No. 97M28929.

RI.

Anon. (2009): ABAQUS Analysis User's Manual: Volumes I - VI, Version 6.9, Dassault Systèmes Simulia Corp., Providence, 
Gillespie, S. E. (1988): Manhole NAFLEX Seal Leakage Test, Martin Marietta Manned Space Systems Test Report 826-2369, September 1988.

Phillips, D. R. and Wingate, R. J. (2010): "Seal Analysis for the Ares-I Upper Stage Fuel Tank Manhole Covers," Proceedings of the $51^{\text {st }}$ AIAA SDM Conference, Orlando, Florida, April 12-15, 2010, Paper No. AIAA-2010-2783.

Phillips, D. R. (2010): Phone conversation with Mr. Silvano Bosdachin, Design Engineer at Saint-Gobain, documented in email dated 28 October 2010.

Pilet, J. and Geiman, W. (1997): Space Shuttle External Tank Stress Analysis, Lockheed Martin Report MMC-ET-SE05-439, Section D.9.3, December 1997.

Robbins, R. F. and Ludtke, P. R. (1964): "Review of Static Seals for Cryogenic Systems," Journal of Spacecraft, Vol. 1, No. 3, May-June 1964. 


\title{
Seal Joint Analysis and Design for the Ares-I Upper Stage LOX Tank
}

\author{
Dawn R. Phillips \\ NASA Marshall Space Flight Center \\ Robert J. Wingate \\ NASA Marshall Space Flight Center
}




\section{Objective}

- Assess the feasibility of using an existing Space Shuttle External Tank Naflex seal design in the Ares-I Upper Stage LOX tank sump joint.

- Assess alternative designs if the Naflex seal does not meet requirements. 


\section{Outline}

- Problem description

Background

- Approach for LOX tank analyses

Analyses and results

Summary 


\section{Ares-I Upper Stage LOX Tank}
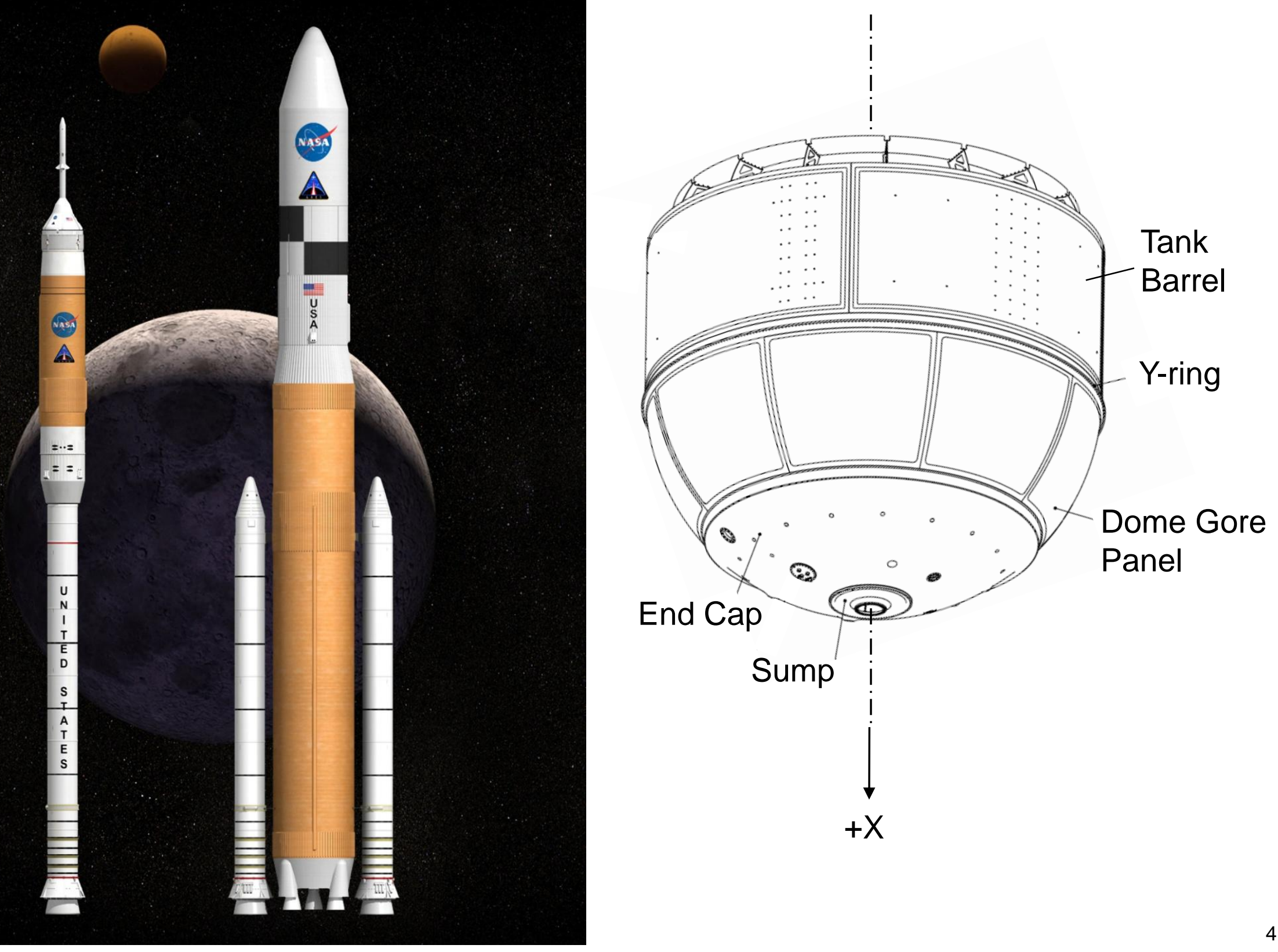


\section{Naflex Pressure-Assisted Seal}
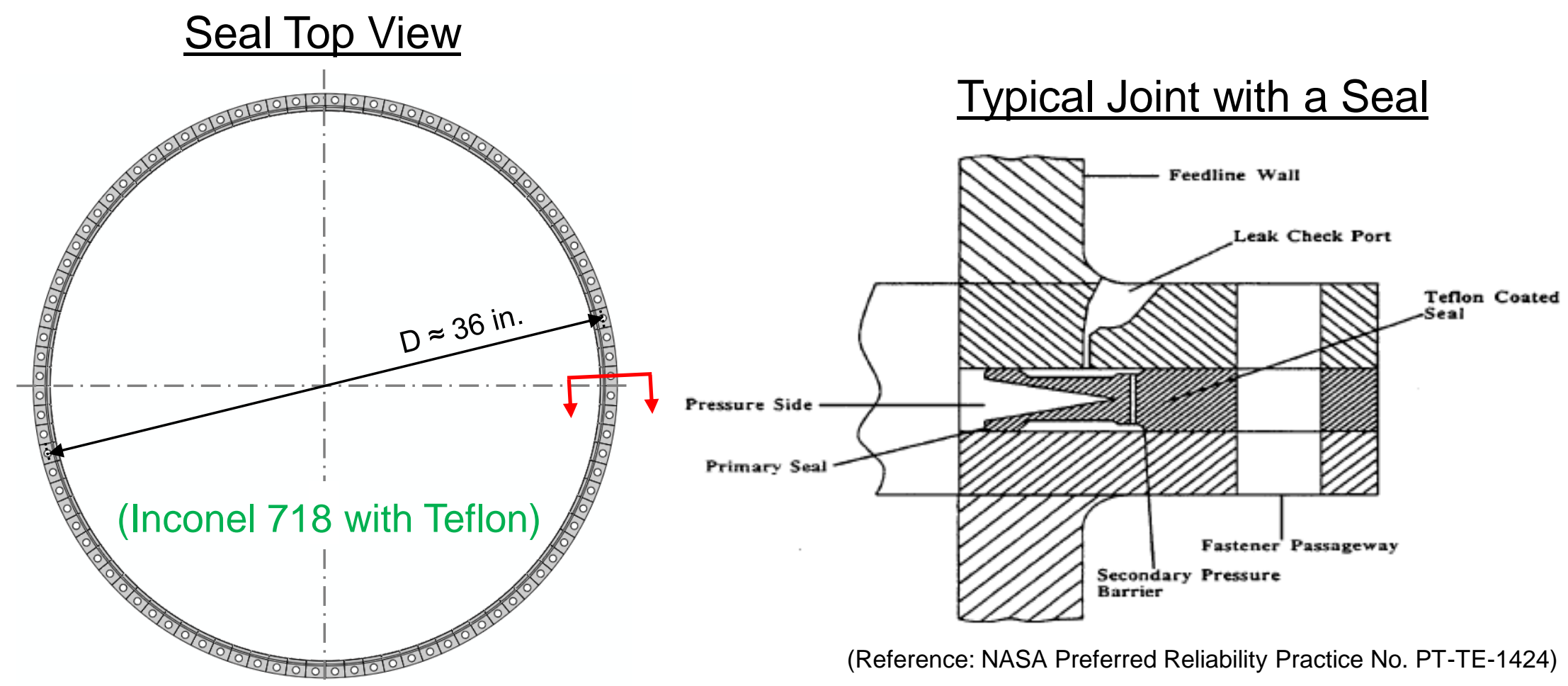

(Reference: NASA Preferred Reliability Practice No. PT-TE-1424)

Seal Section View

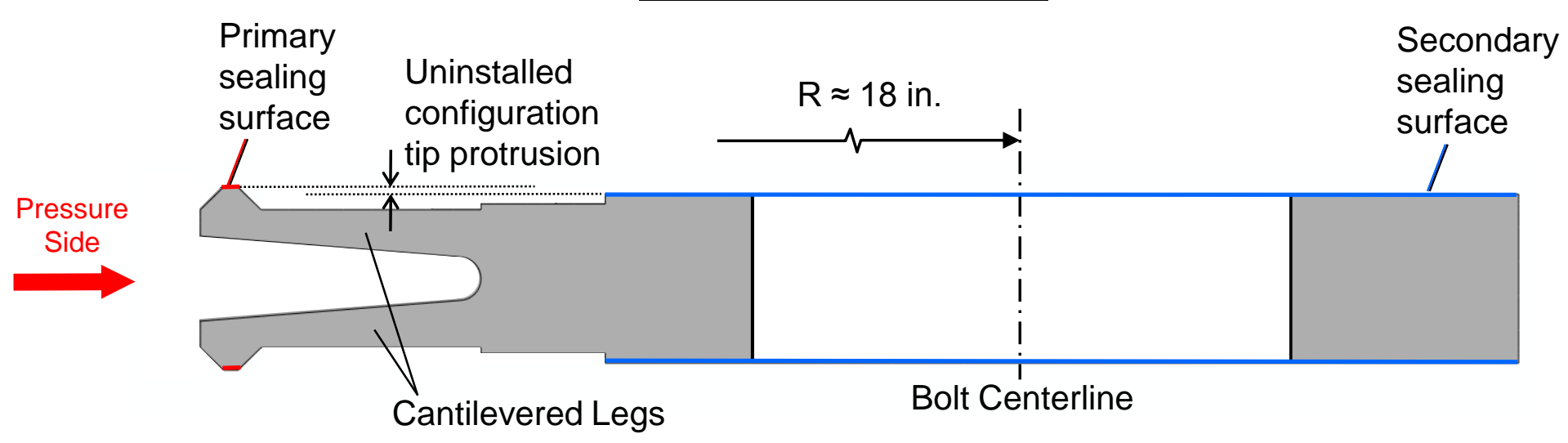




\section{Background}

- Naflex seals have long history of use in launch vehicle components, including Saturn stages and Space Shuttle External Tank

- Ares-I Upper Stage tank design, pressures, and external loads are different than $\mathrm{ET}$, requiring performance verification of heritage seal design in new tank configurations

- Previous analyses performed to assess use of ET Naflex seal with Upper Stage LH2 tank manhole covers

- 3D finite element analyses

- Modeling practices anchored to historic ET test

- Design shown to perform adequately

- New analyses required to assess use of Naflex seal with Upper Stage LOX tank sump

- Sump provides interface between LOX feedline and tank

- Sump is bolted, rather than welded, to tank to provide access to inside of tank in lieu of a manhole cover 


\section{Approach for LOX Tank Analyses}

Use anchored modeling practices of heritage ET test and Upper Stage LH2 tank analyses

- Calculate joint opening and compare to requirement defined in seal specification control drawing 


\section{Baseline Model for Naflex Seal Analyses}

\section{Seal Symmetry}

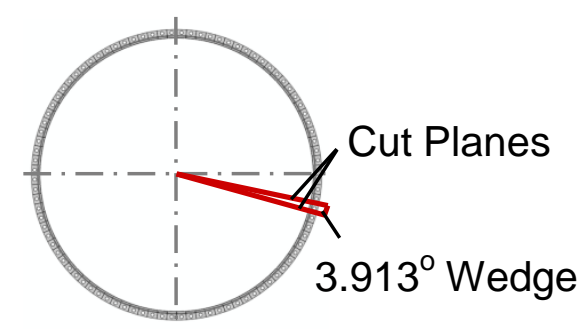

Temperature-Dependent Material Properties

\begin{tabular}{|c|c|}
\hline Part & Material \\
\hline $\begin{array}{c}\text { Dome Gore } \\
\text { Panel }\end{array}$ & Al 2195 \\
\hline $\begin{array}{c}\text { End Cap, } \\
\text { Sump }\end{array}$ & Al 2219 \\
\hline $\begin{array}{c}\text { Seal } \\
\text { Bolt }\end{array}$ & Inconel-718 \\
\hline
\end{tabular}
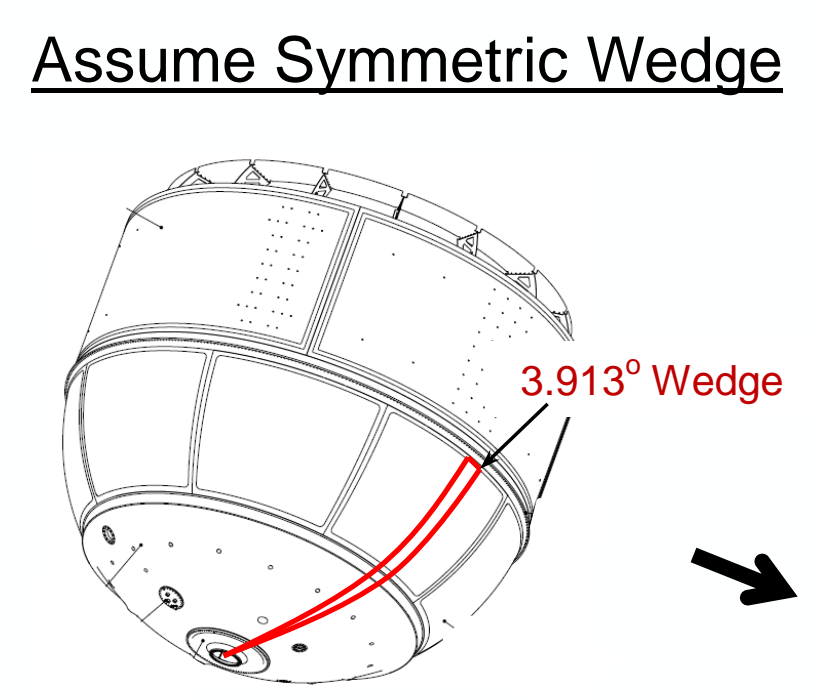

$\underline{3.913^{\circ} \text { Symmetric }}$ Geometry 


\section{Baseline Model for Naflex Seal Analyses}

Three-Step Analysis: ABAQUS v.6.9-EF

- Bolt preload applied

- Temperature load applied $\left(-297^{\circ} \mathrm{F}\right)$

- Pressure load and feedline interface loads applied

Element Type and Mesh Refinement

- Sump, seal, and end cap: Solid elements, C3D8I

- Dome gore panel: Shell elements, S4

- Bolt: Beam elements, B31

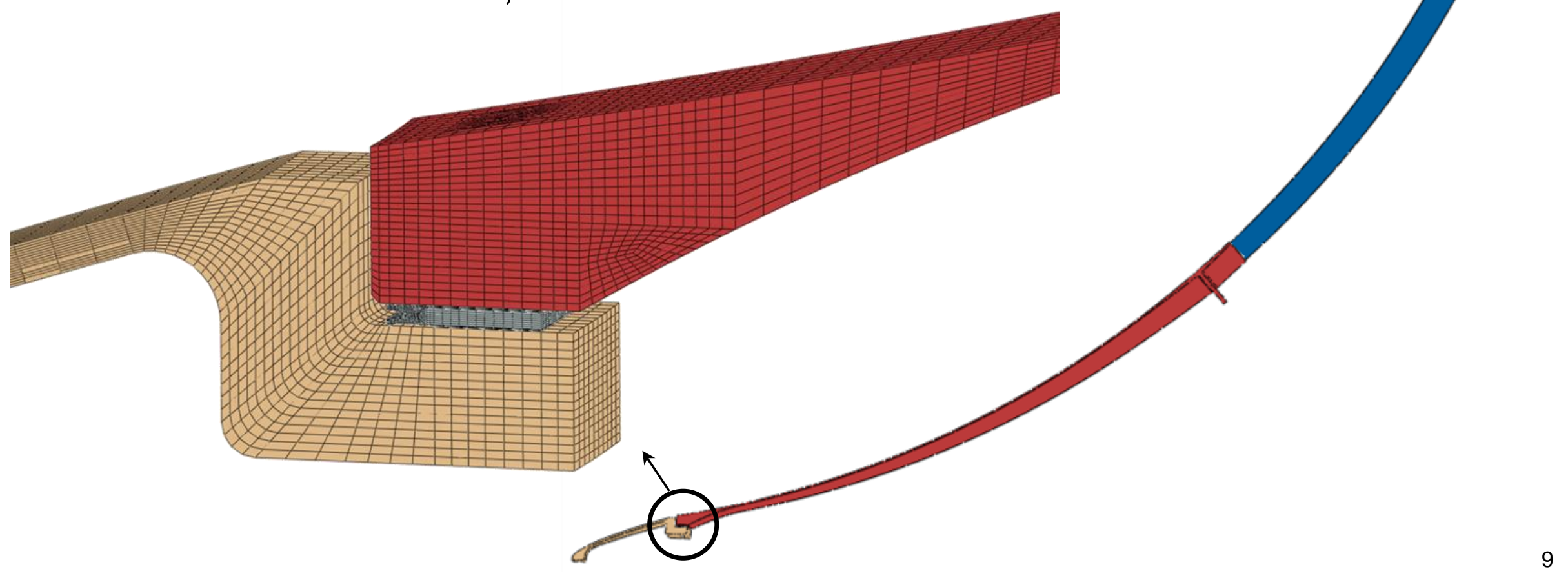




\section{Baseline Model for Naflex Seal Analyses}

\section{Boundary Conditions and Shell-To-Solid Coupling}

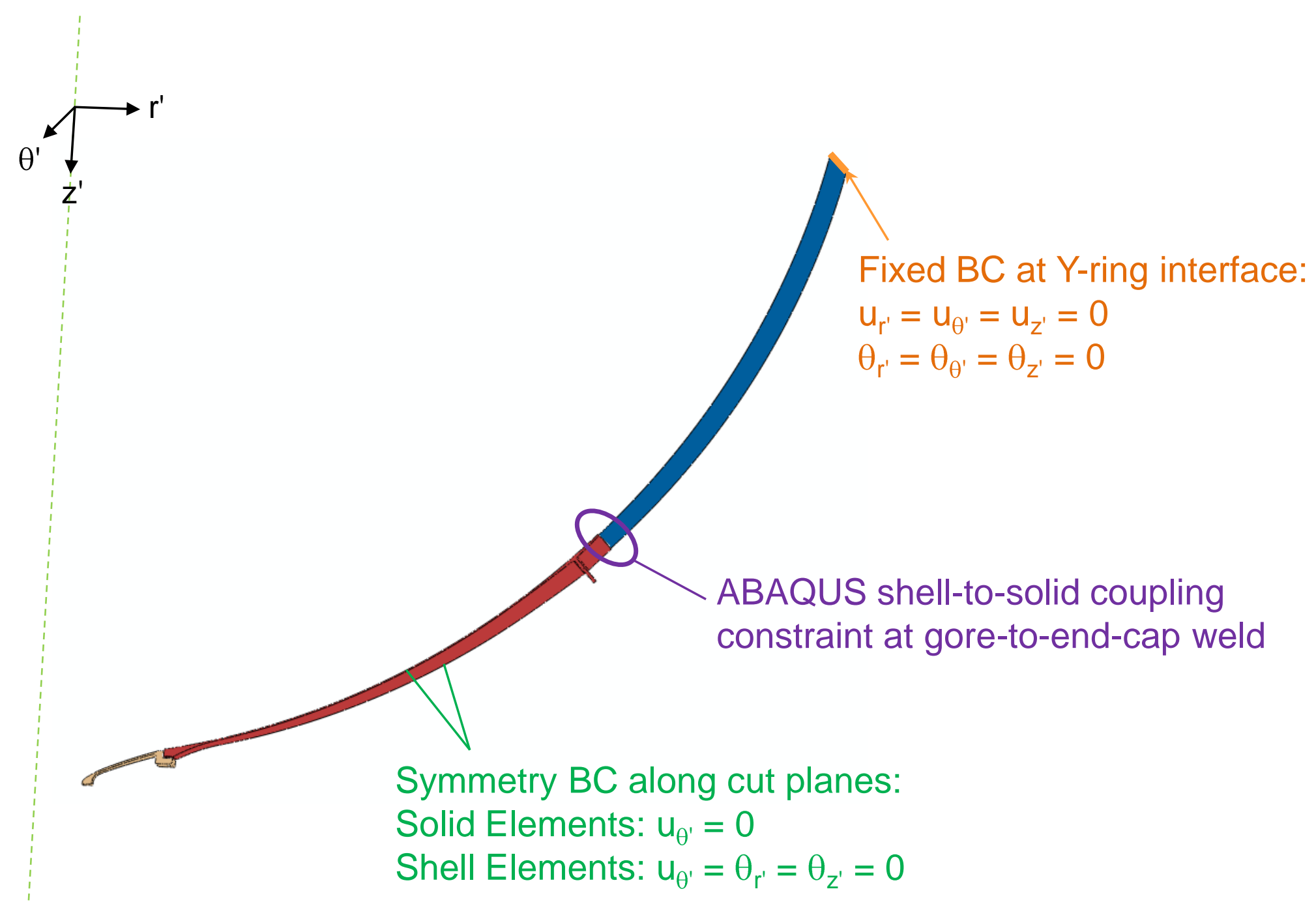




\section{Baseline Model for Naflex Seal Analyses}

\section{Bolt Modeling and Spider Constraints}

Bolted Joint in Sump Seal Joint

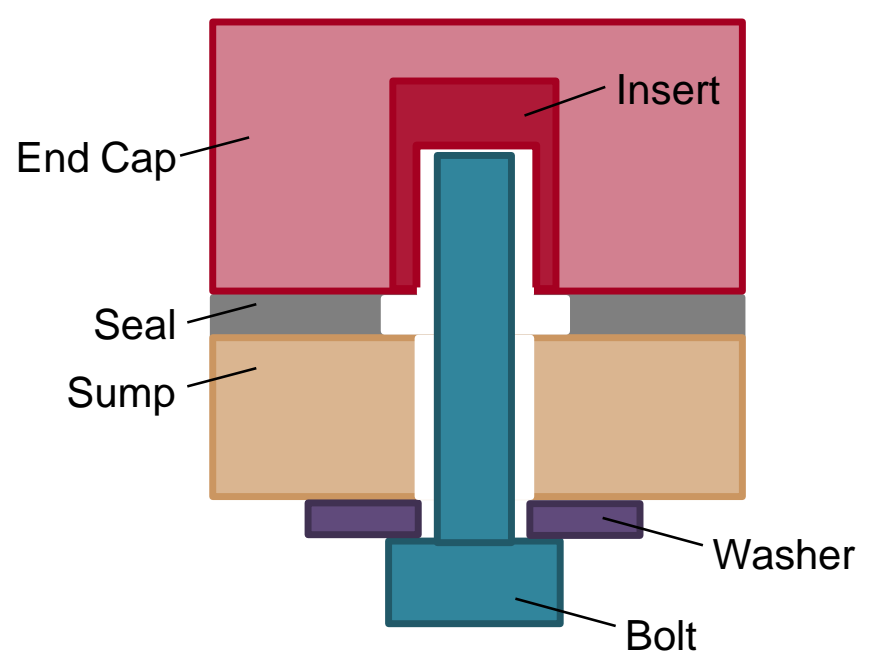

Spider Constraints in Finite Element Model

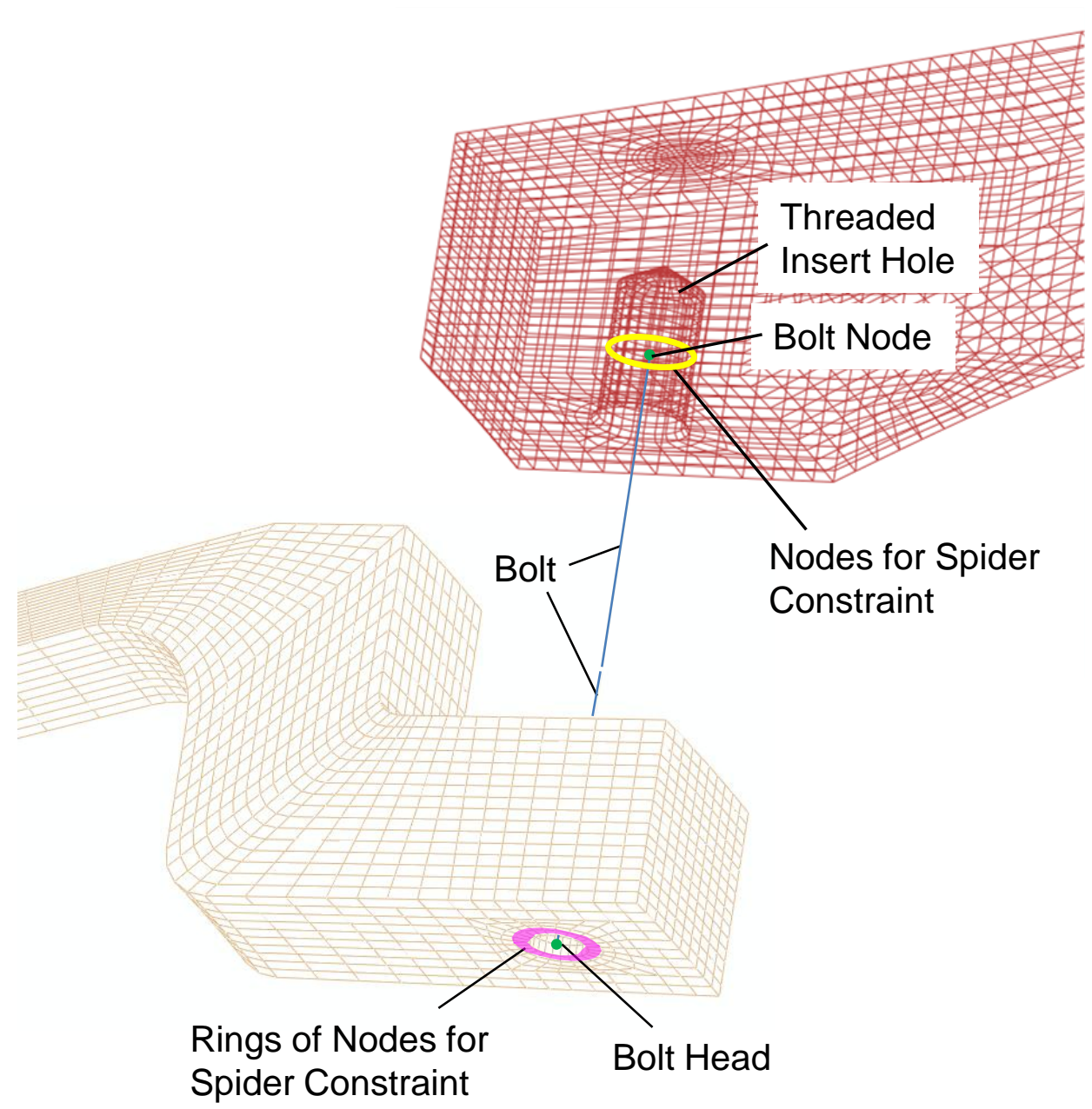




\section{Baseline Model for Naflex Seal Analyses}

Contact Modeling at Seal Primary and Secondary Sealing Surfaces

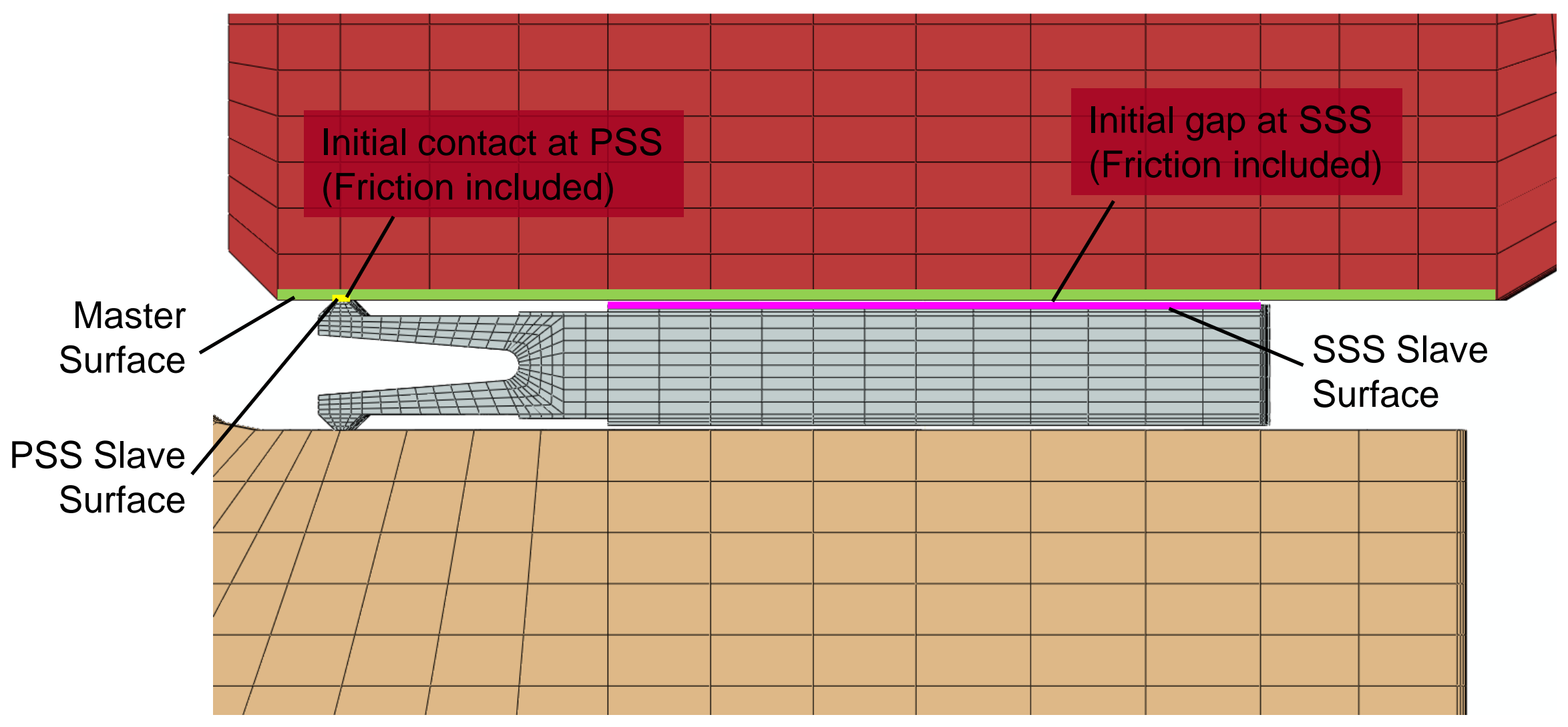

Teflon coating: coefficient of friction $\mu=0.05$ 


\section{Baseline Model for Naflex Seal Analyses}

\section{$\underline{\text { Ultimate Loads }}$}

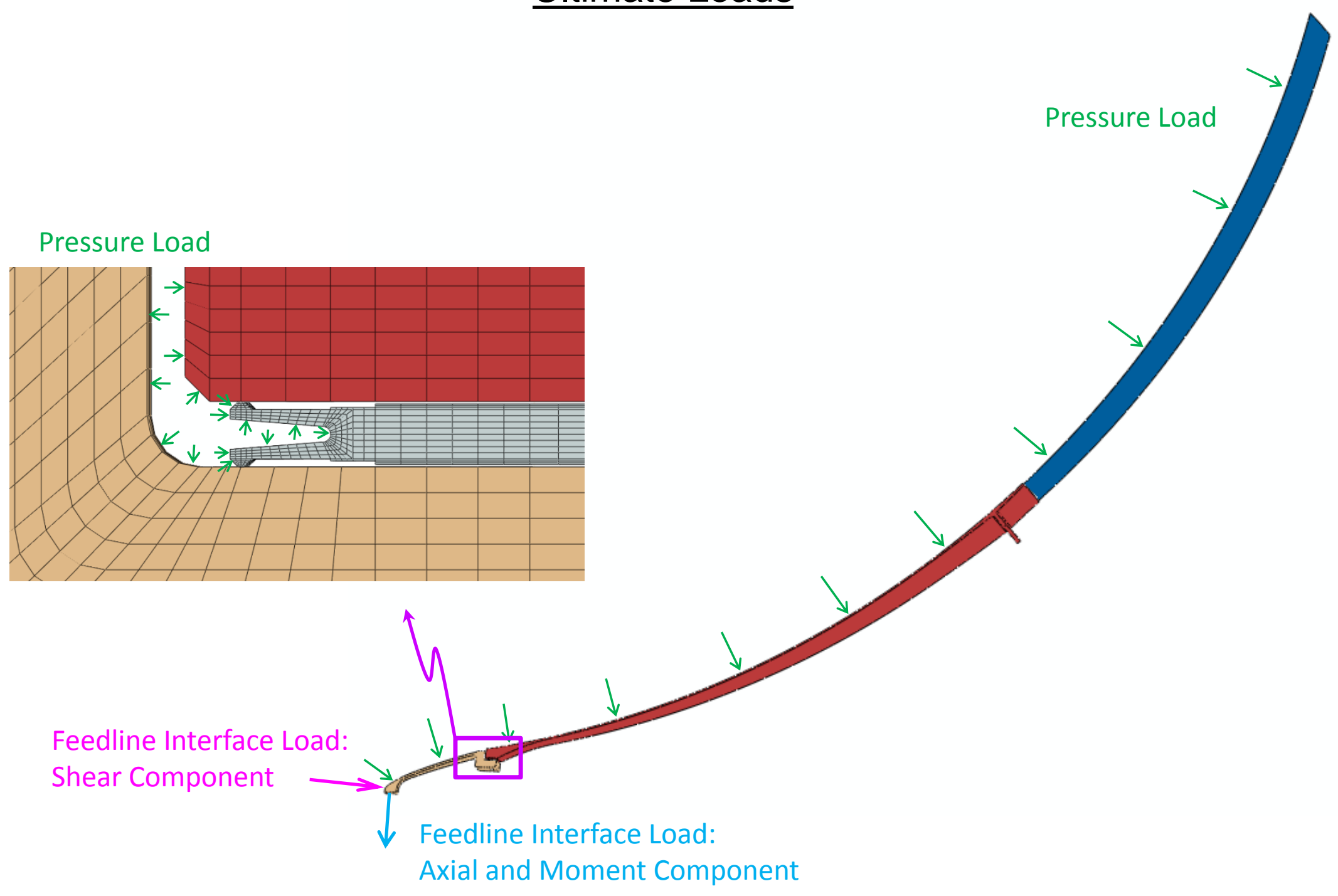




\section{Naflex Seal Behavior and Joint Opening}

$\underline{\text { After Bolt Preload Applied }}$

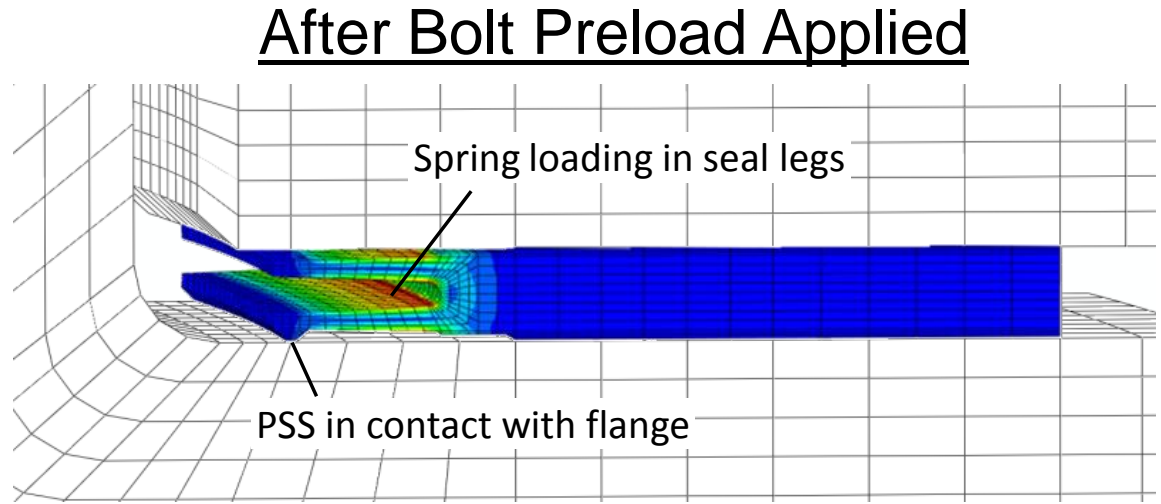

After Some External Load Applied

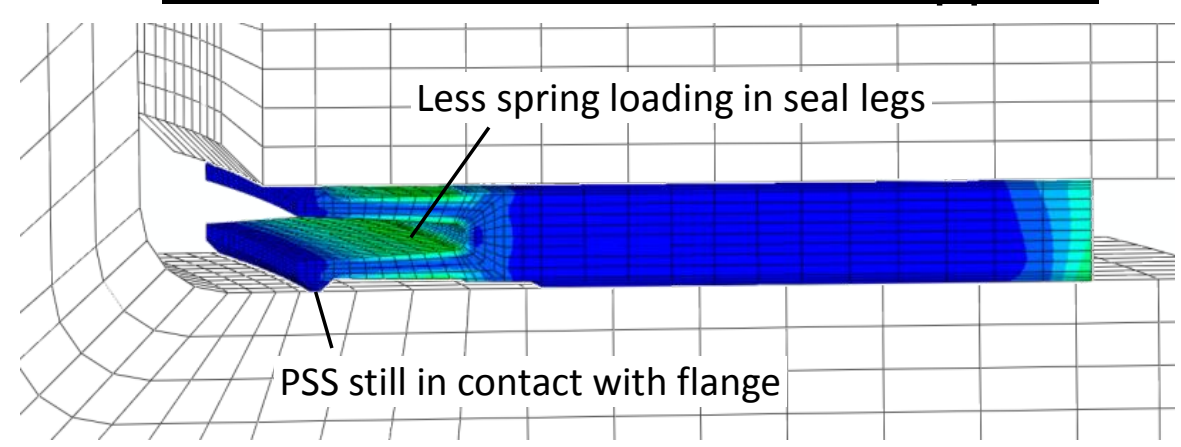

After More External Load Applied

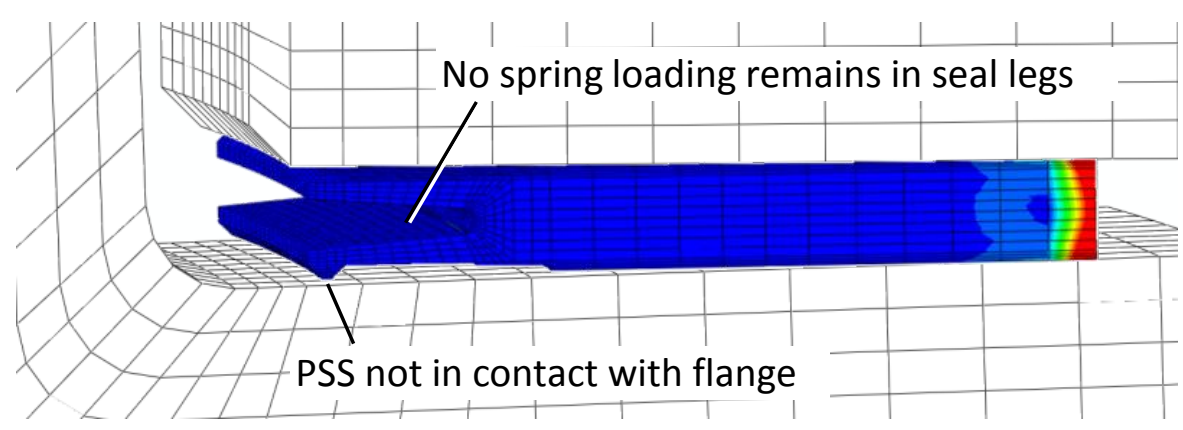




\section{Naflex Seal Behavior and Joint Opening}

Joint Opening Computation

$$
\Omega=\delta_{\mathrm{x}}^{\text {load }}-\delta_{\mathrm{x}}^{\text {preload }}
$$
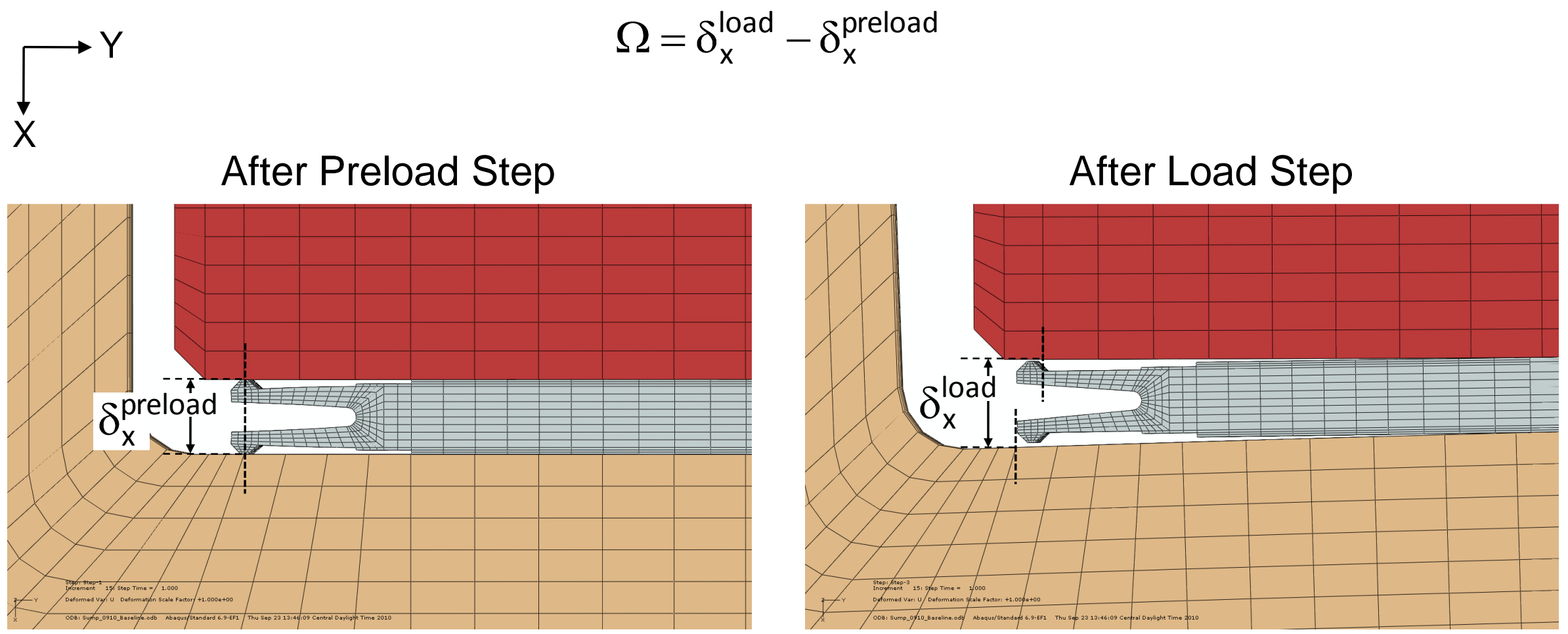

Seal Specification Joint Opening Requirement:

- Flanges must be designed to permit no more than $\Omega_{\text {spec }}$ relative deflection under worst-case design load conditions

$\curvearrowright / \Omega_{\text {spec }} \leq 1.0$ 


\section{Joint Redesign Using Naflex Seal}

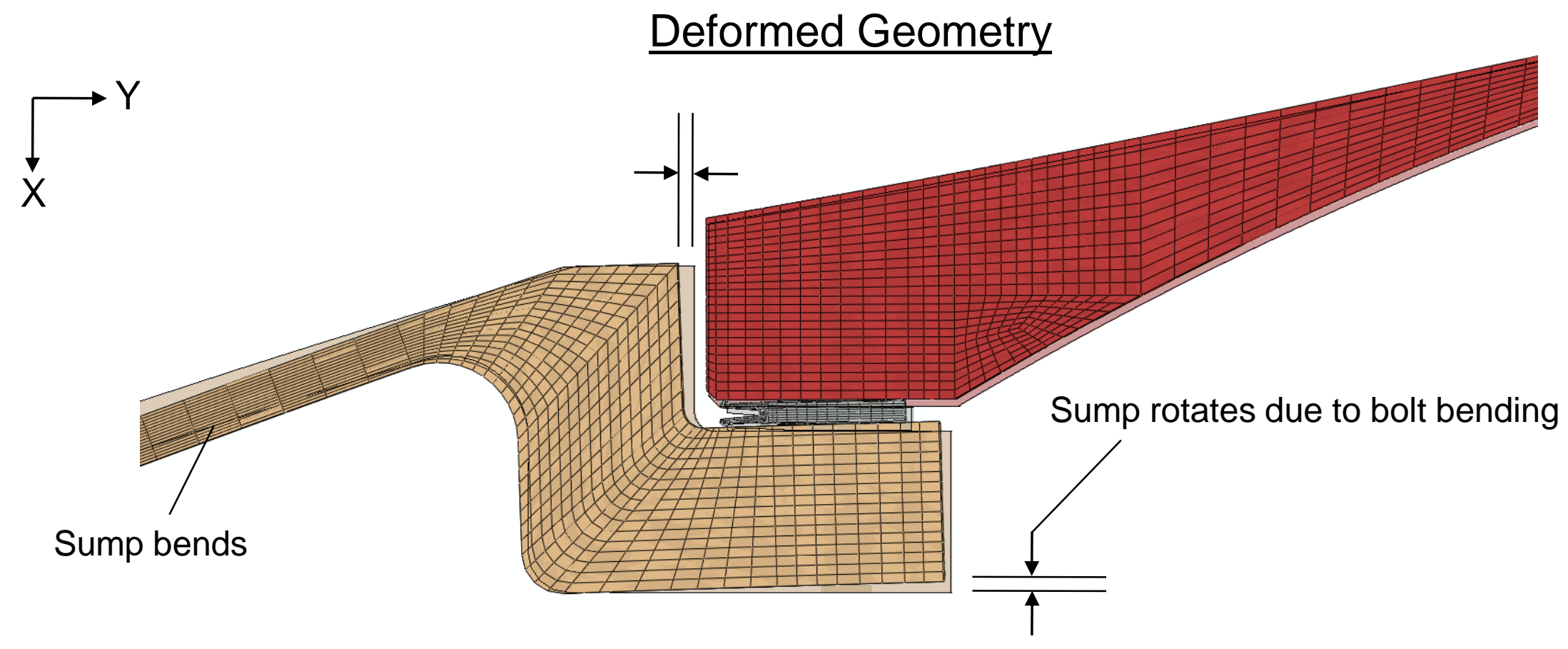

Joint opening does not meet specification

- $\Omega / \Omega_{\text {spec }}=6.5$

Redesign necessary to reduce joint opening

- Strong desire to use Naflex seal because it's an existing ET part

$>$ Three redesign options to reduce sump rotation and bending 


\section{Joint Redesign Option \#1}

\section{Incorporate mechanical stop feature}

\section{Previously Analyzed Ares-I Upper Stage LH2 Tank Manhole Cover}

\section{Before Load Applied}

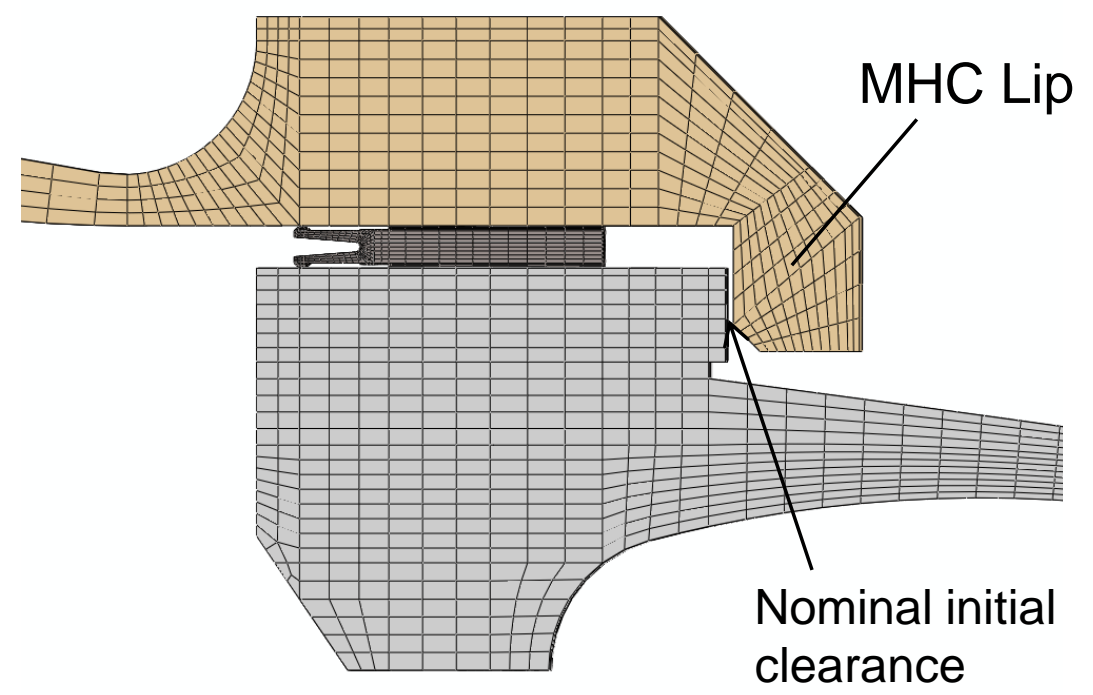

After Load Applied

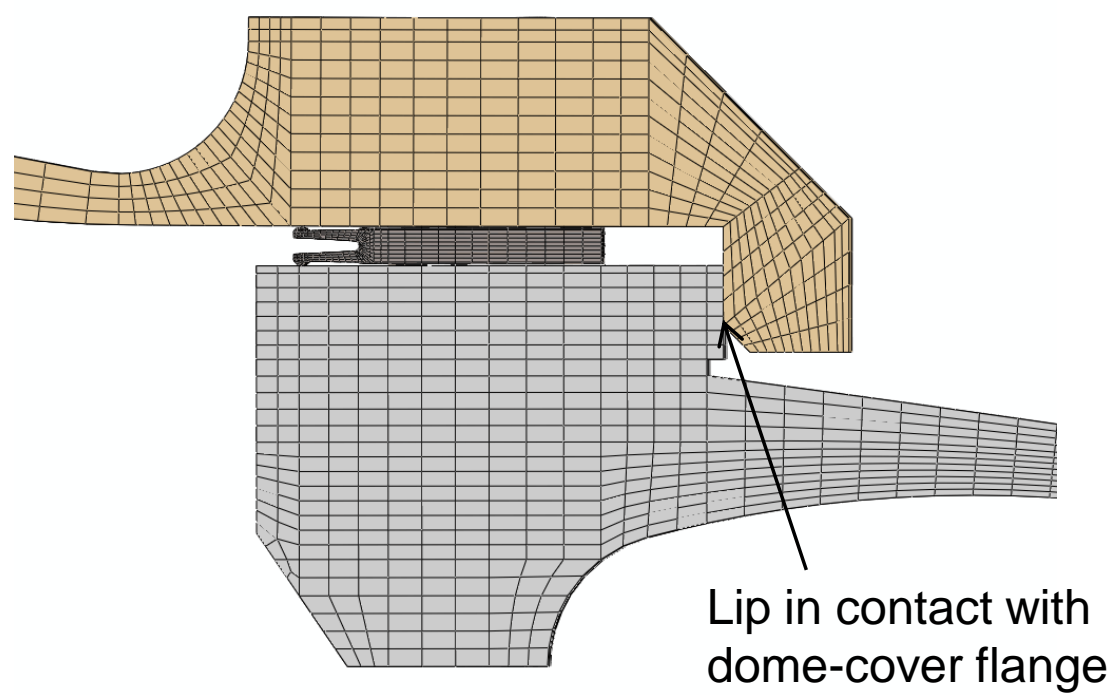

MHC Lip

- Provides a mechanical stop feature

- Makes contact with dome-cover flange, reducing MHC rotation

- This was not likely the original design intention; however it is a side-effect 


\section{Joint Redesign Option \#1}

\section{Incorporate Lip into Sump Design}

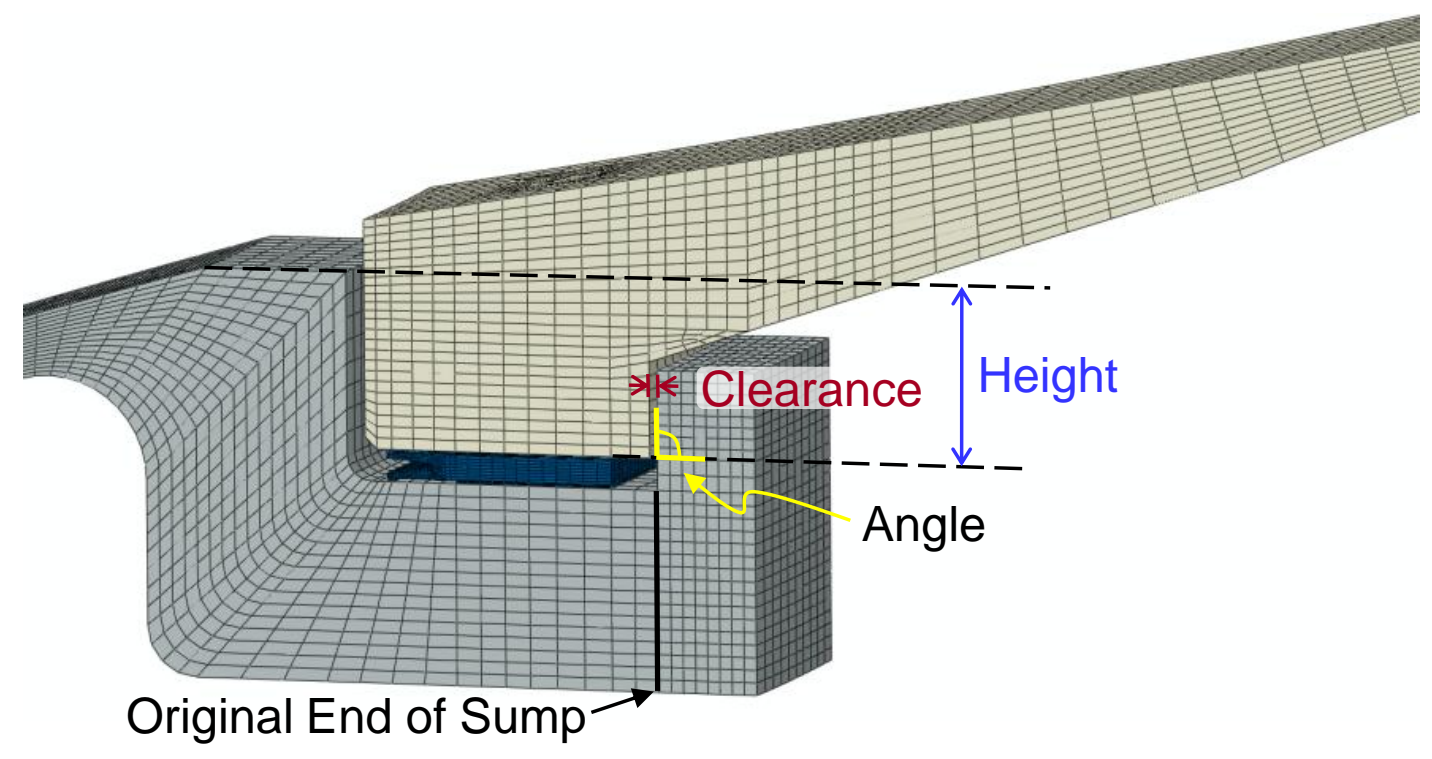

Perform Design of Experiments Learn which factors affect the response the most Learn how factors interact with each other

Design of Experiments: 3 factors, 2 levels each

\begin{tabular}{|c|c|c|}
\hline \multirow{2}{*}{ Factor } & \multicolumn{2}{|c|}{ Level } \\
\cline { 2 - 3 } & + & - \\
\hline A. Lip height & Full & Half \\
\hline B. Lip angle & $45^{\circ}$ & $90^{\circ}$ \\
\hline $\begin{array}{c}\text { C. Clearance } \\
\text { (Dimension and tolerance } \\
\text { from LH2 MHC drawing) }\end{array}$ & Minimum & Maximum \\
\hline
\end{tabular}

$L^{f}=2^{3}=8$ unique experiments 


\section{Joint Redesign Option \#1}

Orthogonal Experiment Matrix
\begin{tabular}{|c|c|c|c|}
\hline Experiment \# & A & B & C \\
\hline 1 & + & + & + \\
\hline 2 & + & - & + \\
\hline 3 & + & + & - \\
\hline 4 & + & - & - \\
\hline 5 & - & + & + \\
\hline 6 & - & - & + \\
\hline 7 & - & + & - \\
\hline 8 & - & - & - \\
\hline
\end{tabular}

Experiment \#1

Experiment \#8
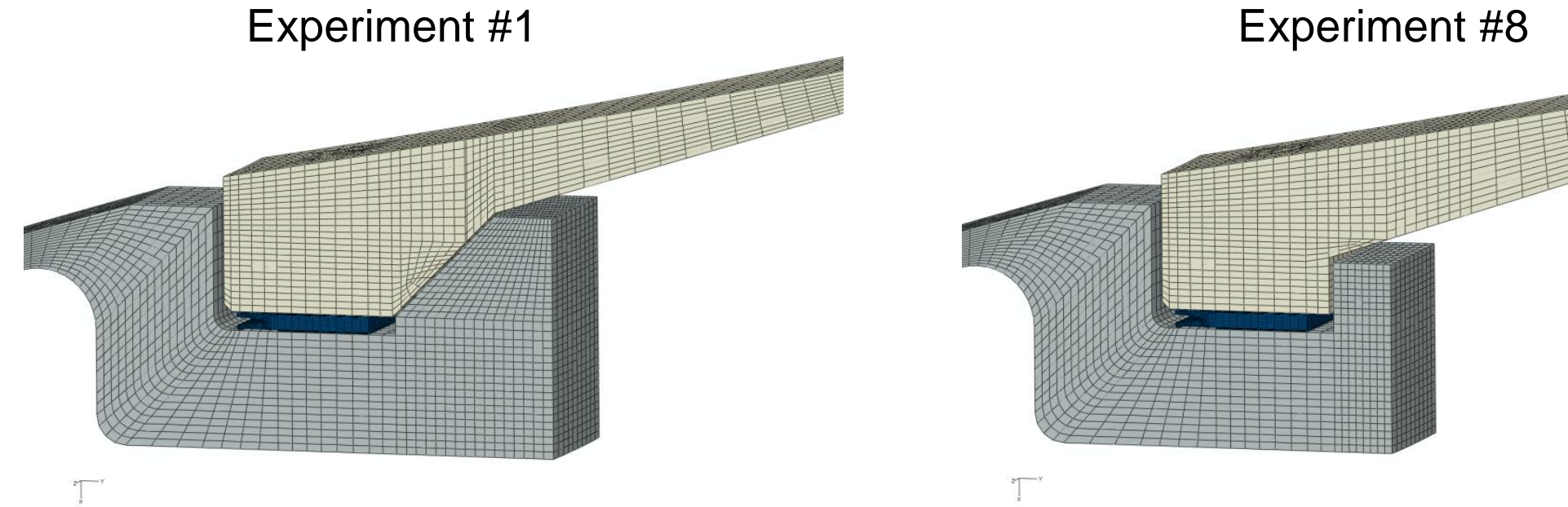


\section{Design of Experiments Results}

Baseline $\Omega / \Omega_{\text {spec }}=6.5$

\begin{tabular}{|c|c|c|c|c|c|c|c|c|}
\hline Experiment \# & 1 & 2 & 3 & 4 & 5 & 6 & 7 & 8 \\
\hline$\Omega / \Omega_{\text {spec }}$ & 1.33 & 3.75 & 1.45 & 4.00 & 1.73 & 4.15 & 2.85 & 4.75 \\
\hline
\end{tabular}

- Full Lip Height

- $45^{\circ}$ Lip Angle

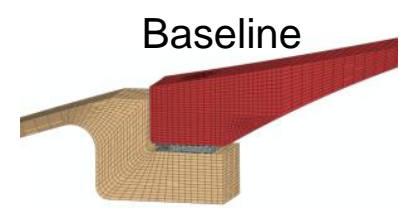

Experiment \#1

Minimum Clearance

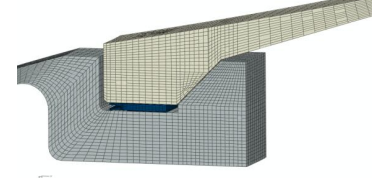

Experiment \#3
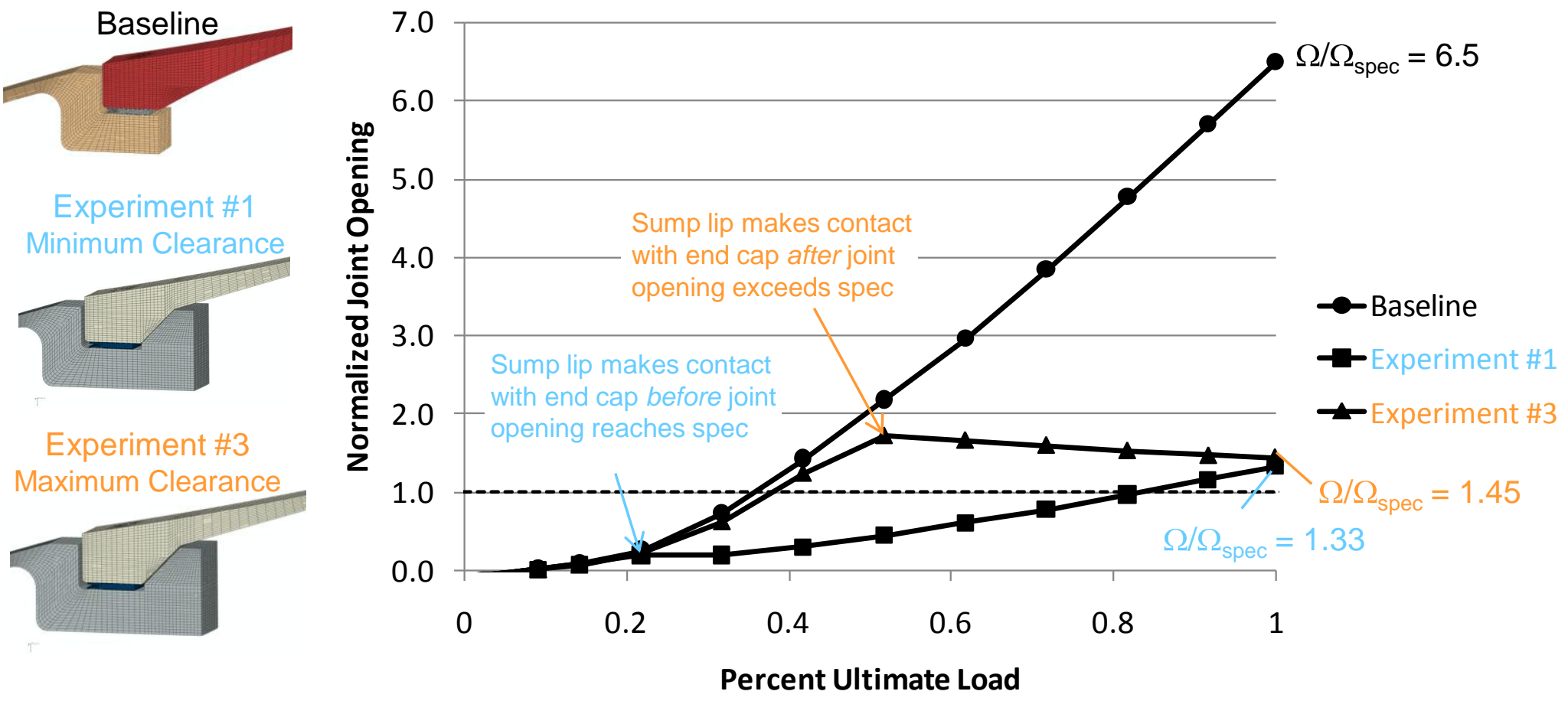

- All configurations violate specification

- Further study Experiments \#1 and \#3 to see if refined preload or bolt selection gives improved joint performance 


\section{Effect of Bolt Size and Increased Preload}

- Larger diameter and higher preload expected to reduce bolt bending

- No changes made to FE model mesh

\begin{tabular}{|c|c|c|}
\hline Bolt Diameter & Minimum Preload $^{*}$ & Increased Preload $^{\dagger}$ \\
\hline $5 / 16 "$ & $6394 \mathrm{lb}$ & $11045 \mathrm{lb}$ \\
\hline $3 / 8 "$ & $9207 \mathrm{lb}$ & $15840 \mathrm{lb}$ \\
\hline $7 / 16 "$ & $12530 \mathrm{lb}$ & $21600 \mathrm{lb}$ \\
\hline \multicolumn{2}{|c|}{$\begin{array}{r}(0.65 \times 180 \mathrm{ksi}) \times 0.75 \times 0.95 \times \mathrm{A}_{\text {bolt }}=\text { Minimum Preload } \\
+(0.8 \times 180 \mathrm{ksi}) \times \mathrm{A}_{\text {bolt }}=\text { Increased Preload }\end{array}$} \\
\hline \multicolumn{2}{|c}{}
\end{tabular}




\section{Effect of Bolt Size and Increased Preload}

\section{Experiment \#1 Further Studies}

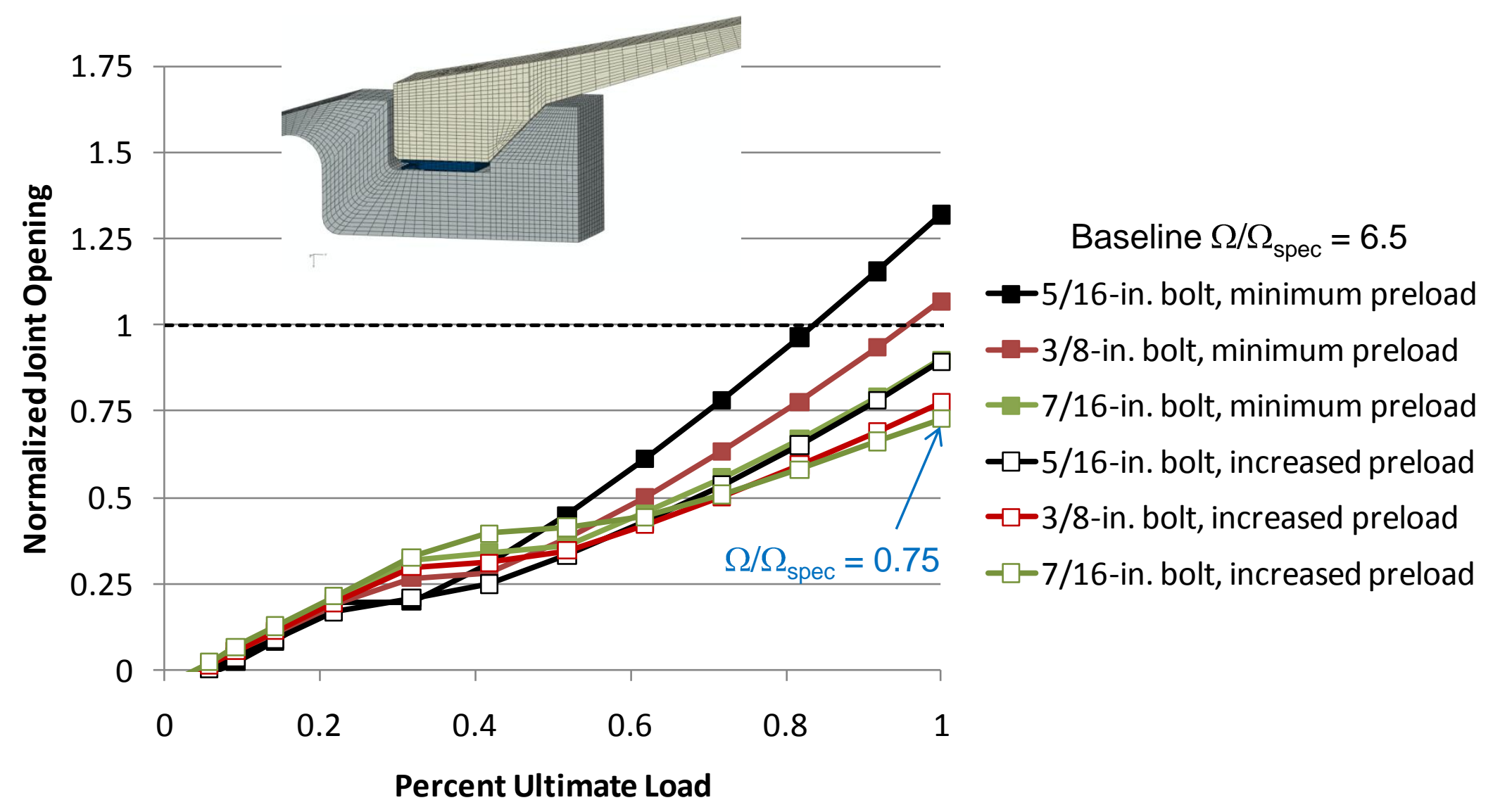

As preload is increased, joint opening is decreased

- Configuration with minimum clearance can meet joint opening specification 


\section{Effect of Bolt Size and Increased Preload}

\section{Experiment \#3 Further Studies}

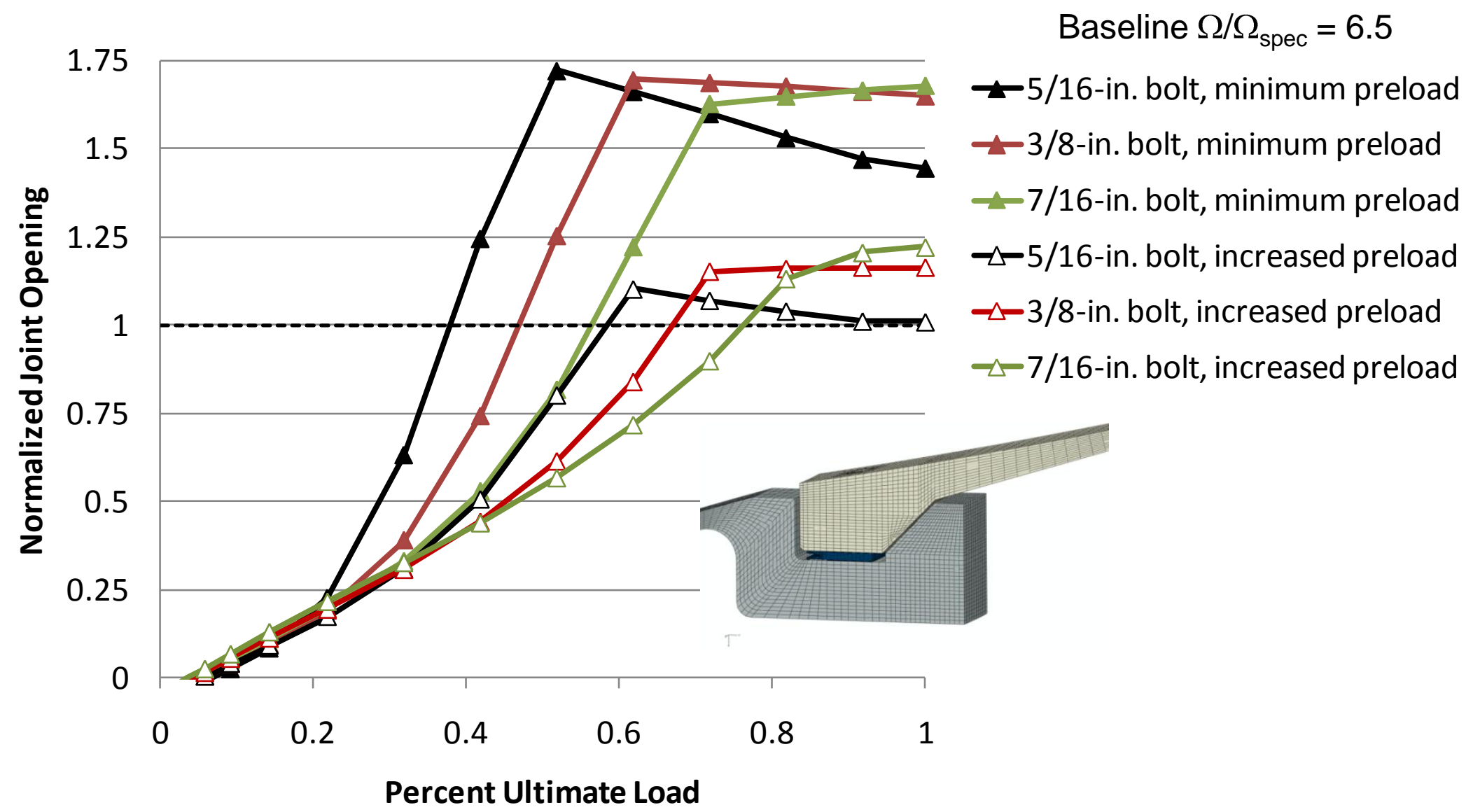

As preload is increased, load at which sump lip makes contact with end cap is increased

- Load at which sump lip makes contact with end cap influences the joint opening

Joint deflection exhibits complex behavior

Configuration with maximum clearance cannot meet joint opening specification 


\section{Joint Redesign Option \#2}

\section{Have Naflex seals manufactured with larger outer diameter}

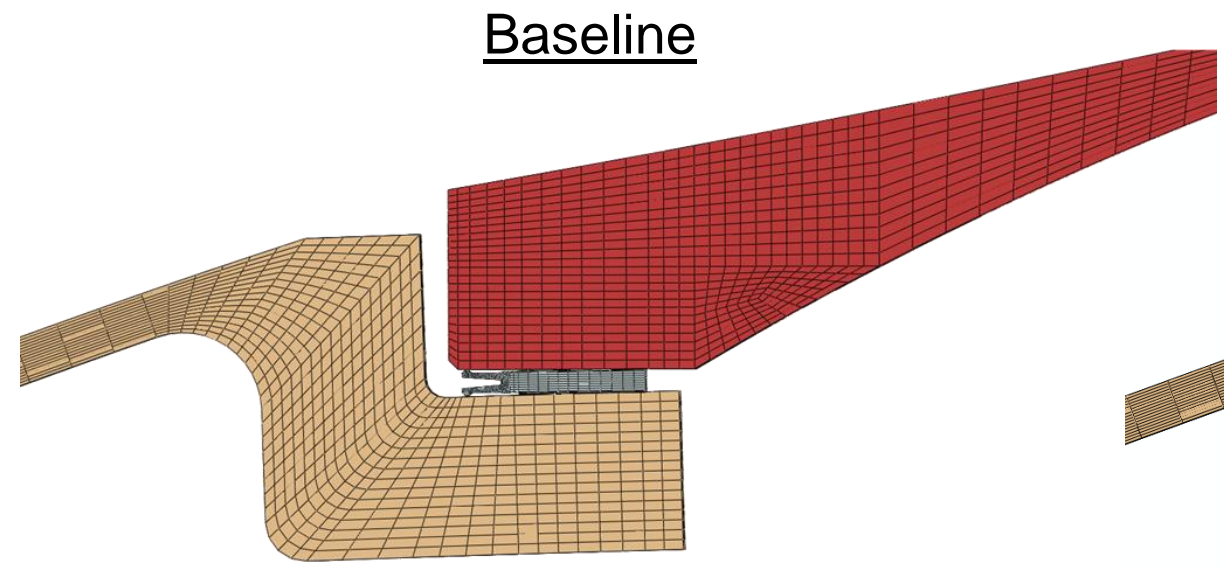

$\Omega / \Omega_{\text {spec }}=6.5$
Seal With Larger OD

$\Omega / \Omega_{\text {spec }}=3.8$

Joint opening does not meet specification 


\section{Joint Redesign Option \#3}
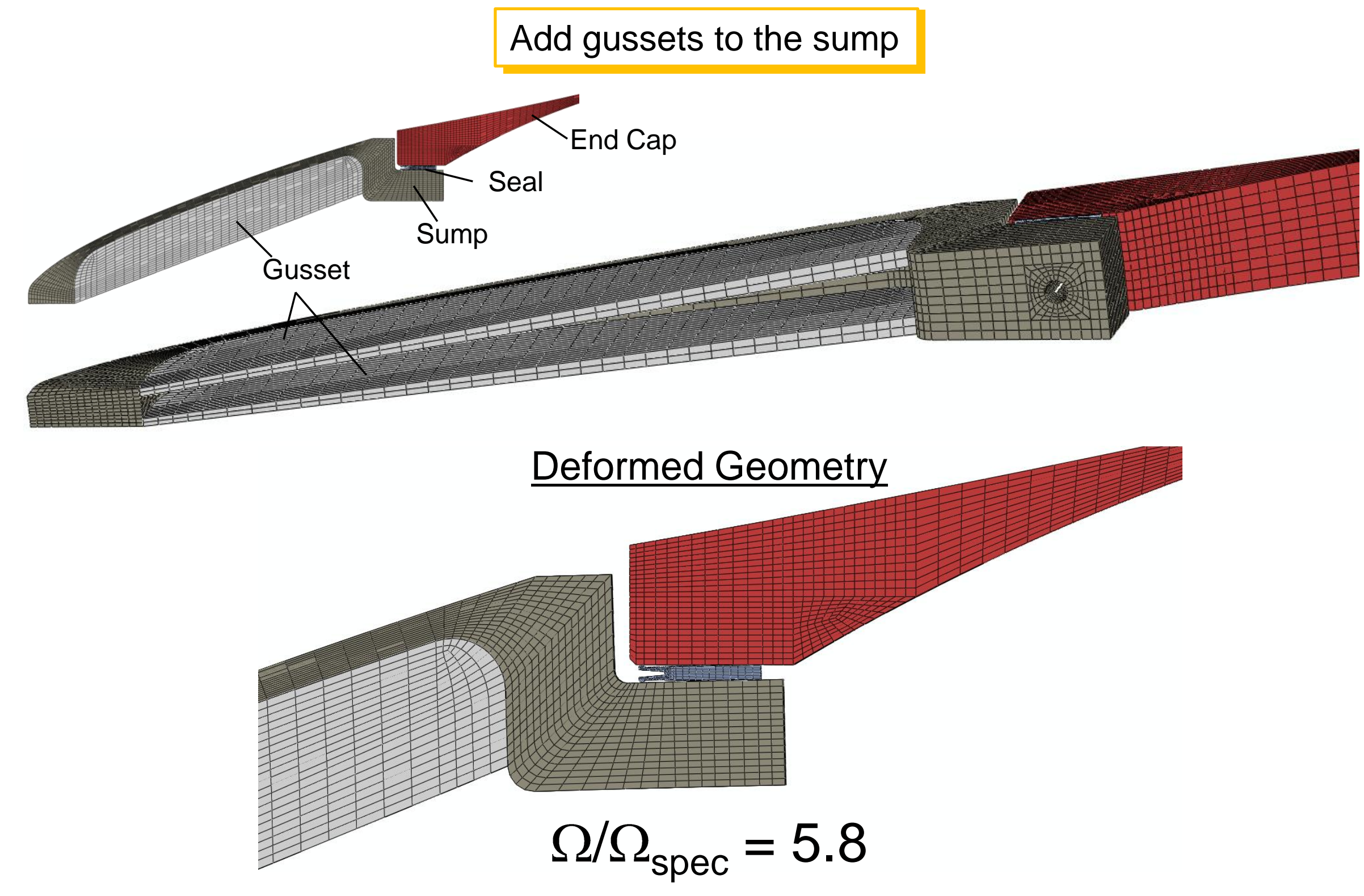

Joint opening does not meet specification 


\section{Naflex Seal Analysis Results Summary}

- Baseline configuration with minimum preload and "worst-case" loads yields joint opening of $\Omega / \Omega_{\text {spec }}=6.5$

Three redesign options considered

- Incorporate a lip on the sump to provide a mechanical stop: $0.75 \leq \Omega / \Omega_{\text {spec }} \leq 4.75$

- Have seals manufactured with larger outer diameter: $\Omega / \Omega_{\text {spec }}=3.8$

- Add gussets to the sump: $\Omega / \Omega_{\text {spec }}=5.8$

Redesign configurations that meet joint opening specification all incorporate sump lip with minimum clearance

- Minimum clearance cannot be guaranteed

- Naflex seal does not provide sufficient capability for LOX tank sump seal joint 


\section{Joint Redesign Using RACO Seal}

\section{$\underline{\text { RACO } \text { and Creavey Seals Have Heritage in Space Shuttle ET }}$ LO2 Feedline Sections}
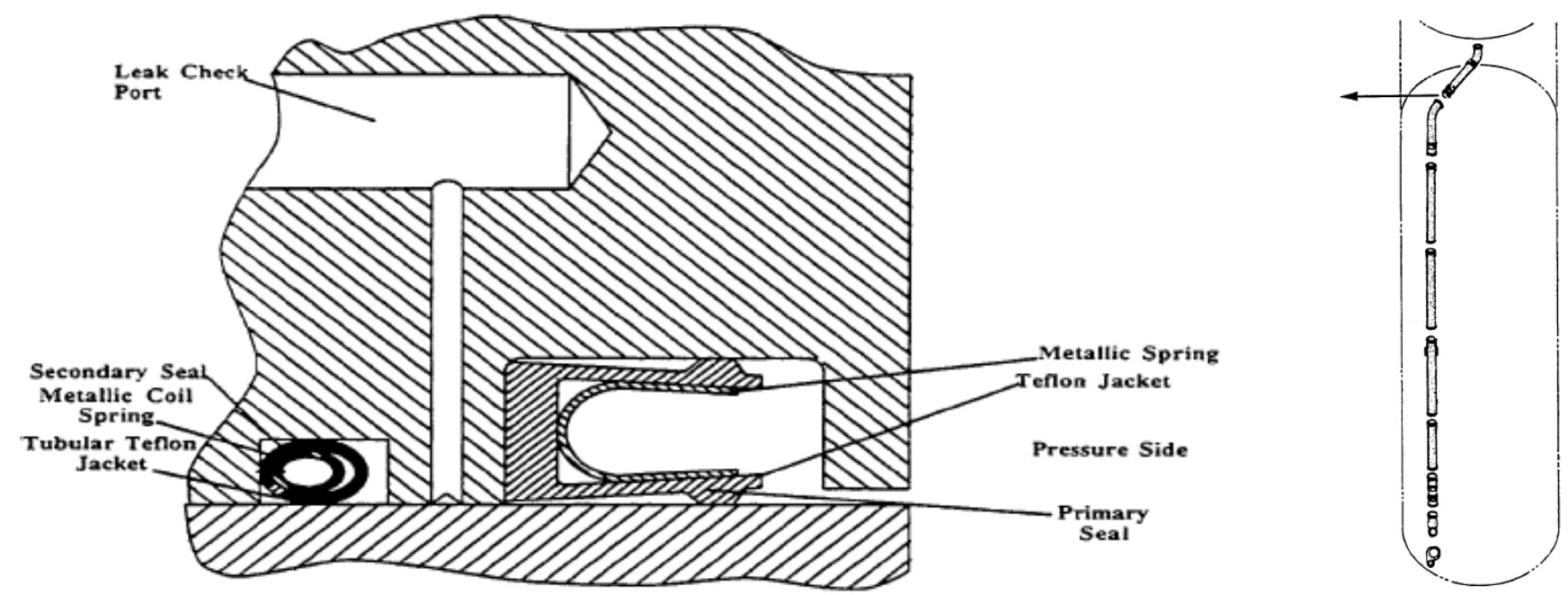

(References: Space Shuttle SLWT System Definition Handbook, Vol. I and NASA Preferred Reliability Practice No. PT-TE-1424)

- RACO is primary seal, Creavey is secondary seal

- RACO joint opening allowable much larger than specification for Naflex seals 


\section{RACO Seal}

Recommended for extreme sealing conditions and cryogenic temperatures

Spring-actuated, pressure-assisted

Polymer jacket (Teflon) and metal spring (Inconel-718)

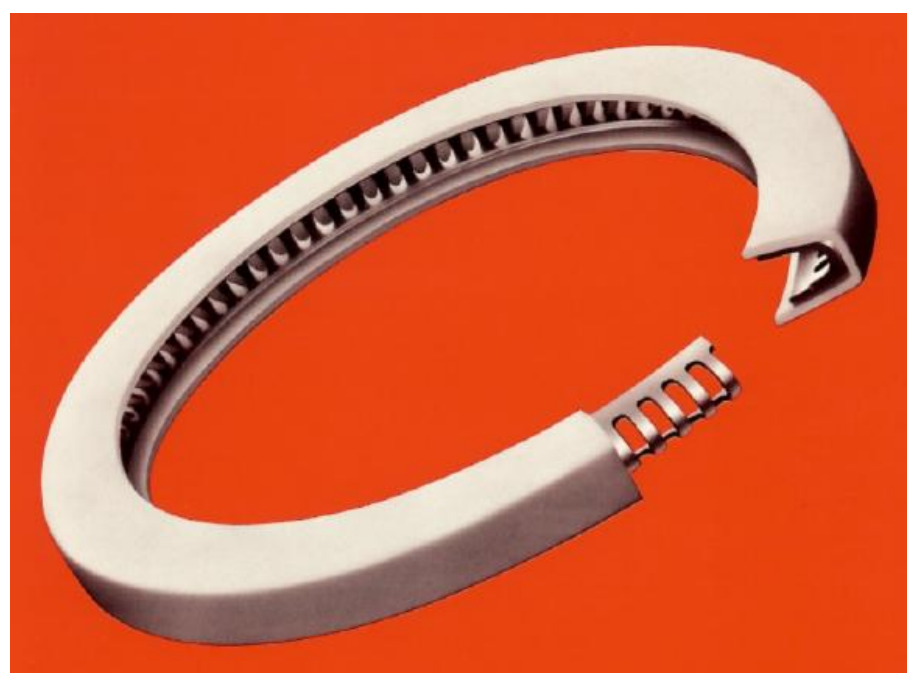

(Reference: RACO Face Seals Series 1100 Catalog)

Typical Flange Joint
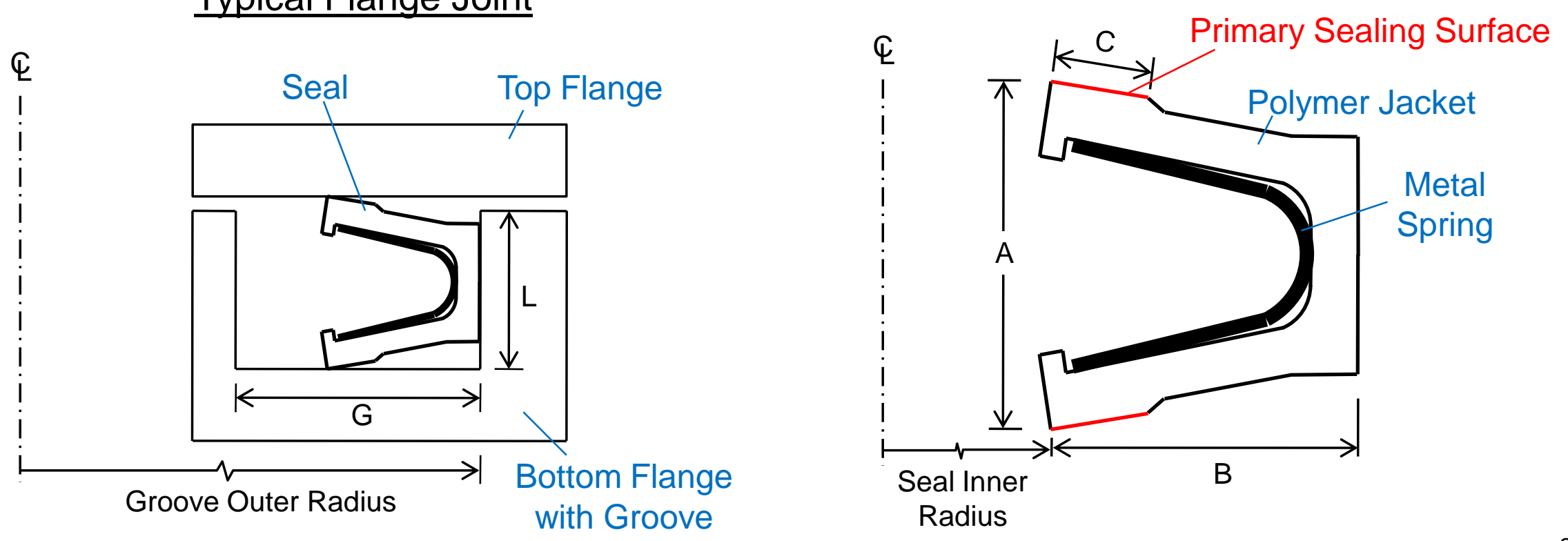


\section{Baseline Model for RACO Seal Analysis}

Baseline Cross-Section for Joint with Naflex Seal

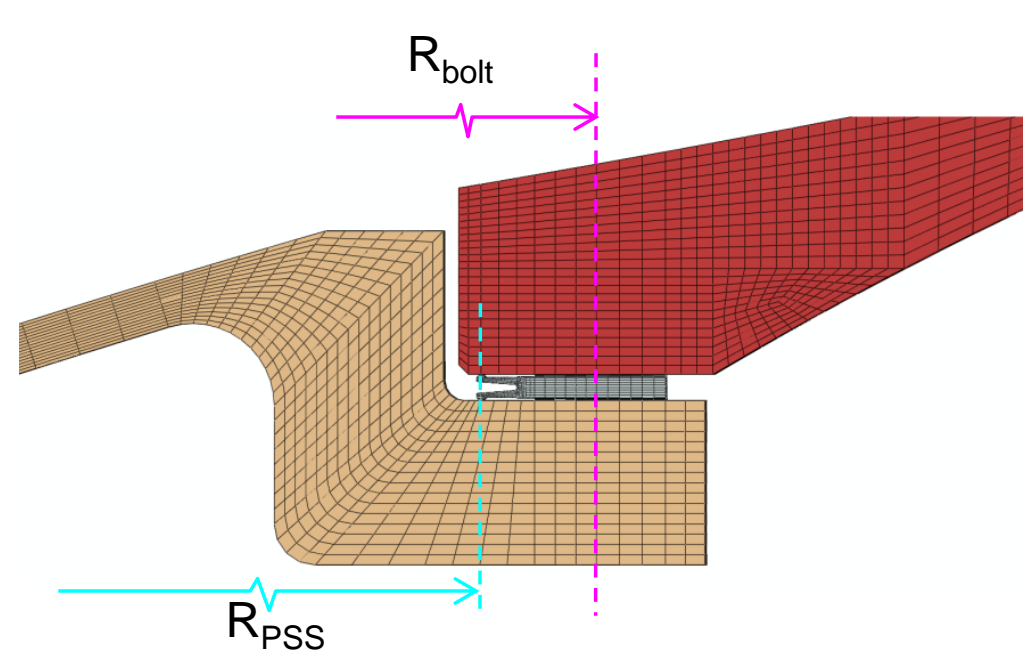

\section{Modified Cross-Section for RACO Seal}

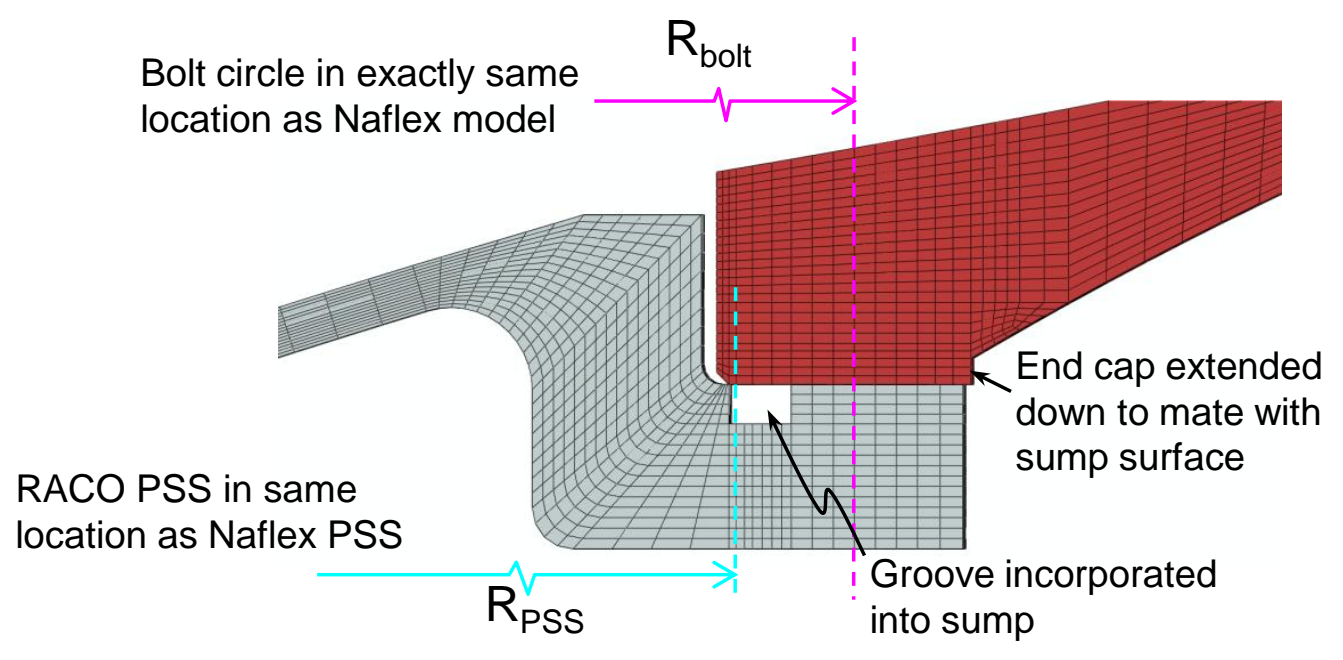

Seal not explicitly modeled

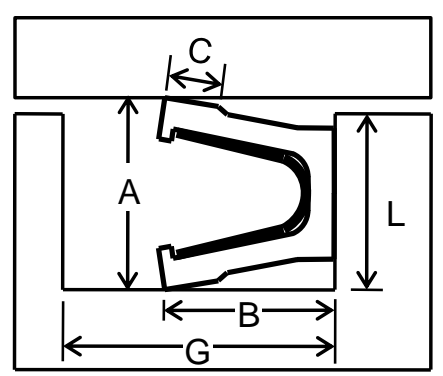




\section{Baseline Model for RACO Seal Analysis}

Assume $5^{\circ}$ wedge - number of bolts around circumference not predefined

Consider 3/8" diameter bolt

Use same BCs and loads from Naflex seal analyses 


\section{RACO Seal Behavior and Joint Opening}

\section{Joint Opening Computation}

$$
\Omega=\delta_{x}^{\text {load }}-\delta_{x}^{\text {preload }}
$$

- Computed midway between adjacent bolts (symmetry plane), at primary sealing surface ID

\section{After Preload Step}

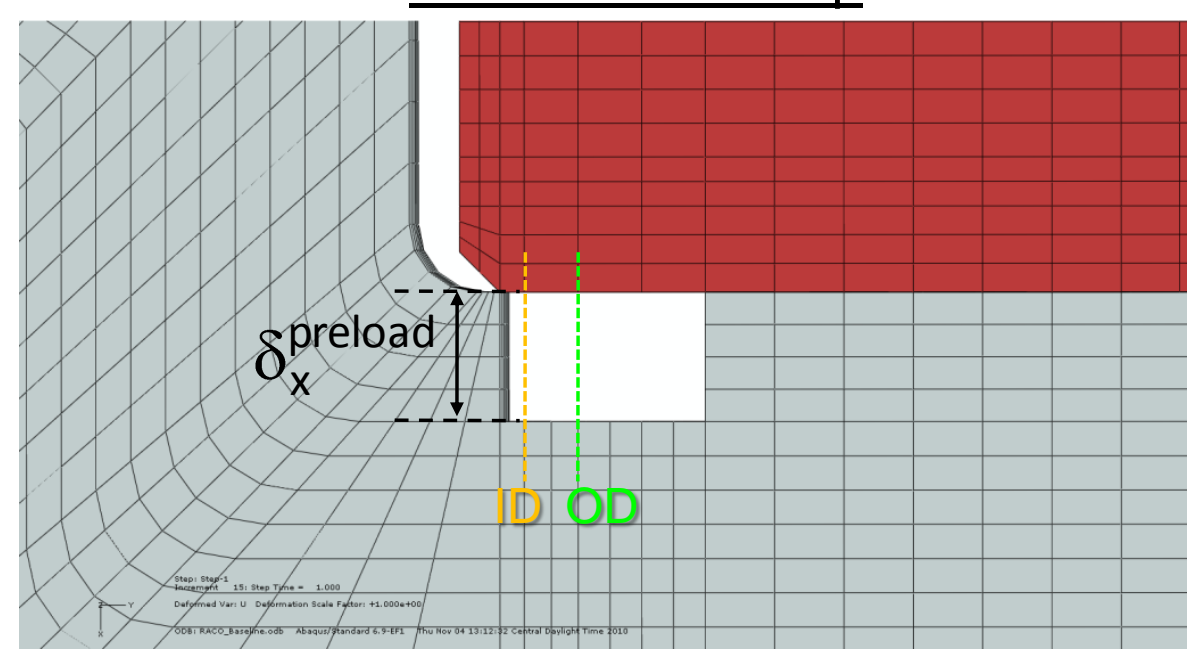

\section{After Load Step}

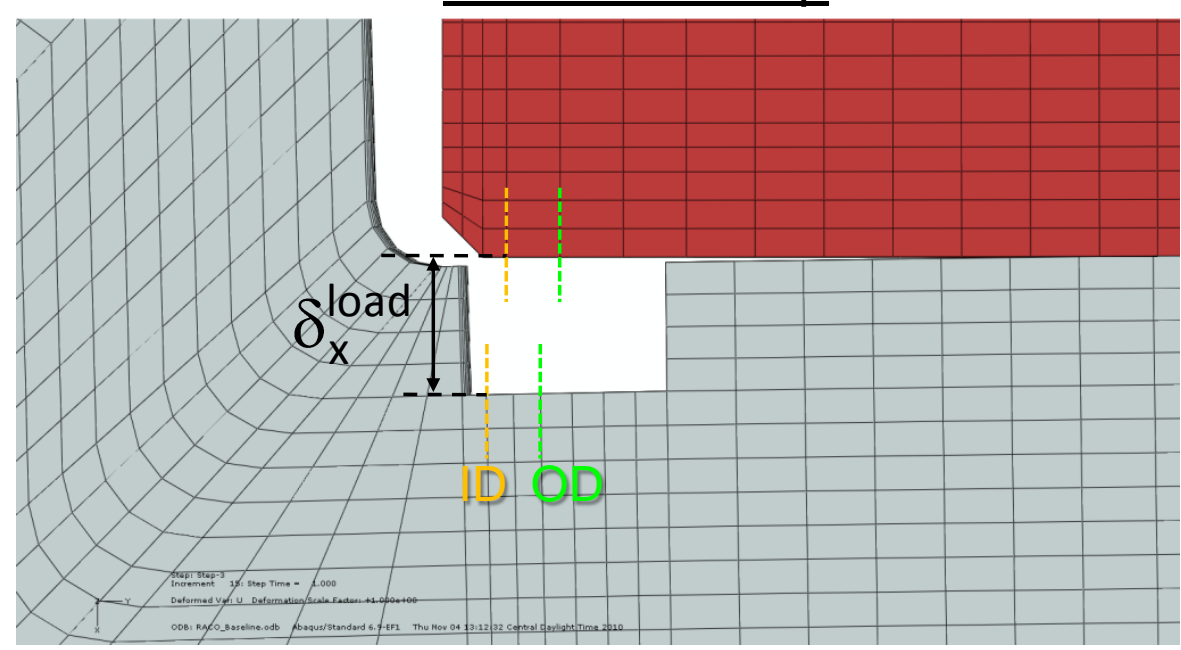

Joint Opening Allowables

Heritage ET pretest requirement:

Design value after heritage ET test:

Seal vendor recommendation:
$\Omega_{\text {pre-ET }}$

$\Omega_{\text {post-ET }}$

$\Omega_{\text {vendor }}$
$\left(\Omega_{\text {post-ET }}>\Omega_{\text {pre-ET }}\right)$

$\left(\Omega_{\text {pre-ET }}<\Omega_{\text {vendor }}<\Omega_{\text {post-ET }}\right)$ 


\section{RACO Baseline Model Joint Opening Results}

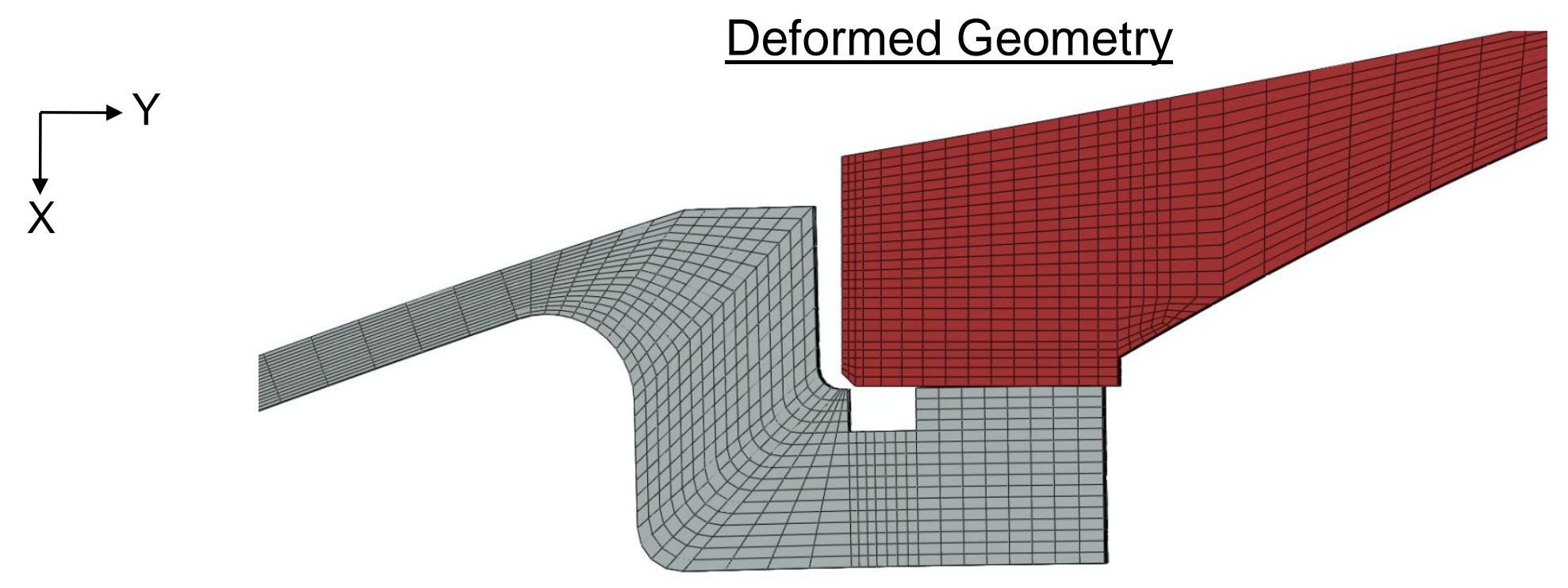

\begin{tabular}{|c|c|c|}
\hline$\Omega / \Omega_{\text {pre-ET }}$ & $\Omega / \Omega_{\text {vendor }}$ & $\Omega / \Omega_{\text {post-ET }}$ \\
\hline 2.01 & 1.61 & 1.07 \\
\hline
\end{tabular}

Joint opening exceeds all available recommendations for joint opening allowable 


\section{Effect of Bolt Size and Increased Preload}

\begin{tabular}{|c|c|c|}
\hline Bolt Diameter & Minimum Preload $^{*}$ & Increased Preload $^{\dagger}$ \\
\hline $3 / 8 "$ & $9207 \mathrm{lb}$ & $15840 \mathrm{lb}$ \\
\hline $7 / 16 "$ & $12530 \mathrm{lb}$ & $21600 \mathrm{lb}$ \\
\hline
\end{tabular}

$*(0.65 \times 180 \mathrm{ksi}) \times 0.75 \times 0.95 \times \mathrm{A}_{\text {bolt }}=$ Minimum Preload

$\dagger(0.8 \times 180 \mathrm{ksi}) \times \mathrm{A}_{\text {bolt }}=$ Increased Preload

$\underline{\text { Results }}$

\begin{tabular}{|c|c|c|c|c|}
\hline Bolt & Preload & $\Omega / \Omega_{\text {pre-ET }}$ & $\Omega / \Omega_{\text {vendor }}$ & $\Omega / \Omega_{\text {post-ET }}$ \\
\hline \multirow{2}{*}{$3 / 8 "$} & Minimum & 2.01 & 1.61 & 1.07 \\
\cline { 2 - 5 } & Increased & 1.20 & 0.96 & 0.64 \\
\hline \multirow{2}{*}{$7 / 16 "$} & Minimum & 1.49 & 1.19 & 0.79 \\
\cline { 2 - 5 } & Increased & 0.79 & 0.63 & 0.42 \\
\hline
\end{tabular}




\section{RACO Seal Analysis Results Summary}

\section{Does the Joint Opening Meet the Allowable?}

\begin{tabular}{|c|c|c|c|}
\hline Bolt & pre-ET test & Seal Vendor & post-ET test \\
\hline 3/8", Minimum Preload & No & No & No \\
\hline 3/8", Increased Preload & No & Yes & Yes \\
\hline $7 / 16 "$, Minimum Preload & No & No & Yes \\
\hline $7 / 16 "$, Increased Preload & Yes & Yes & Yes \\
\hline
\end{tabular}

- Analyses and results provide reasonable data to recommend a design change and plan a testing program to determine capability of RACO seals in Ares-I Upper Stage LOX tank sump seal joint 
- Analysis of Ares-I Upper Stage LOX tank sump seal joint

- 3D finite element modeling analyses used anchored modeling practices

- Naflex seal does not provide sufficient sealing capability

- Several redesign options studied

- RACO seal can provide sufficient sealing capability

- Further design studies and development testing are warranted 